Relaciones entre Políticas Públicas de Adolescencia y experiencias en la construcción de ciudadanía para la localidad séptima de Bosa, Bogotá, Distrito Capital. 2015 - 2016.

\author{
Gloria Libia Polanía Aguillón \\ José Sánchez Ramírez
}

Trabajo de grado para optar al título de Magíster en Protección Social

Asesor

Dr. Manuel Vega Vargas

Universidad Santo Tomás

Bogotá, D.C, Colombia

2017 
A nuestros hijos Nicolas y Giuliana, quienes a diario nos llenan de razones para construir un futuro con oportunidades para todos. 
TABLA DE CONTENIDO

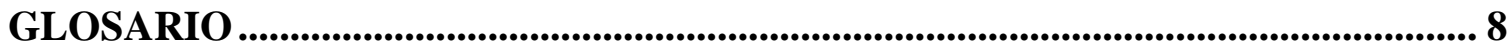

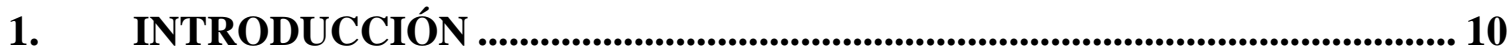

2. DESCRIPCIÓN DEL PROYECTO.......................................................12

2.1. PLANTEAMIENTO DEL PROBLEMA .................................................................12

2.1.1. GENERALIDADES ............................................................................12

2.1.2. PREGUNTA DE INVESTIGACIÓN N...........................................................14

2.2. JUSTIFICACIÓN ……………......................................................................................14

2.3. OBJETIVOS ..............................................................................................17

2.3.1. OBJETIVO GENERAL...................................................................................17

2.3.2. OBJETIVOS ESPECÍFICOS....................................................................17

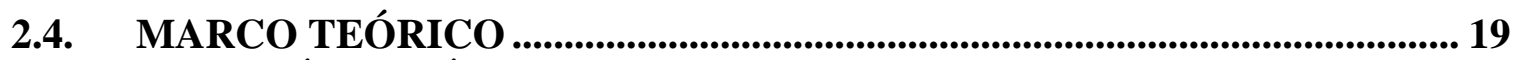

2.4.1. POLÍTICA PÚBLICA Y SUJETOS DE DERECHOS. ......................................19

2.4.2. INFANCIA, ADOLESCENCIA Y CONSTRUCCIÓN DE SUJETOS DE

DERECHOS. ...............................................................................................................

3. ANÁLISIS DEL MARCO NORMATIVO VIGENTE.................................... 36

4. MARCO SITUACIONAL LOCALIDAD SÉPTIMA DE BOSA, D.C.......... 74

5. ANÁLISIS DE LA INFORMACIÓN CUALITATIVA ......................................91

6. RECOMENDACIONES DE POLÍTICA PÚBLICA ..................................... 125

7. CONCLUSIONES............................................................................................ 134

8. Referencias.................................................................................................................. 142

Listado de figuras

Figura 1. Relaciones dialógicas en el diseño de Políticas Públicas para la adolescencia en Colombia ...69

Figura 2. Pirámide poblacional, localidad de Bosa, comparativo $2000-2005-2015$..........................76

Figura 3. Distribución poblacional según régimen de aseguramiento en salud, localidad de Bosa, $2013-$

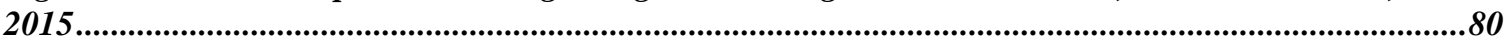

Figura 4. Erradicación y prevención del trabajo infantil y adolescente, Ámbito Laboral, localidad de Bosa, 2011 - 2014.

Figura 5. Análisis de los Determinantes Sociales a los que se exponen los adolescentes;Error! Marcador no definido.

Figura 6. Ejemplo de redes semánticas para el análisis de la representación de adolescencia. 97

\section{Listado de cuadros}

Cuadro 1. Políticas Públicas Vigentes para la adolescencia seleccionada para la evaluación y análisis 41 Cuadro 2. Criterios de evaluación

Cuadro 3 Criterios técnicos para la evaluación de la política pública de Adolescencia 


\section{Listado de tablas}

Tabla 1. Distribución de la población por momentos del curso vital, localidad de Bosa, 2000 - 2015 .....77

\section{Listado de mapas}

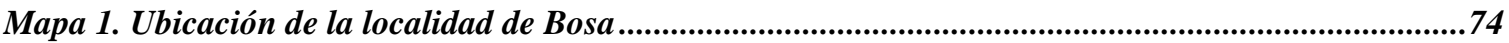

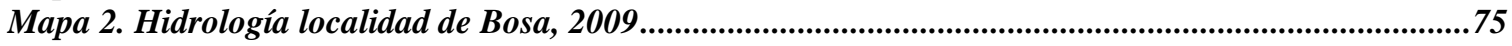




\section{RESUMEN}

El presente estudio busca analizar los procesos de construcción de ciudadanía desde las posibles relaciones entre las políticas públicas de adolescencia y las experiencias particulares en el contexto local de Bosa. Para ello, fue necesario recopilar información sobre las políticas públicas vigentes para la adolescencia que permitiera un marco de evaluación del diseño de las mismas. A su vez, se recolectó información cualitativa que permitiera una aproximación a la representación social de la adolescencia en el contexto territorial, socioeconómico, cultural y ambiental de su desarrollo humano. Desde allí se llevó a cabo una confrontación de la normatividad vigente versus la expresión social de la población adolescente.

Siendo así, este estudio demuestra cómo el éxito en la construcción de la ciudadanía a partir de los derechos, se encuentra supeditado a los contextos de vulneración, donde las políticas públicas formuladas no alcanzan a adaptarse de manera adecuada a la complejidad de las necesidades. De otro lado, el carácter transitorio otorgado al momento de la adolescencia funciona como excusa para evitar su estandarización y ubicarlo en un vacío al final de la infancia y al inicio de la juventud.

Bajo el modelo político económico actual, la protección social a partir de las políticas públicas ha focalizado y fraccionado al desarrollo humano por momentos en el continuo del curso vital, con lo que ha permitido señalar el abandono de etapas como la adolescencia, cuyo cuidado y auto designación determinan su aporte a la construcción de capital humano. 


\begin{abstract}
The present study seeks to analyze the processes of construction of citizenship from the possible relationships between public policies of adolescence and particular experiences in the local context of Bosa. For this, it was necessary to collect information on public policies in force for adolescence that would allow a framework to evaluate their design. At the same time, qualitative information was collected that allowed an approximation to the social representation of adolescence in the territorial, socioeconomic, cultural and environmental context of its human development. From there, a confrontation of the current norms versus the social expression of the adolescent population was carried out.
\end{abstract}

This being the case, this study shows how success in the construction of citizenship based on rights is subordinated to the contexts of vulnerability, where the public policies formulated do not manage to adapt adequately to the complexity of the needs. On the other hand, the transitory nature granted at the time of adolescence serves as an excuse to avoid its standardization and place it in a vacuum at the end of childhood and the beginning of youth.

Under the current political-economic model, social protection based on public policies has focused and fractioned human development at times in the continuum of the life course, which has made it possible to point out the abandonment of stages such as adolescence, whose care and self-designation determine their contribution to the construction of human capital. 


\section{PALABRAS CLAVE}

Políticas Públicas, Adolescencia, Derechos, Condiciones de Vida, Desarrollo Humano.

\section{KEYWORD}

Public Policies, Adolescence, Rights, Living Conditions, Human Development. 


\section{GLOSARIO}

BID: Banco Interamericano de Desarrollo

Celade: Centro Latinoamericano y Caribeño de Demografía

Cepal: Comisión Económica para América Latina y el Caribe

Cioms: Consejo de Organizaciones Internacionales de las Ciencias Médicas

Conpes: Consejo Nacional de Política Económica y Social

DANE: Departamento Administrativo Nacional de Estadística

DESC: Derechos Económicos Sociales y Culturales

DILE: Dirección Local de Educación

ICBF: Instituto Colombiano de Bienestar Familiar

IDRD: Instituto Distrital de Recreación y Deporte

Inmlycf: Instituto Nacional de Medicina Legal y Ciencias Forences

IPS: Institución Prestadora de Servicios de Salud

Lgbti: Lesbianas, Gays, Bisexuales, Transexuales e Intersexuales

OEA: Organización de Estados Americanos

OIJ: Organismo Internacional de Juventud para Iberoamérica

OMS: Organización Mundial de la Salud

ONU: Organización de las Naciones Unidas

PDSP: Plan Decenal de Salud Pública

PNUD: Programa de las Naciones Unidad para el Desarrollo

SDIS: Secretaría Distrital de Integración Social

SDP: Secretaria Distrital de Planeación

SDS: Secretaria Distrital de Salud 
Sgsss: Sistema General de Seguridad Social en Salud

SPA: Sustancias Psicoactivas

UTI: Unidades de Trabajo Informal

UPZ: Unidad de Planeación Zonal 


\section{INTRODUCCIÓN}

El presente es un estudio cualitativo observacional descriptivo de corte transversal, el cual parte de la concepción de la protección social promulgada por la Comisión de Desarrollo Social de las Naciones Unidas: "Un conjunto de políticas y programas gubernamentales y privados con los que las sociedades dan respuestas a diversas contingencias a fin de compensar la falta o reducción sustancial de ingresos provenientes del trabajo, brindar asistencia a las familias con hijos y ofrecer atención médica y vivienda a la población" (1).

De esta manera, el estudio se focaliza en el análisis de políticas públicas y sus apartados sobre protección social para los adolescentes, específicamente, para la población entre los 10 años y los 13 años de edad mediante el estudio de la implementación de las mismas en la localidad séptima de Bosa. Estas edades se entienden en la teoría del desarrollo biológico como pre-adolescencia y adolescencia temprana.

En la actualidad, el tema de la política pública recobra gran importancia, tanto en el distrito capital, como en relación con los resultados obtenidos por la nación en el seguimiento a compromisos internacionales sobre desarrollo sostenible. Si bien las políticas públicas han hecho visibles a las poblaciones y situaciones prioritarias para la definición de intervenciones oportunas, su operación sobre el territorio es difusa y, en ocasiones, no logra los objetivos propuestos. 
Particularmente, interesa indagar a las políticas públicas que atañen a la adolescencia, específicamente, con la protección social, ya que las mismas particularidades de los adolescentes los hace proyectarse como potencialmente trasformadores de realidades sociales experimentadas en territorios vulnerables.

El despliegue metodológico del presente estudio parte de una revisión de la normatividad y los lineamientos que contemplan al grupo poblacional objeto de estudio, desde el panorama internacional, nacional, distrital, local e institucional, si llegase a existir. A su vez, se realiza un marco contextual de la situación actual de los preadolescentes y los adolescentes (tomando únicamente de los 10 a 13 años de edad) residentes en la localidad de Bosa, para entender el marco de determinantes en el cual se desarrolla esta población.

Acto seguido, se adelanta el trabajo de campo, en el cual se levanta información de tipo cualitativo mediante entrevistas y grupos focales, que permite la representación categórica de la población adolescente de Bosa, según la disponibilidad de actores, principalmente, en los sectores: salud, educación e integración social.

Siendo así, se da lugar a la definición de tensiones existentes entre la política pública y su expresión social en el territorio local. De igual forma, se busca aportar a la construcción de políticas públicas en coherencia con los contextos sociales de su implementación, más aún en poblaciones en transición como la adolescencia. 


\section{DESCRIPCIÓN DEL PROYECTO}

\subsection{PLANTEAMIENTO DEL PROBLEMA}

\subsubsection{GENERALIDADES.}

En general se considera que la población adolescente (entre los 10 años y los 19 años) son un grupo con condiciones saludables de vida. No obstante, se continúan presentando muertes prematuras en esta población, debido a accidentes, suicidios, violencia, complicaciones relacionadas con el embarazo a temprana edad y enfermedades prevenibles o tratables (2). A pesar de la percepción de la etapa de adolescencia como el momento de la vida en el cual se goza de una salud plena, los adolescentes se ven enfrentados a retos, que de no ser tratados a tiempo pueden producir enfermedades crónicas o discapacidades en la edad adulta(2).

La adolescencia se define como el periodo de la vida en el cual el individuo adquiere la capacidad de reproducirse, transita los patrones psicológicos de la niñez a la adultez y consolida su independencia económica (2). Si se entiende al desarrollo humano como un continuo a lo largo del ciclo vital (3), para efectos de la presente investigación (como se había mencionado), se focalizan las personas entre los 10 años y los 13 años de edad, habitantes de la localidad séptima de Bosa, entendiendo que se encuentran dentro de las subetapas de preadolescencia y adolescencia temprana (4); se pretende reflejar la implementación de políticas públicas en éste territorio, al realizar un paralelo entre lo que 
expresa la norma en su promulgación y lo que se expresa en la cotidianidad de esta población.

Los datos de estratificación (5) y aseguramiento (6) muestran la profunda inequidad en el territorio de Bosa, la cual es heredada por las nuevas generaciones como una predisposición a riesgos sociales que conducen inevitablemente a la perpetuación de la pobreza si no se toman las medidas necesarias a tiempo con estrategias efectivas de protección social; sin embargo, la implementación de estrategias de protección social no solamente tiene que ver con que el Estado garantice el acceso a ciertos servicios o bienes necesarios para el bienestar, sino con la trasformación de condiciones sociales y culturales que a su vez definen a los adolescentes como sujetos de derechos.

De otro lado, la asociación recurrente del término adolescencia con palabras como "tránsito no reconocido" o "limbo" habla de una agrupación semántica que define la adolescencia desde una dificultad misma de delimitación o definición, desde la ambigüedad. Para que la política pública sea eficaz en su implementación, permeando las instituciones y sus marcos programáticos, se hace un cuestionamiento de la falta de estandarización en la edad que comprende la adolescencia, ya que distintas edades en ocasiones pueden dejar por fuera de los programas a los adolescentes que se encuentren en el límite superior o inferior del grupo etario. 


\subsubsection{PREGUNTA DE INVESTIGACIÓN.}

¿Cómo se dan los procesos de construcción de ciudadanía en la adolescencia, en relación con el marco de política pública vigente y su implementación en un contexto local de inequidad social?

\subsection{JUSTIFICACIÓN}

Para el 2014, la población entre los 10 años y los 14 años en la localidad de Bosa, ascendía a 57.627 habitantes, es decir, el 9,2\% del total de la población local (7). De acuerdo a indicadores de salud, los nacidos vivos de madres adolescentes entre los 10 y los 14 años presentaron una proporción de 0,5\% en el 2010, valor que se repite en el año 2014 (8).

Aunado a lo anterior, vale la pena considerar que, según la estratificación socioeconómica de la población local, un $87 \%$ se encuentra en el estrato bajo y el 3\% se ubica en el estrato medio, que corresponde a la estratificación más alta en la localidad. El restante $10 \%$ se encuentra clasificado sin estratificación, representado por algunas zonas industriales y de usos dotacionales de gran escala en la UPZ Apogeo, así como zonas por desarrollar proyectadas como expansión urbana que rivalizan con la tradición Muisca del territorio ancestral en la UPZ Tintal Sur (5). A su vez, según la distribución de la afiliación en salud, un $64 \%$ pertenece al régimen contributivo, mientras el $22 \%$ se encuentra en el régimen subsidiado; el 14\% restante se ubica entre el no asegurado y excepción (9). 
De acuerdo con cifras del Inmlycf, para el año 2008 en Bogotá, se reportaron 978 casos por presunto delito de maltrato infantil en la población entre los 10 años y los 14 años de edad, lo cual representa un $32.7 \%$ del total de los casos notificados para ese año, considerada la mayor proporción en la población entre los 0 y los 17 años (10). Según datos del mismo Instituto, en relación con los dictámenes sexológicos, para el 2008, se identificaron 1.202 casos correspondientes a población entre los 10 años y los 14 años de edad, siendo la población de este grupo de edad la principal afectada por situaciones de abuso sexual (10).

Ahora bien, cabe mencionar que tanto la normativa como la psicología del adolescente se mueven entre dos nociones, la de la protección, que le sigue de la infancia y la de la independencia propia de la etapa adulta. Justamente por tratarse de una etapa de transición, la adolescencia asume rasgos de las etapas previas y posteriores del curso de vida. El principal marco normativo internacional que orienta las acciones de Colombia y de los 190 países que la firmaron en 1989, es la Convención Internacional sobre los Derechos del Niño propuesta por la ONU, la cual fue ratificada en el país por medio de la Ley 12 de 1991. Desde entonces, el Estado colombiano viene realizando importantes esfuerzos para garantizar y hacer efectivos los derechos consagrados en los instrumentos internacionales y en la Carta Política; ésta, se ha convertido en un marco orientador de las políticas y programas nacionales y territoriales. 
En el orden nacional, el marco que orienta las acciones de política es la Constitución de 1991, que introduce una revaloración de los niños, niñas y adolescentes. Los artículos 44 y 45, consagran sus derechos fundamentales, la obligación de protección y asistencia en cabeza del Estado, la sociedad y la familia y la prevalencia de sus derechos sobre los derechos de los demás.

De igual manera, la ley 1098 de 2006 o código de la infancia y la adolescencia tiene por finalidad garantizar a los niños, niñas y adolescentes su pleno y armonioso desarrollo para que crezcan en el seno de la familia y de la comunidad, en un ambiente de felicidad, amor y comprensión. De acuerdo a esta Ley y sin perjuicio de lo establecido en el artículo 34 del Código Civil, se entiende por niño o niña a las personas entre los 0 y los 12 años de edad, y por adolescente las personas entre los 13 y los 18 años de edad, los cuales son sujetos titulares de derecho.

En coherencia con el código de infancia y adolescencia, los menores de 14 años no cuentan con vinculación a procesos judiciales; sin embargo, se reconocen menores infractores de la ley. Son diversas las causas que conllevan a que los adolescentes se inicien en el mundo de la delincuencia (...) es resultado de la confluencia de múltiples factores en los ámbitos individual, familiar y del ambiente en el cual ellas y ellos crecen, además de los factores de tipo social, político, jurídico y económico (11).

A su vez, la nación ampara a los niños, niñas y adolescentes en su Plan Nacional del 2009 - 2019; sin embargo, no se describen intervenciones específicas por grupos etarios, éstas 
son englobadas para ambos momentos (infancia y adolescencia) como una minoría de edad. A partir de este plan, se produce el Conpes 109 de 2009, el cual define líneas estratégicas para la elaboración de la Política Pública Nacional de Primera Infancia "Colombia por la Primera Infancia”.

Para el 2011, a través del Plan Nacional de Desarrollo "Prosperidad para todos", inicia la implementación del modelo de atención integral "De Cero a Siempre", enfocado a la estimulación adecuada de las diferentes dimensiones del desarrollo infantil temprano. Con esto, Colombia denota prioridad a la primera infancia, pero al mismo tiempo, queda implícita la desprotección de la adolescencia como un periodo relegado a la voluntad política del momento.

\subsection{OBJETIVOS}

\subsubsection{OBJETIVO GENERAL.}

Analizar los procesos de construcción de ciudadanía desde las posibles relaciones entre las políticas públicas de adolescencia y las experiencias particulares en el contexto local de Bosa.

\subsubsection{OBJETIVOS ESPECÍFICOS.}

1. Recopilar información sobre políticas públicas vigentes para la adolescencia. 
2. Recolectar información cualitativa que permita una aproximación a la representación social de la adolescencia en la localidad séptima de Bosa.

3. Realizar un ejercicio analítico a través de métodos cualitativos, donde se confronte la normatividad vigente y la expresión social de la población adolescente.

4. Describir las tensiones resultado de la construcción de sujetos de derechos desde la política pública versus la representación social del contexto local. 


\subsection{MARCO TEÓRICO}

\subsubsection{POLÍTICA PÚBLICA Y SUJETOS DE DERECHOS.}

Diversas son las concepciones que se pueden encontrar en la literatura acerca de la definición exacta de política pública y, sin embargo, sigue siendo un campo de interés y de estudio para muchos académicos, dados los cambios en la política actual y la fuerza que ha tomado la participación ciudadana en procesos de toma de decisiones.

Para Bazúa y Valenti (12), es necesario comprender las políticas públicas desde dos ángulos diferentes. El primero se ocupa de los problemas considerados como públicos y/o los procesos de decisión de las autoridades jurídicamente públicas, ya sea para indagar su compleja multicausalidad y/o para dilucidar la mejor opción de decisión y acción frente a un específico problema público de gobierno (análisis de política o policy analysis). Desde un segundo ángulo, la política pública designa las políticas gubernamentales, estatales o de alguna organización no gubernamental, cuando reúnen ciertas condiciones (12).

En este sentido, el ámbito de la política pública donde se da una profundización técnica sobre los problemas actuales, es la tipología que busca un mayor grado de racionalidad en las decisiones que sobre lo público tome el gobierno; pero dicha racionalidad, será visible a través de la complejidad de la situación a analizar, convocando una serie de actores multidisciplinarios que aporten a la comprensión del problema público. 
Es así que la política pública puede entenderse como las políticas del gobierno de turno o los planes de desarrollo del mandatario actual, teniendo en cuenta que puede darse también en el caso de organizaciones no gubernamentales, pero que optan por unas líneas programáticas en determinado momento.

Siguiendo a Bazúa y Valenti, adoptar un enfoque de política pública implica tanto un abordaje técnico y científico de los problemas públicos, como una indagación sistemática del grado en que se materializa el carácter o naturaleza pública del Estado. Lo anterior permitiría "problematizar lo público de la vida social más allá de los buenos deseos" (12). Con estas afirmaciones, podría decirse que las sociedades fundamentadas en el Estado social de derecho deben propender por la construcción de políticas públicas que partan de una base sólida de la realidad, a través de estudios y análisis producto del ejercicio científico, el cual permita ampliar la comprensión de las situaciones complejas que recaen sobre las poblaciones vulnerables.

Se encuentran otras definiciones en la bibliografía respecto a las políticas públicas. Por ejemplo, Velásquez realiza una exhaustiva pesquisa de los diferentes conceptos de política pública para analizarlos uno a uno y así encontrar el suyo propio. En este ejercicio, el autor realiza un recorrido que va desde James Anderson, quien definió la política pública como un "curso de acción intencional realizado por un actor o grupo de actores que tratan con un problema o asunto preocupante"(13), hasta Carlos Salazar Vargas, quien comprende la política pública como un "conjunto de sucesivas respuestas del Estado frente a situaciones consideradas socialmente como problemáticas" (13). 
Una primera objeción a las definiciones planteadas sobre política pública trata de su dimensión de normatividad. Para Velásquez (13), los conceptos de política pública están ubicados en el "deber ser" como políticas de gobierno. Con lo anterior, se deja de lado otro tipo de políticas que se ocupan de lo público, pero muchas veces resultan de procesos no tan transparentes y hasta autoritarios. Siendo así, el “deber ser” de la política pública se revela como la decisión de la autoridad y muchas veces carece de la participación de los actores que deberían aportar, tanto para ampliar la comprensión del problema, como para diseñar las estrategias de respuesta.

Después del minucioso análisis realizado por el profesor Velásquez sobre cerca de 29 conceptos de política pública rastreados en la literatura especializada, y sometiendo sus ideas al juicio de distintos estudiantes de algunas universidades, el autor se atreve a dar su propia definición del tema, afirmando que:

Política pública es un proceso integrador de decisiones, acciones, inacciones, acuerdos e instrumentos, adelantado por autoridades públicas con la participación eventual de los particulares, y encaminado a solucionar o prevenir una situación definida como problemática. La política pública hace parte de un ambiente determinado del cual se nutre y al cual pretende modificar o mantener. (13)

Con este concepto, el autor pretende integrar la multiplicidad de variables observadas en la política pública, no solo a luz de sus fases de implementación, sino en la contemplación 
de los fenómenos político y social e incluso, ambiental. Con ello, Velásquez parece plantear la importancia de un análisis de los determinantes sociales del ambiente en que se desarrolla la política pública, y de los cuales depende el éxito de la misma, como posibilidad de impactar positivamente en las condiciones problemáticas sobre las cuales se han planteado las políticas.

A su favor, se puede argumentar que se trata de un proceso dinámico en el que están inmersas una serie de relaciones, en las que cada actor adquiere su momento de visibilidad; no se trata de un dictamen o una imposición del deber ser. Velásquez afirma que "para que una política sea pública tiene que contar necesariamente con la participación de autoridades públicas, esto es, con personas e instituciones facultadas expresamente por el ordenamiento jurídico para hacer parte del proceso de formación de las políticas” (13).

Seguir las múltiples concepciones de la política pública no es el objetivo de este marco teórico. Se han trazado ya algunas ideas sobre lo que en definición busca la política pública, pero se ha dejado hasta ahora de lado la cuestión sobre quién es el sujeto de la política pública, a quiénes debe beneficiar, y cuáles son las características particulares de las poblaciones beneficiadas. Más allá de algunos tecnicismos como el listado de sus definiciones, se tratará de dar lugar al sujeto de la política pública y así poder vislumbrar la posibilidad de su construcción, a través de ella misma.

Con las nuevas corrientes políticas, las políticas públicas adquieren un nuevo matiz tanto para su comprensión como para su implementación. Dado que las situaciones más 
problemáticas acaecen sobre las poblaciones más vulnerables, es necesario hablar de una política social que atienda la pobreza extrema y la indigencia. De esta manera, la política pública da lugar a una política social que desde la década de los 80 se caracteriza por su tono neoliberal.

Según Ponzone y Garello, "la política social constituye el ámbito de producción y reproducción de la vida social de los sujetos, en tanto dispone de la acción estatal en el conjunto de la sociedad" (14). En esta medida, se crea una protección social centrada en los más vulnerables, que terminará siendo asistencialista, puesto que atiende solo las necesidades más básicas, dejando de lado la afectación del contexto propio en el que el individuo se desarrolla y en el que las personas conviven. Este tipo de protección social deseable, marca la pauta para evaluar las políticas desde índices de pobreza e indigencia que no reflejan la complejidad de las situaciones de inequidad de las poblaciones.

La política social en gobiernos neoliberales, ha convertido a la protección social en proyectos asistencialistas encaminados a reducir la pobreza mediante la garantía de los mínimos biológicos, como los denomina Álvarez Leguizamón (15). Esto significa que las garantías de este tipo de políticas solo permiten que la población permanezca en las barreras de la subsistencia, olvidando otros factores determinantes para la construcción de sujetos como la capacidad de cambiar las condiciones desfavorables de su entorno desde el ejercicio de los derechos humanos. 
En efecto, lo que ocurre durante el recorrido de la política pública está asociado con la historia política de la región latinoamericana, la cual transita entre una mirada asistencialista de la protección social, y la adopción de los derechos humanos como enfoque principal para la construcción de sujetos desde la equidad.

Los convenios internacionales reivindican el papel de los derechos humanos en la implementación de programas y políticas sociales que dan líneas y enfoques para la realización de intervenciones que fortalezcan las comunidades menos favorecidas. Sin embargo, en su afán por proclamarse desde la globalidad, dichas políticas abandonan cierto matiz necesario para generar eficazmente los cambios requeridos por las poblaciones locales.

Ahora bien, la persona que se constituye durante las primeras etapas del ciclo vital debe adaptarse a las exigencias de las políticas actuales. En el caso de la adolescencia, se ha asumido como un grupo etario bajo el imaginario social de la "minoría de edad", con el potencial de realizar los cambios necesarios para el desarrollo social. El camino para salir de dicha minoría produce el ingreso de los adolescentes a la comunidad económica, la cual lo inserta en un ambiente abierto a la satisfacción de las necesidades propias del desarrollo humano y social, condicionado por la ocupación laboral del individuo.

Dicha adaptación no suele producirse de manera equitativa para todos. La exposición al riesgo del contexto singular donde ocurre el desarrollo humano y social no se realiza de 
una manera universal, sino que se da bajo condiciones que propician o no el acceso a oportunidades para el desarrollo.

El individuo se ve abocado a la búsqueda de oportunidades o influencias para facilitar su desarrollo; no obstante, pueden no ser las suficientes para la satisfacción, incluso de sus necesidades más básicas; los Estados han sido responsables en ello, para lo cual se han formulado políticas públicas para la atención a problemas sociales que soporten los efectos de la inequidad. En tanto políticas públicas sociales, justifican la operación de respuestas encaminadas a satisfacer las necesidades pendientes en los individuos con menor capacidad económica.

Pero en ese afán por encontrar las razones más simples, surge el ámbito familiar como un pilar para la protección social, encargado de garantizar las expectativas de los individuos frente al bienestar, es decir, los problemas sociales son adjudicados a fallas familiares (14). Con esto, la política social del neoliberalismo encarga al orden privado la resolución de problemas públicos.

Al respecto, Lautier expone que la garantía de la protección social está ligada a una comprensión de lo social entendido como "un conjunto de mediaciones entre tres órdenes: el económico, el político y el doméstico, que no son otra cosa que la triada institucional compuesta por la empresa, el Estado y la familia" (16). 
Siguiendo esta idea, los sujetos construidos por la política social neoliberal siguen siendo los más vulnerables: acceden a los proyectos para atender a las necesidades básicas en su territorio, pero dichos sujetos permanecen atados a la idea neoliberal de merecedores de la asistencia, idea que contiene la noción de contraprestación como promoción del capital humano (14).

Ahora, introducir el concepto de derecho en las políticas públicas, ocasiona una mirada diferente de la protección social, con un espectro mucho más amplio, permitiendo la construcción de los sujetos que la sociedad demanda. Sin embargo, hay que tener en cuenta que la visión del derecho no es tanto canónica como producto de las transformaciones sociales que se han instaurado en los convenios y tratados internacionales como defensa de los principios básicos de la humanidad.

En la aproximación que Castrillón (17) hace de la construcción de sujetos institucionales, el autor alude a Geertz para explicar que el estudio cultural de los derechos humanos es "un espectro variado de "modos de ver (de representar) la relación entre hecho y ley, que no designa únicamente una cuestión formal (...) pues en este aspecto se definen maneras de imaginar lo real" (17). En ese sentido, el enfoque de derechos humanos estaría permeando la apuesta social de las políticas públicas, y la forma de comprender la población que dichas políticas buscan impactar.

Sin el ánimo de querer aún definir el concepto de derecho, es importante resaltar la incursión de este concepto en las políticas públicas, dado que esto marca la transición, por 
ejemplo, en Colombia, del código del menor, al código de la infancia y la adolescencia. Como ya se ha mencionado, la relación entre hecho y ley significa aquí un cambio estructural en el modo de comprender este grupo etario. Para el anterior código, el problema se señalaba como situación irregular, donde los niños y adolescentes eran tratados como objetos de compasión y represión; bajo el nuevo código, el objetivo está fundamentado en la protección integral de niños y adolescentes, vistos como sujetos de derechos.

\subsubsection{INFANCIA, ADOLESCENCIA Y CONSTRUCCIÓN DE SUJETOS DE DERECHOS.}

Históricamente, las comprensiones sobre las diferentes etapas de la vida han tenido múltiples transformaciones. Durante la Edad Media, los niños y niñas eran considerados como "adultos en miniatura" (18). Posteriormente, a raíz de procesos modernos como la expansión del Estado y el individualismo, se fue transformando la concepción de infancia en la sociedad occidental. Particularmente, después de la segunda guerra mundial, las conceptualizaciones referentes a la infancia se enmarcaron en políticas dirigidas a la formación y bienestar de los niños, niñas y jóvenes en el marco más amplio del Estado de bienestar (18).

Respecto a la infancia, el periodo inicia en el nacimiento, pero mientras que algunos autores dan por finalizada esta etapa a los 12 o 14 años, para organismos como la ONU se acepta un intervalo más amplio, que comprende entre los 0 y 18 años (19); sin embargo, ésta 
última perspectiva parece incluir dos etapas diferenciables, la infancia y la adolescencia. Ahora bien, para comprender los conceptos de infancia y adolescencia, se deben hacer varias salvedades. Como lo mencionan diversos autores, si bien se puede abordar dichos conceptos entendidos como un periodo determinado de la vida de un ser humano medible, no hay un acuerdo generalizado respecto a qué años abarca con exactitud $(19,20)$.

Sin embargo, algunos autores, hacen referencia a subetapas incluso al interior de la categoría poblacional. Para Blos (4), la preadolescencia se entiende entre los 9 años y los 11 años. En este periodo de tiempo, cualquier experiencia (ya sean pensamientos y actividades sin ninguna connotación erótica o sexual) se transforma en estímulos sexuales y tienen función de descarga.

De otro lado, en la adolescencia temprana, referida al periodo entre los 12 años y los 14 años, la principal característica se encuentra marcada por el inicio del alejamiento de los objetos primarios de amor (madre-padre), y en la búsqueda de nuevos objetos se establecen nuevas relaciones. El interés de la población en esta etapa se centra en la genitalidad, la adopción de valores, reglas y leyes adquieren cierta independencia de la autoridad parental, lo cual se representa como una amenaza para quebrantar el autocontrol (4).

Se puede decir que la adolescencia es una etapa de la vida en donde se realiza la transición de la niñez a la adultez. Como lo mencionan Moreno y del Barrio (20), el comienzo de dicha etapa está asociado con la aparición de la pubertad, referida ésta al proceso de cambios de tipo biológico que se dan en los jóvenes y que concluyen en la maduración 
sexual y física. Efectivamente, Trujillo (21) expone que desde la perspectiva del ciclo vital se considera que la adolescencia es ante todo un constructo teórico para denominar cambios a nivel biológico, psicológico y social, que acaecen entre la pubertad y el posicionamiento de una persona en la adultez.

A pesar de lo anterior, esta conceptualización se ha hecho en gran parte desde el mundo adulto. Casas (19) hace referencia a que justamente la construcción de las representaciones sociales de la infancia, que a su vez definen los derechos de esta población, aquellas que son transmitidas a los niños y niñas a través de relaciones padres-hijos, la población en general y los medios de comunicación, son ideadas por los adultos. Esto puede dificultar el proceso de auto-designación de la infancia, debido a dos cuestiones fundamentales: por un lado, a la idea de que los niños y niñas, por el momento mismo en que se encuentran dentro del proceso de desarrollo, no siempre son capaces de auto-designarse por su relativamente corta historia y memoria (en comparación, por supuesto, con aquellas de los adultos); y por otro lado, la falta de capacidad de auto-designación se encuentra en la resistencia de los adultos a reconocer en los niños y niñas la capacidad de interlocución, por el hecho de ser menores.

Ahora bien, la agencia de los niños y niñas ha estado limitada debido a su pertenencia a una temprana etapa del desarrollo; sin embargo, en la actualidad, esfuerzos como los del gobierno escolar constituyen mecanismos de empoderamiento de los niños y niñas en decisiones referentes a su vida escolar, lo que habla de una concepción de los niños como actores sociales (18), y sujetos de derechos (ya no solamente objetos de derechos). Asumir 
a los niños, niñas y adolescentes como sujetos de derecho implica que ellos mismos tienen capacidades de auto-determinación y agencia, es decir que tiene la capacidad de comprender las normas que regulan su sociedad, de materializar y exigir sus derechos en el marco del respeto del acuerdo social al que pertenece.

En ese orden de ideas, resulta coherente que la proyección en términos de los sueños realizables se valorice aún más durante la infancia, y se articule con proyectos comunes; pero, esto implica el supuesto de que los niños y niñas sean partícipes y artífices de su propio destino. Los adultos deben entonces abandonar la idea de un diálogo "unilateral" en el que al niño se le enseña como si fuera una pintura en blanco, y en cambio, abrir canales de comunicación que permitan justipreciar las opiniones infantiles, esto sin querer decir que un lineamiento o guía adulta deje de ser necesaria para la protección de la infancia. Así como Corvera (22) argumenta la importancia de la participación de los niños y niñas en la elaboración y el diseño de las políticas públicas, Torney-Purta \& Amadeo (23) mencionan que, en el desarrollo del pensamiento político, se presenta tanto una construcción individual como una social, lo que habla de la bidireccionalidad del proceso.

La protección se empezó a transformar históricamente en un propósito social, cuyos mecanismos enmascaraban una necesidad de "control de la infancia y su adecuación a nuevas formas de organización de la sociedad" (24). Y si la construcción del concepto de infancia ha sido complicada, aún más la de adolescencia, debido a su carácter transitorio y ambiguo; esto explica la contradicción evidenciada por los adolescentes, cuyo conflicto actual es en gran medida la ruptura de la inocencia infantil, que quisiera perpetuarse en la 
conciencia moral del mundo adulto (24). Es decir, la inocencia infantil pretende prolongarse tanto como sea posible, a pesar de que el proceso biológico evidencia cambios como el crecimiento físico y el desarrollo de los rasgos secundarios de atracción sexual.

Si se trata entonces de hablar de la auto-designación adolescente, es igualmente complicado, justamente porque los adolescentes están en una etapa transitoria en donde experimentan cambios, que los hace cercanos tanto a la niñez como a la juventud y adultez. En ese sentido, la identidad como construcción parte, no solamente de una dicotomía con el mundo exterior y aquello que tiene éste de diferente, sino que también se enmarca dentro de una dicotomía interna referente a la vaguedad del cuerpo durante la etapa adolescente.

Sin embargo, y precisamente por ser éste un momento transitorio por excelencia, tiene grandes responsabilidades en términos de un proceso de ganancia de autonomía importante respecto a la de la infancia. En ese sentido, el despertar sexual del cuerpo no solamente refiere a cambios biológicos, sino a nuevas formas de relacionarse con los demás y con el mundo, lo que implica que se desarrolle una proyección en términos del cuidado a sí mismo, aún más evidente que el de la niñez.

Después de la etapa adolescente, se vive un periodo referido como juventud, y que hace alusión a esa "moratoria social" (25) que transcurre desde la adolescencia hasta la integración a la vida social adulta. Ser joven depende no únicamente de una condición de edad en términos del desarrollo, sino que también sugiere aspectos económicos, sociales y culturales que hablan de una heterogeneidad de la juventud. Por ende, los discursos auto- 
designativos de los jóvenes son múltiples, ya que las memorias que fundamentan su identidad narrativa vienen cargadas de experiencias sumamente distintas, de contextos completamente diferentes, incluso si los medios masivos de comunicación interfieren cada vez en mayor medida en estas narraciones.

Ahora bien, una visión idealista del joven como agente de cambio ha marcado tendencias a la hora de acercarse a una conceptualización de las juventudes. En esa medida, las tribus urbanas mencionadas por Margulis \& Urresti (25) juegan un papel fundamental en la resistencia al sistema imperante. Estas resistencias activas son exponentes de "una lucha de clases (...) y de un enfrentamiento entre generaciones, síntomas de un futuro incierto” (25). Pero vale la pena resaltar que, a pesar de esta utopía de lo juvenil, el sistema se ha encargado de construir un imaginario que sea acorde con los presupuestos neoliberales del mercado y la economía: la imagen del joven mito como heredero de la tradición capitalista es manifestada bajo mecanismos de publicidad, enalteciendo valores como la competencia y el estatus social de una clase dirigente. Por lo tanto, el agenciamiento de los jóvenes en términos de posibilidad de transformación social se contradice constantemente, y transita entre los imaginarios impuestos culturalmente y una confrontación con el sistema que impone dichos imaginarios.

La proyección de los jóvenes resulta por lo tanto incierta, marcada por discursos, referentes y prácticas contradictorias. Encaminar a la juventud mediante mecanismos jerárquicos de relación resulta por eso inútil, por no decir contraproducente. Si se quiere realmente hablar de una proyección en términos de lo que se puede realizar, el superar una apatía o una 
desesperanza frente al mundo actual implica construir una autonomía crítica frente a esa realidad, así como empezar a realizar transformaciones desde ámbitos micro sociales que devuelvan la esperanza en que un proyecto común es posible. Se hace necesario rescatar el sentido utópico de una comunidad de destino (26), ya que solo en esa medida, es posible hablar de subjetividades políticas.

La construcción de dicha subjetividad se mueve en dos direcciones que a pesar de poder ser entendidas como discordantes, conviven en un mismo espacio. Se promueve un ordenamiento social del sistema, a modo de normativa que busca el bienestar de la sociedad y, sin embargo, se encuentra bajo el énfasis del control.

Esa paradoja se evidencia en el texto de Donzelot (27), quien expone que el advenimiento de la familia moderna se caracterizó por dos líneas de comprensión acerca del control de la infancia y la adolescencia: mientras que la "familia burguesa" se regía por una lógica de "liberación protegida" en la que los niños y niñas eran controlados a través de una "discreta observación" para transmitirles una serie de normativas corporales y sanitarias que determinaban su desarrollo, la lógica de las clases trabajadoras estaba basada en un control menos sutil de los niños y niñas, en el cual se guiaba a los niños a espacios concretos de vigilancia (como las escuelas o las viviendas). Este segundo modelo pedagógico era el de una "libertad supervisada" (27).

Sin embargo, Donzelot (27) plantea que el hecho que las familias o las escuelas no fueran suficientes para garantizar un control social sobre la infancia, demandó la reglamentación 
jurídica del control y de la protección de la infancia y la adolescencia por parte de agentes educativos y sociales. Lo anterior tiene un impacto particular en las familias con mayores grados de vulnerabilidad económica, y da cuenta de una relación particular entre las instituciones y el desarrollo de los sujetos en un determinado ordenamiento social.

Por otro lado, la construcción de una subjetividad política suscita la formación de una autonomía capaz de reevaluarse críticamente para entrar en diálogo con la realidad social, económica y cultural. Esta tensión representa la lucha de los jóvenes entre aceptación del sistema o resistencia hacia el mismo. Paralelamente, como lo plantea Correa Tapia (28), la adolescencia es la etapa en la que psicológicamente se da una cierta ruptura de los lazos familiares, para pasar a hacer parte de una sociedad global, asumiendo en ese paso el abandono de actitudes de irresponsabilidad, correspondientes a la configuración psíquica infantil, para comenzar una nueva expectativa de responsabilidad.

Existe una "voluntad de conocer" (26), que permitiría a los jóvenes concebirse como protagonistas de su propia historia, contribuyendo así, al interés de éstos frente a dinámicas de poder que tradicionalmente han sido jerárquicas, pero que pueden modificarse en pro de permitir una participación más activa de la población infantil y adolescente. De hecho, James (29) plantea que cuando dichas poblaciones encuentran maneras de ejercer sus derechos en su cotidianidad, son reconocidas como capaces de adquirir un estatus de ciudadanos participativos. 
Cuestionar los hábitos impuestos de una moral tradicional es una forma de ampliar las perspectivas de comprensión del mundo y de las demás personas, apelando a principios de tolerancia que estén por encima de imaginarios excluyentes y que pongan en evidencia que el respeto y la tolerancia deben partir de concebir al otro como un ser humano que merece dicho trato, al igual que uno mismo. En ese sentido, se logra articular el cuidado por uno y el cuidado por los demás, y lo otro perteneciente al mundo exterior.

Así, se construyen sujetos de derechos capaces de pensarse y de pensar a un otro diferente de sí mismo, desde una perspectiva psicoanalítica (30). Adicionalmente, cabe mencionar la importancia de una intersubjetividad indispensable en la construcción de una identidad coherente con la historia particular de cada uno. En esa medida, los adolescentes habitan un "territorio simbólico-conceptual" en donde pueden nacer y desarrollarse (en un sentido no lineal) las subjetividades políticas (26).

Las políticas sociales provienen de un reconocimiento social de necesidades que terminan siendo asumidas como problemas colectivos (19). Resulta entonces primordial que esta colectividad tenga en cuenta su población objetivo para facilitar procesos de construcción de subjetividades. En ese sentido, aún hay una tarea pendiente con los adolescentes que viven en condiciones de vulnerabilidad en Colombia; de ahí que se exponga la resistencia de las políticas públicas a abordar a los jóvenes desde una perspectiva de "construcción de sujetos de derechos", más allá de simplemente llamarlos como tal (31). 


\section{ANÁLISIS DEL MARCO NORMATIVO VIGENTE}

En este capítulo se tratará de moldear un análisis de los documentos de la política pública en Colombia desde el contexto local, que servirá de margen estructural para la aproximación a la garantía de derechos en la población adolescente de la localidad de Bosa.

Como marco teórico se han explorado algunas definiciones de la política pública, desde lo cual se propone delinear una serie de paradigmas creados a partir de la comprensión histórica de la política como material bibliográfico. Para ello, es necesario realizar una revisión de los fundamentos presentados en la promulgación de la política como parte de lo público para responder a lo social. En esta misión, para atender a los requerimientos de la ciudadanía, las políticas se basan en sus propios enunciados como leyes que constituyen el quehacer del gobierno frente a la satisfacción de necesidades apremiantes en la sociedad.

En el resurgir de la política social, ésta se entiende tradicionalmente como una garantía universal. La primera política con estas premisas está cargada de buenas intenciones, como una elaboración del deber ser en una cultura marcada por la globalidad; en estas apuestas se reivindicaba la universalidad desde coberturas que permitieran llegar a los más necesitados. La nueva política tiene como protagonista a la pobreza, con lo cual se hace selectiva y focalizada en una proporción específica de la población.

Los análisis realizados a estos tipos de paradigmas hallados en las políticas públicas permiten plantear un escenario donde la equidad hace parte de una búsqueda avanzada en 
los objetivos de la política social. El paradigma emergente logra integrar el enfoque de derechos para llegar a problemas cada vez más complejos acordes con la dinámica social presentada.

La evaluación y el análisis se encuentran en una estrecha relación (32) en la cual, no podría hablarse de análisis sin una evaluación previa. Por lo tanto, habrá de tener en cuenta que la evaluación tiene un carácter descriptivo, dado por su enfoque retrospectivo, mientras el análisis propone un más allá, al intentar darle sentido a los resultados de la evaluación.

Un análisis de las políticas públicas debe observar los principios rectores y los elementos que son usados permanentemente en su designación (32). Así mismo, Salazar acoge la visión de Weiss respecto a la evaluación, no solo como énfasis de los resultados, sino en el estudio de los diferentes procesos de los que surgen las políticas públicas. Una evaluación bajo esta perspectiva trataría de hallar los valores inscritos en los objetivos de la política pública, entendiendo que dicha política debe estar orientada hacia la resolución de un problema social (32).

Para Weiss, la evaluación y la política mantienen una permanente relación (33). Por ello, las metodologías para estudiar las políticas públicas son cada vez más complejas, puesto que intentan ser aceptadas en la toma de decisiones, toda vez que hayan incluido los enunciados que la política se ha propuesto y no sean evaluaciones aisladas, que desbordan los objetivos de la misma política. 
De esta manera, el presente estudio propone una evaluación y análisis de las políticas públicas para la adolescencia, desde el anterior enfoque en su diseño a través de los documentos de política vigentes en el territorio nacional y aplicados en el territorio de la localidad de Bosa. Al ubicarse en el diseño de la política, se elaborará una evaluación de los contenidos expresados por la misma, para lograr un análisis de los aspectos técnicos, las orientaciones conceptuales hacia una política social y las implicaciones significativas como estrategias de desarrollo.

La política social está en una cercana relación con las políticas económicas en los países latinoamericanos, producto del avance del neoliberalismo en toda la región. En esta medida, la evaluación y análisis de las políticas públicas buscan un abordaje eficiente de los problemas sociales a través de un rediseño institucional y de contenido de las políticas sociales tradicionales (34).

La emergencia de nuevos enfoques para el diseño de políticas públicas supone un cambio de paradigma en la comprensión y en el alcance de las mismas. Esta relación entre la política social y económica ha demostrado que genera más inequidad social de la que se propone reducir, pues plantea una protección social basada en mecanismos de economía del mercado. Hay una noción de la política social como compensatoria de la insatisfacción de las necesidades, estando acompañada de acciones asistencialistas, mientras ocurre el planeado crecimiento económico, lo cual generaría un mayor bienestar en las sociedades neoliberales. 
La formulación de las políticas públicas es una tarea compleja (35). En concordancia con lo promulgado por el BID, se entiende como los efectos de las políticas sobre las condiciones económicas y sociales se encuentran asociadas a las decisiones de agentes económicos y sociales, quienes reflejan en los enunciados de las políticas unos intereses particulares.

Siendo así, al realizar una evaluación y análisis del diseño de las políticas para la adolescencia en Colombia, se mostrará la dinámica en la que se plantean los diferentes elementos conceptuales, en términos de política social para una población focalizada. De igual forma, se trata de ilustrar el modo en el cual el ejercicio de la política social para la adolescencia se adhiere a alguno de los paradigmas de la política pública latinoamericana.

Ubicándose en el diseño de las políticas públicas, el presente trabajo pretende transcender las críticas realizadas a este tipo de análisis. Pues bien, desde una perspectiva institucional, la evaluación y análisis del diseño realizados se mantienen en una esfera de lo formal, entendidos como análisis previo de la política (36); sin embargo, en la medida en que las conclusiones logren presentar recomendaciones prácticas frente a las contradicciones puestas en evidencia mediante el ejercicio evaluativo y analítico del diseño de las políticas vigentes, se alcanzará un nivel esperado en cuanto a la superación de las críticas señaladas.

Hasta ahora, se puede afirmar que el proceso de evaluación y análisis del diseño de las políticas públicas como desarrollo metodológico se muestra complejo dadas las variables técnicas e históricas en las cuáles surgen y se legitiman. Hace falta comprender este análisis 
desde una perspectiva antropológica en la medida en que la política pública se muestra como una actividad sociocultural. Si bien se encuentra regida por leyes, se mantiene inmersa en los procesos sociales cotidianos, en los protocolos lingüísticos, dando sentido a lo humano (37).

Los estudios de políticas públicas aún se muestran como una actividad exclusiva de las élites gubernamentales, a modo de una reflexión de autocontrol para los gobiernos. En esta medida, se entienden los procesos de formulación de manera lineal, "que vienen de arriba hacia abajo" (37). Así, se crea una cadena lógica, la cual inicia con la declaración de unos principios consignados en un texto, pasando a su respectiva versión como legislación, para luego descender por diferentes niveles administrativos hasta llegar a sus beneficiarios.

No obstante, plantear un análisis antropológico del diseño de las políticas públicas se basa en explorar los sistemas de gobierno como mutables, pues reflejan maneras de pensar sobre el mundo (37); se trata de ilustrar el contenido de las políticas públicas como modelos de sociedad donde se relacionan los individuos y el Estado.

Según Majone, citado por Shore, las políticas son siempre instrumentales pues contienen una "voluntad de poder" (37). En esta medida, las políticas crean nuevas categorías de personas y nuevas formas de subjetividad. Por consiguiente, una aproximación antropológica al análisis de las políticas públicas ofrece una oportunidad para reflexionar en las transformaciones de la sociedad, en las categorías socioeconómicas cambiantes y en las emergentes racionalidades de gobierno. 


\section{Cuadro 1. Políticas Públicas Vigentes para la adolescencia seleccionada para la evaluación y análisis}

\begin{tabular}{|c|c|c|}
\hline Nombre & Fecha de expedición & Vigencia \\
\hline $\begin{array}{l}\text { Ley 1098: Código de Infancia y } \\
\text { Adolescencia } \\
\text { Plan Nacional para la Niñez y la } \\
\text { Adolescencia } 2009 \text { - 2019. Colombia: } \\
\text { Niñas, niños y adolescentes felices y } \\
\text { con igualdad de oportunidades }\end{array}$ & $\begin{array}{l}\text { Noviembre } 8 \text { de } 2006 \\
2009-2019\end{array}$ & Pendiente \\
\hline $\begin{array}{l}\text { Política por la calidad de vida de niñas, } \\
\text { niños y adolescentes de Bogotá } 2008 \text { - } \\
2011\end{array}$ & $\begin{array}{l}\text { 2008, ratificada en } \\
2011\end{array}$ & $2011-2021$ \\
\hline $\begin{array}{l}\text { Prosperidad para todos. Plan Nacional } \\
\text { de Desarrollo } 2010 \text { - } 2014 \text { Más empleo, } \\
\text { menos pobreza y más seguridad. }\end{array}$ & Junio 16 de 2011 & $2010-2014$ \\
\hline $\begin{array}{l}\text { Resolución } 1841 \text { de } 2013 \text {. Plan } \\
\text { Decenal de Salud Pública } 2012-2016\end{array}$ & Mayo 28 de 2013 & $2012-2021$ \\
\hline $\begin{array}{l}\text { Plan de Desarrollo } 2012 \text { - } 2016 \text { Bogotá } \\
\text { Humana. }\end{array}$ & $\begin{array}{l}\text { Acuerdo número } 489 \\
\text { del } 12 \text { de junio de } \\
2012\end{array}$ & $2012-2016$ \\
\hline $\begin{array}{l}\text { CONPES social } 147 \text { - lineamientos } \\
\text { para el desarrollo de una estrategia para } \\
\text { la prevención del embarazo en la } \\
\text { adolescencia y la promoción de } \\
\text { proyectos de vida para los niños, niñas, } \\
\text { adolescentes y jóvenes en edades entre } \\
6 \text { y } 19 \text { años. }\end{array}$ & Enero 31 de 2012 & $\begin{array}{l}\text { Este documento para la Prevención del } \\
\text { Embarazo Adolescente, P.E.A., comenzó } \\
\text { en el } 2012 \text { y tiene vigencia hasta el } 2015\end{array}$ \\
\hline Resolución 00412 de 2000 & Febrero 25 de 2000 & $\begin{array}{l}\text { Activa - Esta resolución rige tres (3) } \\
\text { meses después, contados a partir de la } \\
\text { fecha de su publicación y deroga las } \\
\text { disposiciones que le sean contrarias, en } \\
\text { especial la Resolución } 3997 \text { de } 1996 \text {, la } \\
\text { cual continuará aplicándose mientras } \\
\text { entra en vigencia la presente resolución. }\end{array}$ \\
\hline Decreto 031 de 2007 & Enero 24 de 2007 & $\begin{array}{l}\text { Activa, Este Decreto rige a partir de la } \\
\text { fecha de su publicación y deroga todas las } \\
\text { normas que le sean contrarias. }\end{array}$ \\
\hline $\begin{array}{l}\text { Política pública nacional de primera } \\
\text { infancia, infancia y adolescencia }\end{array}$ & Diciembre de 2013 & $\begin{array}{l}\text { Esta publicación es producto del } \\
\text { Convenio N } \mathrm{N}^{\circ} 3332 / 12 \text { suscrito entre el } \\
\text { ICFB y el PNUD. Los contenidos son } \\
\text { responsabilidad de las entidades } \\
\text { participantes. }\end{array}$ \\
\hline
\end{tabular}

Fuente: elaboración propia, agosto de 2016 
Para el estudio, se clasificaron 10 políticas públicas así: seis en el orden nacional, tres en el orden distrital y una como excepción para algunas regiones focalizadas. Suponiendo que en el Estado Social de Derecho la base jurídica es la constitución política de la nación, (no obstante, se basa en las actuales tendencias de la política pública nacional, la cual introduce los acuerdos internacionales frente al desarrollo sostenible) dentro de las políticas públicas, se consideraron las leyes, decretos y resoluciones, a su vez, se incluyeron planes de desarrollo tanto para la nación como para el distrito y se seleccionaron dos documentos técnicos, los cuales no son de obligatorio cumplimiento, pero sirven como lineamientos o guías técnicas para la intervención con la población sujeto del proyecto de investigación.

\section{Cuadro 2. Criterios de evaluación}

\begin{tabular}{ll}
\hline Criterios & Contenidos \\
\hline Fundamentación & Tipología \\
& Vigencia \\
& Objetivos \\
& Principios \\
& Paradigma \\
& Aceptabilidad \\
Manejo de lo público & Efectividad \\
& Histórico \\
& Potencial de intervención \\
& Transparencia \\
Conceptualización de la adolescencia & Inclusión \\
como sujeto de la política & Definición \\
& Ejercicio de los derechos \\
Enfoques & \\
Estructura & \\
Evaluación &
\end{tabular}

Fuente: elaboración propia, 2016

Para los fines del presente trabajo se requiere establecer unos criterios propios que son resultados de modelos de evaluación de políticas públicas consultados según la literatura 
mencionada al inicio del presente capítulo, pero que ordenada de esta manera, ofrece una mirada integral y novedosa de los requerimientos posibles de rastrear en el diseño de las políticas públicas establecidas en el territorio nacional para la adolescencia.

Fundamentación: bajo este criterio se busca evaluar las bases de la reflexión encontrada en el diseño de política pública en Colombia, para relacionarla con los paradigmas de los procesos de política pública de la región latinoamericana y del caribe. Para evaluar dicho criterio se definieron los siguientes contenidos:

- Tipología: la política resulta de una designación que en primer lugar se reglamenta como expresión del Estado mediante la ley. En este sentido, puede resultar como resolución, decreto, acuerdo o política.

- Vigencia: se entiende como el periodo de tiempo en el cual tiene incidencia la política pública sobre la definición de prioridades para el Estado. En ocasiones se condiciona al gobierno actual y, en casos donde la problemática es apremiante, logra trascender las administraciones para pensar en impactos a largo plazo.

- Objetivos: son las apuestas realizadas por la política en el momento de su diseño y formulación. Revelan unos compromisos puntuales frente a lo que se espera de la política; así mismo, el objetivo refleja una adherencia conceptual y teórica con un modo de entender la política en un determinado momento de la historia.

- Principios: son la base para iniciar el debate alrededor de la política pública. Los principios representan una intencionalidad frente al deber ser de una época. 
- Paradigma: es el modo en que se ha venido usando la política pública. En el caso del presente documento se toman tres paradigmas identificados en la región latinoamericana, los cuales se relacionan estrechamente con la política social: política social tradicional, una nueva política y una política emergente.

Manejo de lo público: el segundo criterio tiene que ver con el manejo que la política hace del concepto de lo público. Para ello, se ha revisado el marco conceptual de la formulación del PDSP, el cual plantea una serie de contenidos temáticos, de los cuales se han seleccionado los siguientes:

- Aceptabilidad: es la validación tanto del problema como de la intervención. La aceptabilidad de la salud implica que, entre un conjunto de posibilidades, las personas puedan elegir en torno al manejo de su propia salud. Desde una perspectiva del diseño de políticas, se entiende la aceptabilidad como el reconocimiento de la sociedad sobre la búsqueda del bienestar.

- Efectividad: es la capacidad de producir el efecto deseado y lograr el resultado. Mide el éxito de la política propuesta. De acuerdo con la metodología, se evaluará la efectividad del diseño en la medida en que se logren identificar los recursos técnicos, financieros y humanos necesarios para la implementación de la política.

- Histórico: hace referencia a la tendencia y permanencia en el tiempo de los problemas de salud. Una política pública pensada para atender a 
problemáticas sociales debe encargarse de reducir o erradicar la situación diagnosticada.

- Potencial de intervención: este contiendo pretende hallar la red de actores planteada por la política para la intervención del problema diagnosticado. La política debe plantear cómo se responde al problema por otros sectores y actores. La determinación social de la salud, convoca a intervenciones integrales e integradas del sector salud con otros sectores y actores del desarrollo.

- Transparencia: hace referencia al proceso metodológico y de rendición de cuentas. Es el acto que consiste en abrir la información gubernamental al público, al escrutinio de la sociedad; no implica un acto de rendir cuentas a una persona en específico, sino la práctica democrática de colocar la información gubernamental en la vitrina publica, para que la gente pueda revisarla, analizarla y de requerirse, usarla como mecanismo de sanción.

Conceptualización de la adolescencia como sujeto de la política: la conceptualización en este momento de diseño de la política pública es de gran relevancia, pues determina la comprensión realizada sobre la población sujeto. Para ello, se han propuesto tres contenidos temáticos:

- Inclusión: este contenido busca hallar dentro de las políticas públicas algún tipo de alusión a los adolescentes. Hasta aquí, se trata de verificar que se haya 
incluido a dicha población como sujeto de la política, aun cuando se limite a su enunciación dentro del diseño de la política pública.

- Definición: se trata de identificar la definición que la política pública presente a cerca de la adolescencia. Se considera indispensable contar con una definición de la población a la cual responde, para tomarla como punto de partida para el despliegue de estrategias de acción; sin embargo, aunque se alude a la adolescencia como sujeto de la política, no es usual encontrar su definición en el diseño de la política pública.

- Ejercicio de los derechos: por medio de este contenido se busca el reconocimiento que la política pública hace del enfoque de derechos, en este caso, para los adolescentes, desde su diseño.

Enfoques: el cuarto criterio tiene que ver con los enfoques en los cuales se fija la política pública, en el sentido de orientar los planes y programas hacia la concreción de los objetivos planteados. Los enfoques reconocen una comprensión de la integralidad que debe garantizar la política púbica como respuesta a una situación compleja previamente identificada.

Estructura: el quinto criterio busca identificar la estructura sobre la cual se ha planteado la política. En algunos casos puede confundirse con las fases para la constitución de la política pública; no obstante, en el presente ejercicio, por estar focalizado en el diseño de la política pública, buscará los apartados en los cuales está 
diseñada la política para su despliegue y operación. La estructura organiza la acción de la política pública desde el diseño.

Evaluación: el sexto criterio indaga por la evaluación planteada en los documentos de política pública. Se trata identificar el modo en que se concibe el seguimiento a la política pública y su coherencia con los objetivos.

A continuación, se presenta la matriz consolidada con el seguimiento a los criterios de evaluación propuestos para el ejercicio:

Cuadro 3 Criterios técnicos para la evaluación de la política pública de Adolescencia 
CRITERIOS TÉCNICOS POLÍTICA PÚBLICA

LEY 1098: CÓDIGO DE INFANCIA $Y$ ADOLESCENCIA

PLAN NACIONAL PARA LA NIÑEZ Y LA

ADOLESCENCIA 2009 -

2019. COLOMBIA: NIÑAS, NIÑOS Y ADOLESCENTES FELICEN Y CON

IGUALDAD DE

OPORTUNIDADES

\begin{tabular}{|c|c|c|c|}
\hline FECHA DE EXPEDICIÓN & VIGENCIA & OBJETIVO O FINALIDAD & PRINCIPIOS \\
\hline Noviembre 8 de 2006 & Actual & $\begin{array}{l}\text { Este código tiene por finalidad garantizar a los niños, } \\
\text { a las niñas y a los adolescentes su pleno y armonioso } \\
\text { desarrollo para que crezcan en el seno de la familia } \\
\text { y de la comunidad, en un ambiente de felicidad, } \\
\text { amor y comprensión. Prevalecerá el reconocimiento } \\
\text { a la igualdad y la dignidad humana, sin } \\
\text { discriminación alguna. } \\
\text { El presente código tiene por objeto establecer } \\
\text { normas sustantivas y procesales para la protección } \\
\text { integral de los niños, las niñas y los adolescentes, } \\
\text { garantizar el ejercicio de sus derechos y libertades } \\
\text { consagrados en los instrumentos internacionales de } \\
\text { Derechos Humanos, en la Constitución Política y en } \\
\text { las leyes, así como su restablecimiento. Dicha } \\
\text { garantía y protección será obligación de la familia, } \\
\text { la sociedad y el Estado. }\end{array}$ & $\begin{array}{l}\text { 1) Protección Integral, } \\
\text { 2) Interés superior de los niños, las niñas y los } \\
\text { adolescentes. } \\
\text { 3) Prevalencia de los derechos. } \\
\text { 4) Corresponsabilidad. } \\
\text { 5) Exigibilidad de los derechos. } \\
\text { 6) Perspectiva de género. } \\
\text { 7) Derechos de los niños, las niñas y los adolescentes de } \\
\text { los pueblos indígenas y demás grupos étnicos. } \\
\text { 8) La responsabilidad parental. } \\
\text { 9) Ejercicio de los derechos y responsabilidades. } \\
\text { 10) Deber de vigilancia del Estado. }\end{array}$ \\
\hline 2009 & $\begin{array}{l}\text { 2019. Actual } \\
\text { según vigencia, } \\
\text { pero hace parte } \\
\text { del plan de } \\
\text { desarrollo del } \\
\text { gobierno } \\
\text { anterior }\end{array}$ & $\begin{array}{l}\text { Establece doce objetivos por las Niñas, Niños y } \\
\text { Adolescentes: } \\
\text { Existencia: } \\
\text { 1. Todos vivos (que ninguno muera cuando puede } \\
\text { evitarse). } \\
\text { 2. Ninguno sin familia } \\
\text { 3. Todos saludables } \\
\text { 4. Ninguno desnutrido o con hambre } \\
\text { Desarrollo } \\
\text { 5. Todos con educación de calidad y no } \\
\text { discriminante } \\
\text { 6. Todos jugando } \\
\text { 7. Todos capaces de manejar los afectos y las } \\
\text { emociones } \\
\text { Ciudadanía } \\
\text { 8. Todos registrados } \\
\text { 9. Todos participando en la vida de la comunidad. } \\
\text { Protección } \\
10 . \text { Ninguno maltratado o abusado } \\
1 \text { 1. Ninguno en una actividad perjudicial o } \\
\text { violenta. } \\
\text { 12. Los adolescentes acusados de violar la ley con } \\
\text { debido proceso y sanciones educativas y } \\
\text { proporcionales }\end{array}$ & $\begin{array}{l}\text { Estos objetivos se consideran como: } \\
\text { 1) mínimos irrenunciables. } \\
\text { 2) Son deseables. } \\
\text { 3) Son posibles. }\end{array}$ \\
\hline
\end{tabular}




\section{CRITERIOS TÉCNICOS}

POLÍTICA PÚBLICA

POLÍTICA POR LA

CALIDAD DE VIDA DE

NIÑAS, NIÑOS Y

ADOLESCENTES DE

BOGOTÁ 2008 - 2011.

PROSPERIDAD PARA

TODOS. PLAN NACIONAL DE DESARROLLO 2010 -

2014 MÁS EMPLEO,

MENOS POBREZA Y MÁS

SEGURIDAD.

\section{RESOLUCIÓN 1841 DE}

2013. PLAN DECENAL DE

SALUD PÚBLICA 2012 -

2016

\begin{tabular}{|c|c|c|c|}
\hline FECHA DE EXPEDICIÓN & VIGENCIA & OBJETIVO O FINALIDAD & PRINCIPIOS \\
\hline 2008 , ratificada en 2011 & $2011-2021$ & $\begin{array}{l}\text { Objetivo General: } \\
\text { Todos los niños y todas las niñas, desde la primera } \\
\text { infancia hasta la adolescencia en Bogotá desarrollan } \\
\text { sus potencialidades, capacidades y oportunidades en } \\
\text { ejercicio de sus derechos. } \\
\text { Objetivos específicos: } \\
\text { 1. El Distrito Capital realiza acciones intencionadas } \\
\text { y diferenciales en condiciones de equidad que } \\
\text { aseguran el ejercicio y disfrute de los derechos de } \\
\text { todos los niños y todas las niñas, desde la primera } \\
\text { infancia hasta la adolescencia en Bogotá. } \\
\text { 2. La sociedad en Bogotá reconoce a todos los niños } \\
\text { y todas las niñas, desde la primera infancia hasta la } \\
\text { adolescencia como ciudadanos, ciudadanas y sujetos } \\
\text { titulares de derechos. } \\
\text { 3) El Estado, la sociedad y las familias actúan de } \\
\text { manera conjunta y coordinada en la protección } \\
\text { integral de los derechos de todos los niños y todas } \\
\text { las niñas, desde la primera infancia hasta la } \\
\text { adolescencia. }\end{array}$ & $\begin{array}{l}\text { El interés superior del niño, niña o adolescente, la } \\
\text { prevalencia de los derechos de los niños, las niñas, y los } \\
\text { adolescentes, la protección integral, la equidad, la } \\
\text { integralidad y articulación de políticas, la solidaridad, la } \\
\text { participación social, la prioridad de las políticas públicas } \\
\text { de niñez y adolescencia, la complementariedad, la } \\
\text { prioridad en la inversión social, la financiación, la } \\
\text { perspectiva de género. }\end{array}$ \\
\hline 16 de junio de 2011 & $2010-2014$ & $\begin{array}{l}\text { Consolidar la seguridad con la meta de alcanzar la } \\
\text { paz, dar un gran salto de progreso social, lograr un } \\
\text { dinamismo económico regional que permita } \\
\text { desarrollo sostenible y crecimiento sostenido, más } \\
\text { empleo formal y menor pobreza y, en definitiva, } \\
\text { mayor prosperidad para toda la población. }\end{array}$ & $\begin{array}{l}\text { 1) Convergencia y desarrollo regional. } \\
\text { 2) Prosperidad democrática. }\end{array}$ \\
\hline 28 de mayo de 2013 & $2012-2021$ & $\begin{array}{l}\text { 1) Avanzar hacia la garantía del goce efectivo del } \\
\text { derecho a la salud. } \\
\text { 2) Mejorar las condiciones de vida y salud de la } \\
\text { población. } \\
\text { 3) Lograr cero tolerancias frente a la morbilidad, } \\
\text { mortalidad y discapacidad evitables. }\end{array}$ & $\begin{array}{l}\text { El plan decenal de salud pública } 2012 \text { - } 2021 \text { asume un } \\
\text { abordaje con múltiples enfoques: la salud como un } \\
\text { derecho, el enfoque diferencial, el enfoque poblacional y } \\
\text { el modelo conceptual de los determinantes sociales de la } \\
\text { salud. }\end{array}$ \\
\hline
\end{tabular}


CRITERIOS TÉCNICOS POLÍTICA PÚBLICA

PLAN DE DESARROLLO 2012 - 2016 BOGOTÁ HUMANA

CONPES SOCIAL 147 LINEAMIENTOS PARA EL DESARROLLO DE UNA ESTRATEGIA PARA LA PREVENCIÓN DEL EMBARAZO EN LA ADOLESCENCIA Y LA PROMOCIÓN DE

PROYECTOS DE VIDA PARA LOS NIÑOS, NIÑAS, ADOLESCENTES Y JÓVENES EN EDADES ENTRE 6 Y 19 AÑOS.

\section{RESOLUCIÓN NUMERO} 00412 DE 2000

\begin{tabular}{|c|c|c|c|}
\hline FECHA DE EXPEDICIÓN & VIGENCIA & OBJETIVO O FINALIDAD & PRINCIPIOS \\
\hline $\begin{array}{l}\text { Acuerdo número } 489 \text { del } 12 \\
\text { de junio de } 2012\end{array}$ & $2012-2016$ & $\begin{array}{l}\text { Mejorar el desarrollo humano de la ciudad, dando } \\
\text { prioridad a la infancia y adolescencia con énfasis en } \\
\text { la primera infancia y aplicando un enfoque } \\
\text { diferencial en todas sus políticas. Se buscará que en } \\
\text { Bogotá se reduzcan todas las formas de segregación } \\
\text { social, económicas, espaciales y culturales, por } \\
\text { medio del aumento de las capacidades de la } \\
\text { población para el goce efectivo de los derechos, del } \\
\text { acceso equitativo al disfrute de la ciudad, del apoyo } \\
\text { al desarrollo de la economía popular, así como } \\
\text { también buscará aliviar la carga del gasto de los } \\
\text { sectores más pobres y la promoción de políticas de } \\
\text { defensa y protección de los derechos humanos de los } \\
\text { ciudadanos y las ciudadanas. }\end{array}$ & $\begin{array}{l}\text { Desarrollo Humano, Enfoque diferencial, segregación } \\
\text { social, económicas, espaciales y culturales. goce efectivo } \\
\text { de los derechos. Cambio climático, sostenibilidad } \\
\text { ambiental, ciudadanía, transparencia y seguridad. }\end{array}$ \\
\hline Enero 31 de 2012. & $\begin{array}{l}\text { Este documento } \\
\text { para ra } \\
\text { Prevención del } \\
\text { Embarazo } \\
\text { Adolescente, } \\
\text { P.E.A., } \\
\text { comenzó en el } \\
2012 \text { y tiene } \\
\text { vigencia hasta el } \\
2015 .\end{array}$ & $\begin{array}{l}\text { Orientar el diseño de una estrategia que haga énfasis } \\
\text { en los proyectos de vida de los niños, niñas, } \\
\text { adolescentes y jóvenes desde los } 6 \text { hasta los } 19 \text { años, } \\
\text { la permanencia escolar y la culminación del ciclo } \\
\text { educativo, y el logro de familias funcionales, } \\
\text { trascendiendo los enfoques biológicos y de riesgo } \\
\text { planteados hasta el momento en algunas } \\
\text { instituciones y proyectos, y reconociendo las } \\
\text { diferencias culturales, regionales, y poblacionales. }\end{array}$ & $\begin{array}{l}\text { Se promueven los factores protectores y la toma de } \\
\text { decisiones responsables, informadas y autónomas sobre } \\
\text { el propio cuerpo, la fecundidad, la construcción de } \\
\text { relaciones de pareja, familiares y sociales, los Derechos } \\
\text { Sexuales y Reproductivos (DSR) y el desarrollo humano; } \\
\text { con el propósito de prevenir el embarazo en la } \\
\text { adolescencia, con especial énfasis en el embarazo en } \\
\text { menores de } 14 \text { años, el embarazo no planeado y el } \\
\text { embarazo producto del abuso u otras formas de violencia. }\end{array}$ \\
\hline Febrero 25 de 2000 & $\begin{array}{l}\text { Activa - Esta } \\
\text { resolución rige } \\
\text { tres (3) meses } \\
\text { después, } \\
\text { contados a partir } \\
\text { de la fecha de su } \\
\text { publicación y } \\
\text { deroga las } \\
\text { disposiciones } \\
\end{array}$ & $\begin{array}{l}\text { Por la cual se establecen las actividades, } \\
\text { procedimientos e intervenciones de demanda } \\
\text { inducida y obligatorio cumplimiento y se adoptan } \\
\text { las normas técnicas y guías de atención para el } \\
\text { desarrollo de las acciones de protección específica y } \\
\text { detección temprana y la atención de enfermedades } \\
\text { de } \\
\text { interés en salud pública. Los contenidos de las } \\
\text { normas técnicas de protección específica }\end{array}$ & $\begin{array}{l}\text { Las apuestas que aplican a la Adolescencia son: a) } \\
\text { Vacunación según el Esquema del Programa Ampliado } \\
\text { de Inmunizaciones (PAI); b) Atención Preventiva en } \\
\text { Salud Bucal; c) Atención del Parto; d) Atención al Recién } \\
\text { Nacido; e) Atención en Planificación Familiar a hombres } \\
\text { y mujeres. Detección temprana: } \\
\text { a) Detección temprana de las alteraciones del } \\
\text { Crecimiento y Desarrollo (menores de 10 años); } \\
\text { b) Detección temprana de las alteraciones del }\end{array}$ \\
\hline
\end{tabular}


CRITERIOS TÉCNICOS POLÍTICA PÚBLICA

\begin{tabular}{|c|c|c|c|}
\hline FECHA DE EXPEDICIÓN & VIGENCIA & OBJETIVO O FINALIDAD & PRINCIPIOS \\
\hline &  & $\begin{array}{l}\text { serán actualizados periódicamente, de acuerdo } \\
\text { con los cambios en la estructura demográfica de } \\
\text { la población, el perfil epidemiológico, la } \\
\text { tecnología disponible en el país, el desarrollo } \\
\text { científico y la normatividad vigente }\end{array}$ & $\begin{array}{l}\text { desarrollo del joven (10-29 años); c) Detección temprana } \\
\text { de las alteraciones del embarazo; } \\
\text { g) Detección temprana de las alteraciones de la } \\
\text { agudeza } \\
\text { seno. } \\
\text { Guías de atención para el manejo de enfermedades de } \\
\text { interés en salud pública: a) Bajo peso al nacer; b) } \\
\text { Alteraciones asociadas a la nutrición (Desnutrición } \\
\text { proteico calórica y obesidad); c) Infección respiratoria } \\
\text { aguda (menores de cinco años) Alta: Otitis media, } \\
\text { Faringitis estreptococcica, laringotraqueitis. Baja: } \\
\text { Bronconeumonía, bronquiolitis, neumonía. d) } \\
\text { Enfermedad Diarreica Aguda /Cólera; e) Tuberculosis } \\
\text { Pulmonar y Extrapulmonar; f) Meningitis } \\
\text { Meningocóccica; g) Asma bronquial; h) Síndrome } \\
\text { convulsivo; i) Fiebre reumática; j) Vicios Retracción de } \\
\text { Estrabismo, Cataratas; k) Enfermedades de Transmisión } \\
\text { Sexual (Infección gonocóccica. Sífilis, VIF; l) } \\
\text { Hipertensión arterial; m) Hipertensión arterial y } \\
\text { Hemorragias asociadas al embarazo; n) Menor y Mujer } \\
\text { Maltratados; o) Diabetes Juvenil y del Adulto; p) } \\
\text { Lesiones pre neoplásicas de cuello uterino; } \\
\text { q) Lepra; r) Malaria; s) Dengue; t) Leishmaniasis } \\
\text { cutánea y visceral; u) Fiebre Amarilla }\end{array}$ \\
\hline Enero 24 de 2007 & $\begin{array}{l}\text { Activa, Este } \\
\text { Decreto rige a } \\
\text { partir de la } \\
\text { fecha de su } \\
\text { publicación y } \\
\text { deroga todas las } \\
\text { normas que le } \\
\text { sean contrarias. }\end{array}$ & $\begin{array}{l}\text { Por el cual se reglamenta el Acuerdo } 238 \text { de } 2006 \text {, } \\
\text { que crea y estructura en el Distrito Capital el sistema } \\
\text { de monitoreo de las condiciones de vida de la } \\
\text { infancia y la adolescencia. Cuyo objetivo es dar } \\
\text { cuenta de manera permanente del estado del } \\
\text { ejercicio de los derechos de los niños, las niñas y } \\
\text { adolescentes de Bogotá. }\end{array}$ & $\begin{array}{l}\text { La veracidad, oportunidad, pertinencia, relevancia, } \\
\text { suficiencia y comparabilidad. }\end{array}$ \\
\hline
\end{tabular}


CRITERIOS TÉCNICOS

POLÍTICA PÚBLICA

POLÍTICA PÚBLICA

NACIONAL DE PRIMERA

INFANCIA, INFANCIA Y

ADOLESCENCIA

\begin{tabular}{|c|c|c|c|}
\hline FECHA DE EXPEDICIÓN & VIGENCIA & OBJETIVO O FINALIDAD & PRINCIPIOS \\
\hline Diciembre de 2013 & $\begin{array}{l}\text { Esta publicación } \\
\text { es producto del } \\
\text { Convenio } \mathrm{N}^{\circ} \\
3332 / 12, \\
\text { suscrito entre el } \\
\text { Instituto } \\
\text { Colombiano de } \\
\text { Bienestar } \\
\text { Familiar (ICFB) } \\
\text { y el Programa de } \\
\text { las } \\
\text { Naciones } \\
\text { Unidas para el } \\
\text { Desarrollo } \\
\text { (PNUD). }\end{array}$ & $\begin{array}{l}\text { Para facilitar la construcción de la política pública } \\
\text { de primera infancia, infancia y adolescencia, en el } \\
\text { marco del articulo } 204 \text { de la Ley } 1098 \text { del } 2006 \text {, se } \\
\text { ordena a los alcaldes y gobernadores como } \\
\text { responsables principales del cumplimiento de } \\
\text { derechos de los niños, las niñas y los adolescentes. }\end{array}$ & Política con enfoque de derechos, diferencial y territorial. \\
\hline
\end{tabular}

\begin{tabular}{|c|c|c|c|c|c|}
\hline \multirow{2}{*}{$\begin{array}{l}\text { CRITERIOS TÉCNICOS } \\
\text { POLÍTICA PÚBLICA }\end{array}$} & \multicolumn{5}{|c|}{ 2. MANEJO DE LO PÚBLICO } \\
\hline & ACEPTABILIDAD & EFECTIVIDAD & HISTÓRICO & $\begin{array}{c}\text { POTENCIAL } \\
\text { DE INTERVENCIÓN } \\
\end{array}$ & TRANSPARENCIA \\
\hline $\begin{array}{lr}\text { LEY 1098: CÓDIGO DE } \\
\text { INFANCIA } \\
\text { ADOLESCENCIA }\end{array}$ & $\begin{array}{l}\text { Ha tenido aceptabilidad, al menos } \\
\text { administrativa, dada la extensión de su } \\
\text { vigencia, aunque se han corregido } \\
\text { algunos aspectos en leyes posteriores: } \\
\text { Yerros corregidos por el Decreto } 578 \\
\text { de } 2007 \text {. Que en la Ley } 1098 \text { de } \\
\text { noviembre } 8 \text { de } 2006 \text {, se presentaron } \\
\text { yerros en el inciso } 3^{\circ} \text { del artículo } 73 \text {, al } \\
\text { citarse el artículo } 70 \text {, correspondiendo } \\
\text { el artículo } 71 \text { de la ley. En el artículo } \\
138, \text { al citarse el artículo } 51 \text {, } \\
\text { correspondiendo el } 52 \text { de la ley, y en el } \\
\text { inciso } 2^{\circ} \text { el artículo } 216 \text {, al citarse el } \\
\text { artículo } 198 \text {, correspondiendo el } \\
\text { artículo } 199 \text { de la ley. }\end{array}$ & $\begin{array}{l}\text { No se cuenta con los recursos } \\
\text { técnicos, financieros y humanos } \\
\text { para la correcta implementación } \\
\text { del código. }\end{array}$ & $\begin{array}{l}\text { El problema permanece y su } \\
\text { tendencia va en aumento. }\end{array}$ & $\begin{array}{l}\text { El código define una ruta y } \\
\text { unos actores que inciden en } \\
\text { ella. Son diversos factores los } \\
\text { que impiden que los } \\
\text { diferentes sectores se } \\
\text { articulen adecuadamente. }\end{array}$ & $\begin{array}{l}\text { A excepción de algunos } \\
\text { informes publicados en } \\
\text { páginas web oficiales, } \\
\text { no se generan procesos } \\
\text { de retroalimentación } \\
\text { respecto al } \\
\text { funcionamiento de la } \\
\text { ley. }\end{array}$ \\
\hline
\end{tabular}




\begin{tabular}{|c|c|c|c|c|c|}
\hline \multirow{2}{*}{$\begin{array}{l}\text { CRITERIOS TÉCNICOS } \\
\text { POLÍTICA PÚBLICA }\end{array}$} & \multicolumn{5}{|c|}{ 2. MANEJO DE LO PÚBLICO } \\
\hline & ACEPTABILIDAD & EFECTIVIDAD & HISTÓRICO & $\begin{array}{c}\text { POTENCIAL } \\
\text { DE INTERVENCIÓN }\end{array}$ & TRANSPARENCIA \\
\hline $\begin{array}{lrr}\text { PLAN NACIONAL PARA } \\
\text { LA NIÑEZ Y LA } \\
\text { ADOLESCENCIA } \\
\text { 2019. } \\
\text { NIÑAS, COLOMBIA: } \\
\text { NININOS } \\
\text { ADOLESCENTES } \\
\text { FELICES Y Y } \\
\text { IGUALDAD } & \text { CON } \\
\text { OPORTUNIDADES. } \\
\end{array}$ & $\begin{array}{l}\text { Si bien está programado para el } 2019 \text {, } \\
\text { puede que las directrices hayan } \\
\text { cambiado dado el cambio de gobierno } \\
\text { nacional. }\end{array}$ & $\begin{array}{l}\text { El } 6 \text { de marzo de } 2015 \text { se publican } \\
\text { las conclusiones de la convención } \\
\text { sobre los derechos del niño de las } \\
\text { naciones unidas con las } \\
\text { observaciones finales del informe } \\
\text { de Colombia. Ante lo cual acoge } \\
\text { con satisfacción la adopción de } \\
\text { una serie de políticas pertinentes, } \\
\text { entre ellas el Plan Nacional para la } \\
\text { Niñez y la Adolescencia (2009- } \\
\text { 2019), el Plan Nacional de } \\
\text { Desarrollo (2014-2018) y la } \\
\text { Política y Estrategia para la } \\
\text { Atención Integral de la Primera } \\
\text { Infancia. Sin embargo, se expresa } \\
\text { la preocupación que la mayoría de } \\
\text { los esfuerzos se hayan } \\
\text { concentrado en el desarrollo de la } \\
\text { primera infancia, mientras que se } \\
\text { han adoptado medidas } \\
\text { insuficientes para implementar } \\
\text { adecuadamente el Plan Nacional y } \\
\text { tratar los derechos de los niños } \\
\text { mayores de } 6 \text { años de edad. }\end{array}$ & El problema persiste. & $\begin{array}{l}\text { La corresponsabilidad: } \text { La } \\
\text { familia, la comunidad, el } \\
\text { Estado. }\end{array}$ & $\begin{array}{l}\text { No se tiene información } \\
\text { sobre una rendición de } \\
\text { cuentas de este plan, } \\
\text { que al parecer para las } \\
\text { naciones unidas } \\
\text { continua vigente. }\end{array}$ \\
\hline $\begin{array}{lr}\text { POLÍTICA POR } & \text { LA } \\
\text { CALIDAD DE VIDA } & \text { DE } \\
\text { NIÑAS, NIÑOS } & \text { Y } \\
\text { ADOLESCENTES } & \text { DE } \\
\text { BOGOTÁ 2008 - 2011. } & \end{array}$ & $\begin{array}{l}\text { Ha tenido aceptabilidad en tanto ha } \\
\text { logrado superar las administraciones } \\
\text { de turno, viniendo desde el } 2004 \text { al } \\
2008 \text { para ratificarse hasta el } 2021 \text {. }\end{array}$ & $\begin{array}{l}\text { La política no se propone unas } \\
\text { metas claras que permitan su } \\
\text { seguimiento, presenta un conjunto } \\
\text { de indicadores, los cuales, si bien } \\
\text { reúnen las situaciones } \\
\text { problemáticas a responder, no } \\
\text { muestran una línea de base, ni una } \\
\text { proyección al 2021, que garantice } \\
\text { el impacto positivo sobre la } \\
\text { calidad de vida de los niños, las } \\
\text { niñas y los adolescentes. }\end{array}$ & $\begin{array}{l}\text { El problema continúa y podría } \\
\text { decirse que se ha } \\
\text { complejizado. }\end{array}$ & $\begin{array}{l}\text { Se han instaurado comités, } \\
\text { consejos y diferentes espacios } \\
\text { para lograr escuchar la voz de } \\
\text { la niñez y la adolescencia. De } \\
\text { igual forma, sirven para } \\
\text { articular el accionar de los } \\
\text { sectores en el ámbito local, } \\
\text { sin embargo, no siempre se } \\
\text { cuentan con los recursos } \\
\text { financieros, técnicos o } \\
\text { humanos para alcanzar los } \\
\text { objetivos de la política. }\end{array}$ & $\begin{array}{l}\text { Suele incluirse dentro } \\
\text { de la rendición de } \\
\text { cuentas anual distrital, } \\
\text { un apartado para las } \\
\text { acciones de la política, } \\
\text { sin embargo, no se } \\
\text { planea la participación } \\
\text { y el desarrollo } \\
\text { metodológico para } \\
\text { dirigirla a niños, niñas y } \\
\text { adolescentes. Salvo } \\
\text { algunos intentos en } \\
\text { algunas instituciones } \\
\text { distritales del orden } \\
\text { local. }\end{array}$ \\
\hline
\end{tabular}




\begin{tabular}{|c|c|c|c|c|c|}
\hline CRITERIOS TÉCNICOS & & 2. & NEJO DE LO PÚBLICO & & \\
\hline POLÍTICA PÚBLICA & ACEPTABILIDAD & EFECTIVIDAD & HISTÓRICO & $\begin{array}{c}\text { POTENCIAL } \\
\text { DE INTERVENCIÓN }\end{array}$ & TRANSPARENCIA \\
\hline $\begin{array}{lr}\text { PROSPERIDAD } & \text { PARA } \\
\text { TODOS. } & \text { PLAN } \\
\text { NACIONAL } & \text { DE } \\
\text { DESARROLLO 2010 } & -2014 \\
\text { MÁS EMPLEO, } & \text { MENOS } \\
\text { POBREZA Y Y } & \text { MÁS } \\
\text { SEGURIDAD. } & \end{array}$ & $\begin{array}{l}\text { Tuvo aceptabilidad en tanto fue } \\
\text { aprobado y cumplió su ciclo. }\end{array}$ & $\begin{array}{l}\text { Sus líneas de acción continúan } \\
\text { enfocadas en la primera infancia. }\end{array}$ & El problema persiste. & $\begin{array}{l}\text { Se crea una comisión } \\
\text { intersectorial para la primera } \\
\text { infancia, pero la adolescencia } \\
\text { sigue } \\
\text { invisibilizada. }\end{array}$ & \begin{tabular}{lr}
\multicolumn{2}{l}{ Se realiza una rendición } \\
de cuentas del gobierno \\
nacional que no \\
promociona & la \\
participación de la \\
adolescencia.
\end{tabular} \\
\hline $\begin{array}{l}\text { RESOLUCIÓN } 1841 \text { DE } \\
\text { 2013. PLAN DECENAL } \\
\text { DE SALUD PÚBLICA } \\
2012-2016 .\end{array}$ & $\begin{array}{l}\text { La metodología para la elaboración del } \\
\text { PDSP contó con una fase de consulta } \\
\text { con participación de la ciudadanía y de } \\
\text { diferentes actores de la sociedad. El } \\
\text { análisis muestra que la lectura técnica } \\
\text { y la ciudadana frente a los problemas y } \\
\text { necesidades de salud, convergen. }\end{array}$ & $\begin{array}{l}\text { Se encuentra en proceso de } \\
\text { implementación. }\end{array}$ & $\begin{array}{l}\text { El PDSP 2012-2021 se } \\
\text { propone pasar de prioridades } \\
\text { en salud como habían sido } \\
\text { definidas en el PDSP 2007- } \\
2010 \text { a dimensiones } \\
\text { prioritarias como elementos } \\
\text { ordenadores de abordaje y } \\
\text { actuación en salud pública. }\end{array}$ & $\begin{array}{lr}\text { El documento presenta un } \\
\text { amplio desarrollo de las } \\
\text { dimensiones prioritarias a } \\
\text { abordar por medio de } \\
\text { objetivos, metas y estrategias } \\
\text { en cada caso. A su vez, se } \\
\text { presentan lan } \\
\text { responsabilidades de los } \\
\text { diferentes actores de los } \\
\text { sectores salud para la } \\
\text { implementación del plan. No } \\
\text { se presentan las funciones de } \\
\text { otros sectores para la } \\
\text { intervención integral. } \\
\end{array}$ & $\begin{array}{l}\text { El documento es claro } \\
\text { en cuanto el sistema de } \\
\text { monitoreo que hará } \\
\text { seguimiento a las metas } \\
\text { planteadas para su } \\
\text { vigencia. A su vez, se } \\
\text { presentan estrategias } \\
\text { para la difusión y } \\
\text { comunicación que, sin } \\
\text { embargo, no } \\
\text { contemplan ra } \\
\text { rendición de cuentas a } \\
\text { la comunidad. }\end{array}$ \\
\hline $\begin{array}{l}\text { PLAN DE DESARROLLO } \\
2012-2016 \text { BOGOTÁ } \\
\text { HUMANA. }\end{array}$ & $\begin{array}{l}\text { El plan de desarrollo Bogotá Humana } \\
\text { cumplió con los mecanismos de } \\
\text { participación establecidos por el } \\
\text { Estado Colombiano para su validación, } \\
\text { pasando por la voz de los encuentros } \\
\text { ciudadanos, a cargo de los consejos de } \\
\text { planeación tanto local como territorial, } \\
\text { al igual que se realiza su respectivo } \\
\text { debate en el consejo mayor de Bogotá, } \\
\text { obteniendo una votación de } 13 \text { a favor } \\
\text { y } 2 \text { en contra. }\end{array}$ & $\begin{array}{l}\text { El balance de ejecución de metas } \\
\text { registra un cumplimiento } \\
\text { previsible del } 72 \% \text {, es decir, } 274 \\
\text { de las } 478 \text { metas que incluye el } \\
\text { plan de desarrollo. }\end{array}$ & $\begin{array}{l}\text { Metas asociadas a proyectos } \\
\text { estratégicos para la movilidad } \\
\text { de la ciudad se han estancado } \\
\text { o han tenido una ejecución } \\
\text { muy baja. }\end{array}$ & $\begin{array}{l}\text { Plantea la articulación con los } \\
\text { sectores desde el compromiso } \\
\text { de los mismos en el logro de } \\
\text { determinadas metas } \\
\text { compartidas, sin embargo, no } \\
\text { es claro respecto a cómo debe } \\
\text { darse dicha articulación. }\end{array}$ & $\begin{array}{l}\text { El plan no propone por } \\
\text { sí mismo un modo de } \\
\text { realizar rendición de } \\
\text { cuentas, sin embargo, } \\
\text { dentro de uno de los } \\
\text { ejes se destacan } \\
\text { programas } \\
\text { encaminados a mejorar } \\
\text { la transparencia, } \\
\text { probidad, lucha contra } \\
\text { la corrupción y control } \\
\text { social efectivo e } \\
\text { incluyente. }\end{array}$ \\
\hline
\end{tabular}




\begin{tabular}{|c|c|c|c|c|c|}
\hline CRITERIOS TÉCNICOS & & $\overline{\mathbf{M}}$ & NEJO DE LO PÚBLICO & & \\
\hline POLÍTICA PÚBLICA & ACEPTABILIDAD & EFECTIVIDAD & HISTÓRICO & $\begin{array}{c}\text { POTENCIAL } \\
\text { DE INTERVENCIÓN }\end{array}$ & TRANSPARENCIA \\
\hline $\begin{array}{l}\text { CONPES SOCIAL } 147 \text { - } \\
\text { LINEAMIENTOS PARA } \\
\text { EL DESARROLLO DE } \\
\text { UNA EATRATEGIA } \\
\text { PARA LA PREVENCIÓN } \\
\text { DEL EMBARAZO EN LA } \\
\text { ADOLESCENCIA Y LA } \\
\text { PROMOCIÓN } \\
\text { PROYECTOS DE VIDA } \\
\text { PARA LOS NIÑOS, } \\
\text { NIÑAS, ADOLESCENTES } \\
\text { Y JÓVENES EN EDADES } \\
\text { ENTRE } 6 \text { Y } 19 \text { ANOS. }\end{array}$ & $\begin{array}{l}\text { Cuenta con la aprobación de entidades } \\
\text { reconocidas las cuales son: Ministerio } \\
\text { de Educación Nacional, Ministerio de } \\
\text { Salud y Protección Social, Ministerio } \\
\text { de Tecnologías de la Información y las } \\
\text { Comunicaciones Ministerio de } \\
\text { Cultura, Ministerio de Defensa } \\
\text { Nacional, Ministerio del Interior, } \\
\text { Ministerio de Justicia y del Derecho, } \\
\text { Departamento Administrativo para la } \\
\text { Prosperidad Social, Alta Consejería } \\
\text { para la Equidad de la Mujer, Instituto } \\
\text { Colombiano de Bienestar Familiar - } \\
\text { ICBF, Servicio Nacional de } \\
\text { Aprendizaje - SENA, Colombia Joven, } \\
\text { Colciencias, Coldeportes, DANE, } \\
\text { DNP: DDS. No se muestra una } \\
\text { consulta o el mecanismo } \\
\text { implementado para generar la } \\
\text { participación con otros actores. }\end{array}$ & $\begin{array}{l}\text { Los lineamientos presentan ejes } \\
\text { temáticos de la siguiente manera: } \\
\text { fortalecimiento de la } \\
\text { intersectorialidad, promoción del } \\
\text { desarrollo sano y proyecto de vida, } \\
\text { oferta de servicios, educación y } \\
\text { derechos sexuales y } \\
\text { reproductivos, monitoreo, } \\
\text { evaluación, seguimiento. }\end{array}$ & $\begin{array}{l}\text { En Colombia la tasa de } \\
\text { fecundidad general ha } \\
\text { disminuido, pasando de } 91 \\
\text { nacimientos por mil mujeres a } \\
74 \text { sin embargo, la } \\
\text { fecundidad específica para } \\
\text { mujeres de } 15 \text { a } 19 \text { años } \\
\text { presentó un incremento } \\
\text { cercano al } 30 \% \text { entre } 1990 \text { y } \\
2005 \text {, del } 70 \text { por mil a } 90 \text { por } \\
\text { mil, y aunque en el año } 2010 \\
\text { disminuyó a } 84 \text { nacimientos } \\
\text { por mil, todavía continúa } \\
\text { siendo alta. } \\
\text { Según los datos de la ENDS } \\
2010 \text { el país logró en el último } \\
\text { quinquenio detener la } \\
\text { tendencia creciente que } \\
\text { presentó el embarazo en la } \\
\text { adolescencia entre 1990 y } \\
2005 \text {. Sin embargo, la cifra } \\
\text { aún continúa siendo alta; pues } \\
\text { una de cada cinco mujeres de } \\
15 \text { a } 19 \text { años ha estado alguna } \\
\text { vez embarazada; } 16 \% \text { ya son } \\
\text { madres y } 4 \% \text { está esperando } \\
\text { su primer hijo. }\end{array}$ & $\begin{array}{l}\text { Aspectos que se abordan } \\
\text { desde la acción coordinada de } \\
\text { los diferentes sectores } \\
\text { involucrados, incluyendo las } \\
\text { redes sociales de jóvenes y las } \\
\text { comunitarias, los miembros } \\
\text { de las Fuerzas Militares y de } \\
\text { Policía, las entidades } \\
\text { territoriales, los medios de } \\
\text { comunicación y de } \\
\text { movilización social, así como } \\
\text { las poblaciones vulnerables } \\
\text { vinculadas a la Red Unidos, la } \\
\text { estrategia De Cero a Siempre, } \\
\text { Familias en Acción y los } \\
\text { programas de protección del } \\
\text { ICBF. }\end{array}$ & $\begin{array}{l}\text { Se anexo una Matriz de } \\
\text { plan de acción y } \\
\text { financiamiento. }\end{array}$ \\
\hline
\end{tabular}


CRITERIOS TÉCNICOS POLÍTICA PÚBLICA

RESOLUCION NUMERO 00412 DE 2000.

\begin{tabular}{|c|c|c|c|c|}
\hline ACEPTABILIDAD & EFECTIVIDAD & HISTÓRICO & $\begin{array}{c}\text { POTENCIAL } \\
\text { DE INTERVENCIÓN }\end{array}$ & TRANSPARENCIA \\
\hline $\begin{array}{l}\text { La resolución tiene un grado de } \\
\text { flexibilidad, oportunidad } \\
\text { información que la ley no puede tener } \\
\text { y es en este sentido que la } \\
\text { complementa. }\end{array}$ & $\begin{array}{l}\text { Las Entidades Promotoras de } \\
\text { Salud, Entidades Adaptadas y } \\
\text { Administradoras del Régimen } \\
\text { Subsidiado deben entregar al } \\
\text { momento de la afiliación, el } \\
\text { listado de las diferentes } \\
\text { Instituciones Prestadoras de } \\
\text { Servicios con su dirección y } \\
\text { teléfono, indicando las diferentes } \\
\text { actividades, procedimientos e } \\
\text { intervenciones de demanda } \\
\text { inducida y obligatorio } \\
\text { cumplimiento que las mismas } \\
\text { prestan. Las Entidades Promotoras } \\
\text { de Salud, Entidades Adaptadas y } \\
\text { Administradoras del Régimen } \\
\text { Subsidiado, no podrán dejar de } \\
\text { efectuar las actividades, } \\
\text { procedimientos e intervenciones } \\
\text { contenidas en las normas } \\
\text { técnicas. Tampoco podrán } \\
\text { disminuir la frecuencia anual, ni } \\
\text { involucrar profesionales de la } \\
\text { salud que no cumplan las } \\
\text { condiciones a mínimas } \\
\text { establecidas en la norma. }\end{array}$ & $\begin{array}{l}\text { En Colombia, un porcentaje } \\
\text { significativo de jóvenes inicia } \\
\text { su vida sexual durante la } \\
\text { adolescencia. La edad } \\
\text { promedio de esta relación fue } \\
\text { de } 13,4 \text { para los varones y de } \\
14,8 \text { años para las mujeres y la } \\
\text { edad promedio a la cual } \\
\text { ocurre el nacimiento del } \\
\text { primer hijo es de } 16,2 \text { años. El } \\
\text { consumo de alcohol se inicia } \\
\text { entre } 12 \text { y } 15 \text { años. La } \\
\text { prevalencia anual de } \\
\text { alcoholismo entre } 12 \text { y } 29 \\
\text { años de edad es del } 12.2 \% \text {. } \\
\text { La prevalencia de vida de } \\
\text { consumo de tabaco entre los } \\
12 \text { y } 29 \text { años de edad es de } \\
26.35 \% \text {. }\end{array}$ & $\begin{array}{l}\text { Las disposiciones de la } \\
\text { presenteraresolución se } \\
\text { aplicarán a todas las } \\
\text { Entidades Promotoras de } \\
\text { Salud, Entidades Adaptadas } \\
\text { y Administradoras del } \\
\text { Régimen Subsidiado. Las } \\
\text { Entidades Promotoras de } \\
\text { Salud, Entidades Adaptadas y } \\
\text { Administradoras der del } \\
\text { Régimen Subsidiado deberán } \\
\text { elaborar e implementar } \\
\text { estrategias que le garanticen } \\
\text { a sus afiliados, de acuerdo con } \\
\text { las condiciones de edad, } \\
\text { género y salud, el acceso a } \\
\text { las actividades } \\
\text { procedimientos a e e } \\
\text { intervenciones de protección } \\
\text { específica y detección } \\
\text { temprana, así como la } \\
\text { atención de enfermedades de } \\
\text { interés en salud pública. }\end{array}$ & $\begin{array}{l}\text { El Ministerio de Salud, } \\
\text { la Superintendencia } \\
\text { Nacional de Salud, y las } \\
\text { Direcciones } \\
\text { Territoriales de Salud } \\
\text { ejercerán las funciones } \\
\text { de vigilancia y control } \\
\text { de conformidad con las } \\
\text { normas vigentes y lo } \\
\text { establecido en el } \\
\text { artículo } 18 \text { del Acuerdo } \\
117 \text { del Consejo } \\
\text { Nacional de Seguridad } \\
\text { Social en Salud. } \\
\text { Transformación de } \\
\text { prácticas sociales. } \\
\text { Servicios de Salud con } \\
\text { calidad. Servicios de } \\
\text { Educación para la } \\
\text { Sexualidad. Desarrollo } \\
\text { de competencias en } \\
\text { SSR y DSR en la } \\
\text { población objetivo. } \\
\text { Monitoreo, evaluación, } \\
\text { seguimiento y gestión } \\
\text { del conocimiento. }\end{array}$ \\
\hline
\end{tabular}


DECRETO 031 DE 2007 seguimiento y la evaluación a la Política Pública. En ese sentido, la Monitoreo de las Condiciones de vida de la Infancia y la Adolescencia, reglamentado a través del Acuerdo 238 de 2006 y el Decreto reglamentario 031 de 2007. El sistema de monitoreo contribuye a la construcción de un proceso permanente de revisión, ajuste, seguimiento y evaluación de las acciones que los diferentes actores, principalmente, de la administración distrital, desarrollan para garantizar el ejercicio y realización de los derechos de la infancia y adolescencia.
Aumento en la verificación de controles de crecimiento y desarrollo por territorios desde la Secretaria Distrital de Salud, se pasó de 49.216 en el año 2011 a año 2013 Disminución del porcentaje de niños y niñas con bajo peso a nacer, se pasó de $13,3 \%$ en 2011 a 12,3\% en 2014. Disminución en infantil del VIH, se pasó de 3,8 en 2012 a 1,9 en 2014. Disminución en las tasas de mortalidad por EDA y por ERA entre los años 2011 a 2014. 45.263 niñas y niños y adolescentes hayan dejado de trabajar, es decir, en este período el trabajo infantil se redujo en un $23 \% 23$. De cada 100 niños y niñas que trabajan, cada dos años dejan de hacerlo 23 en la Bogotá Humana, crecimiento de la atención integral dirigida a niños, niñas y adolescentes en situación o riesgo de trabajo infantil, entre los años 2011 y 2014 la atención interinstitucional ha pasado de 10.715 a 17.486 , un incremento del $63.2 \%$. Con dicha atención se ha superado la meta de atención distrital para el cuatrienio (proyectada para 23.804 niñas, niños y adolescentes)
Se recomienda, plantear 1 Las entidades y organismos nuevas modalidades educativas flexibles que incorporen los proyectos de vida de las familias, los adolescentes y jóvenes que no se incorporan al sistema educativo formal, a través de la implementación de nueva tecnologías de la información o el desarrollo de actividades educativas con las familias y en los territorios de manera directa y con horarios flexibles. Se recomienda continuar con la articulación creada entre la SDIS, SED, SCRD y entidades adscritas en el proyecto Currículo para la Excelencia Académica y la Formación Integral 40x40 Las actividades enmarcadas en este proyecto permiten fomentar la educación en áreas artísticas y recreativas desde la primera infancia y mejorar la calidad educativa de los colegios oficiales. Persiste la necesidad de trabajar sobre los imaginarios de sexualidad que promueven las personas adultas,
especialmente educativos, a fin de garantizar el acompañamiento del ejercicio positivo de la misma ejercicio positivo de la misma con los niños, niñas,
adolescentes y la primera infancia. Cabe señalar, que hay un déficit notorio de trabajo concreto y aunado sobre prevención. Promoción de la sexualidad con población menor de 14 años. Bogotá debe reforzar sus acciones para el logro de una que hacen parte del Sistema
de Monitoreo son: la Secretaría Distrital de Salud, la Secretaría de Educación Distrital, la Secretari Distrita la Sularia Distrital de Cultura Recreación y Deporte, la Secretaría Distrital de
Ambiente, la Secretaría Distrital de Integración Social y la Empresa de Acueducto y Alcantarillado de Bogotá Parágrafo: En cualquier momento se podrán incorporar al Sistema de Monitoreo otras entidades distritales que con sus acciones aporten a la garantía de los derechos de los niños, niñas y adolescentes.
El Sistema de Monitoreo de las
condiciones de vida de la infancia y la adolescencia de Distrito Capital podrá ser consultado por la ciudadanía y los organismos de control de manera permanente ingresando al Sistema de Información Social, administrado por la Secretaria Distrital de Planeación. 


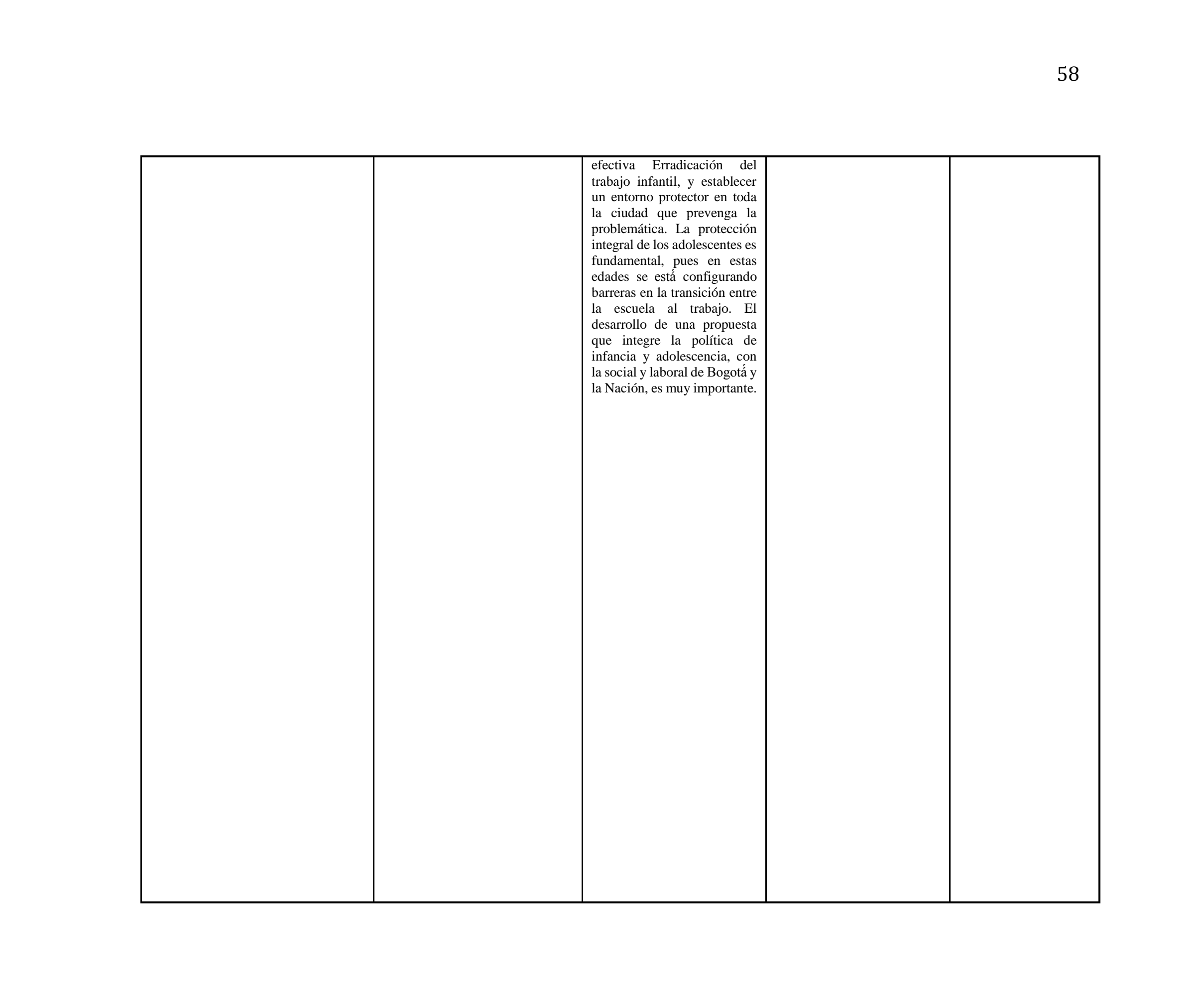




\begin{tabular}{|c|c|c|c|c|c|}
\hline CRITERIOS TÉCNICOS & & 2. & EJO DE LO PÚBLICO & & \\
\hline POLÍTICA PÚBLICA & ACEPTABILIDAD & EFECTIVIDAD & HISTÓRICO & $\begin{array}{c}\text { POTENCIAL } \\
\text { DE INTERVENCIÓN }\end{array}$ & TRANSPARENCIA \\
\hline $\begin{array}{lr}\text { POLÍTICA } & \text { PÚBLICA } \\
\text { NACIONAL } & \text { DE } \\
\text { PRIMERA } & \text { INFANCIA, } \\
\text { INFANCIA } & \text { Y } \\
\text { ADOLESCENCIA } & \end{array}$ & $\begin{array}{l}\text { Este documento parte de premisas de } \\
\text { rigurosidad técnica y de la revisión } \\
\text { documental de propuestas que vienen } \\
\text { siendo ejecutadas en territorio. } \\
\text { Además, está expresado en un lenguaje } \\
\text { sencillo y con la lógica de preguntas y } \\
\text { respuestas para los cinco componentes } \\
\text { y momentos fundamentales de un } \\
\text { proceso de gestión de la política } \\
\text { pública de primera infancia, infancia y } \\
\text { adolescencia. }\end{array}$ & $\begin{array}{l}\text { Al final de este proceso se espera } \\
\text { que la administración territorial } \\
\text { cuente con un documento } \\
\text { construido con todos los actores } \\
\text { corresponsables de la protección } \\
\text { integral de la primera infancia, } \\
\text { infancia y adolescencia, que } \\
\text { contendrá los aspectos } \\
\text { fundamentales descritos al final de } \\
\text { cada uno de los componentes. }\end{array}$ & $\begin{array}{l}\text { Ha servido como insumo para } \\
\text { promover la construcción de } \\
\text { documentos técnicos y } \\
\text { metodológicos más amigables } \\
\text { en aras de que faciliten la } \\
\text { construcción de su política de } \\
\text { primera infancia, infancia y } \\
\text { adolescencia. }\end{array}$ & $\begin{array}{l}\text { Entidades como el ICBF, en } \\
\text { su calidad de rector del } \\
\text { Sistema Nacional de } \\
\text { Bienestar Familiar, el PNUD, } \\
\text { UNICEF, la Fundación } \\
\text { Restrepo Barco, entre otras } \\
\text { instituciones, en } \\
\text { cumplimiento de la función } \\
\text { de cooperación técnica para el } \\
\text { fortalecimiento de } \\
\text { capacidades territoriales, y } \\
\text { experiencias territoriales en } \\
\text { Santander, Nariño y Valle del } \\
\text { Cauca. }\end{array}$ & $\begin{array}{l}\text { Finalmente, en el } \\
\text { quinto componente, } \\
\text { está la rendición } \\
\text { publica de cuentas que } \\
\text { presenta el proceso de } \\
\text { rendición publica de } \\
\text { cuentas para la garantía } \\
\text { de derechos, su } \\
\text { obligatoriedad según la } \\
\text { Ley } 1098 \text { de 2006 y los } \\
\text { pasos para realizarla }\end{array}$ \\
\hline
\end{tabular}

\begin{tabular}{|c|c|c|c|}
\hline \multirow{2}{*}{$\begin{array}{l}\text { CRITERIOS TÉCNICOS } \\
\text { POLÍTICA PÚBLICA }\end{array}$} & \multicolumn{3}{|c|}{ 3. $\quad$ ADOLESCENCIA COMO SUJETO DE POLÍTICA } \\
\hline & inclusión & DEFINICIÓN & EJERCICIO DE DERECHOS \\
\hline $\begin{array}{l}\text { LEY 1098: CÓDIGO DE } \\
\text { INFANCIA Y ADOLESCENCIA }\end{array}$ & $\mathrm{Si}$ & No & $\begin{array}{l}\text { Para todos los efectos de esta ley son sujetos titulares de derechos todas las personas } \\
\text { menores de } 18 \text { años. Sin perjuicio de lo establecido en el artículo } 34 \text { del Código Civil, } \\
\text { se entiende por niño o niña las personas entre los } 0 \text { y los } 12 \text { años, y por adolescente las } \\
\text { personas entre } 12 \text { y } 18 \text { años de edad. }\end{array}$ \\
\hline $\begin{array}{l}\text { PLAN NACIONAL PARA LA } \\
\text { NIÑEZ Y LA ADOLESCENCIA } \\
\text { 2009 - 2019. COLOMBIA: NIÑAS, } \\
\text { NIÑOS Y ADOLESCENTES } \\
\text { FELICEN Y CON IGUALDAD DE } \\
\text { OPORTUNIDADES }\end{array}$ & $\mathrm{Si}$ & No & Ninguna \\
\hline
\end{tabular}


CRITERIOS TÉCNICOS

POLÍTICA PÚBLICA

POLÍTICA POR LA CALIDAD DE VIDA DE NIÑAS, NIÑOS Y ADOLESCENTES DE BOGOTÁ 2008 - 2011.

PROSPERIDAD PARA TODOS.

\author{
PLAN NACIONAL DE
} DESARROLLO 2010 -2014 MÁS EMPLEO, MENOS POBREZA Y EMPLEO, MENOS
MÁS SEGURIDAD.

\section{ADOLESCENCIA COMO SUJETO DE POLÍTICA}

\begin{tabular}{|c|c|c|}
\hline inclusión & DEFINICIÓN & EJERCICIO DE DERECHOS \\
\hline$\overline{\mathrm{Si}}$ & $\begin{array}{l}\text { La adolescencia, como última fase del ciclo supone su } \\
\text { comprensión en relación con los procesos particulares de } \\
\text { relacionamiento con los otros (pares, familiares y adultos) } \\
\text { y su dimensión emocional; la identidad de género y su } \\
\text { construcción social y cultural; los cambios fisiológicos, la } \\
\text { exploración sexual, el desarrollo de la autonomía y la } \\
\text { búsqueda de la independencia; la aceptación y el } \\
\text { reconocimiento social; las relaciones democráticas o no } \\
\text { con sus padres/madres o figuras adultas de autoridad, entre } \\
\text { otros, aspectos en permanente movimiento, mediados por } \\
\text { las oportunidades o la falta de ellas para su desarrollo. } \\
\text { Proponer la generación de condiciones para el ejercicio de } \\
\text { la ciudadanía en los y las adolescentes como actores } \\
\text { transformadores de su propia realidad, radica } \\
\text { esencialmente en el reconocimiento de sus derechos y la } \\
\text { promoción de sus capacidades como sujetos políticos que } \\
\text { realizan sus proyectos de vida y le aportan a la construcción } \\
\text { de una sociedad justa y democrática. }\end{array}$ & $\begin{array}{l}\text { Se adhiere al artículo no. } 3 \text { de la ley } 1098 \text { de } 2006 \text {, niño, o niña es la persona entre } 0 \text { y } \\
12 \text { años y adolescente es la persona entre } 12 \text { y } 18 \text { años de edad. }\end{array}$ \\
\hline si & $\begin{array}{l}\text { La población de } 6 \text { a } 12 \text { años afronta una compleja } \\
\text { problemática que coloca a los menores en situaciones de } \\
\text { riesgo. Algunos de los factores que contribuyen a esta } \\
\text { situación en los niños son las relaciones familiares } \\
\text { disfuncionales, aunadas al no uso adecuado, creativo y } \\
\text { productivo del tiempo libre183, el consumo de sustancias } \\
\text { psicoactivas -en especial a mayores de } 12 \text { años-, violencia } \\
\text { y maltrato - general, intrafamiliar, en el entorno escolar, } \\
\text { sexual-184, entre otros. Se carece también de una oferta de } \\
\text { servicios, con enfoque diferencial y de género; de espacios } \\
\text { adecuados de recreación para el desarrollo de acciones que } \\
\text { permitan a los menores de edad practicar continuamente un } \\
\text { deporte y realizar una actividad física que permita el } \\
\text { cambio de estilos de vida sedentarios y poco saludables. } \\
\text { Los preadolescentes (12-14 años) y aquellos propiamente } \\
\text { adolescentes (14-18 años), se diferencian en la forma que } \\
\text { en que perciben la familia, la sociedad, aś como en su } \\
\text { relación con el Estado. En estos grupos poblacionales la } \\
\text { problemática se centra principalmente en la vulneración o } \\
\text { inadecuada realización de sus derechos sexuales y } \\
\text { reproductivos (embarazo de adolescentes) y a la } \\
\text { vinculación a actividades como bandas y pandillas } 185 \text {, } \\
\text { organizaciones criminales y reclutamiento por parte de } \\
\text { grupos armados irregulares. }\end{array}$ & Ninguna \\
\hline
\end{tabular}


CRITERIOS TÉCNICOS

POLÍTICA PÚBLICA

RESOLUCIÓN 1841 DE 2013. PLAN DECENAL DE SALUD PÚBLICA 2012 - 2016.

PLAN DE DESARROLLO 2012 2016 BOGOTÁ HUMANA.

\section{ADOLESCENCIA COMO SUJETO DE POLÍTICA}

\begin{tabular}{|c|c|c|}
\hline inclusión & DEFINICIÓN & EJERCICIO DE DERECHOS \\
\hline si & $\begin{array}{l}\text { El Plan Decenal de Salud Pública PDSP, 2012-2021 es un } \\
\text { instrumento de política pública llamado a reconocer a las } \\
\text { niñas, niños y adolescentes como sujetos de derechos, cuya } \\
\text { Gestion trasciende los esfuerzos sectoriales y reconoce que } \\
\text { solo en la medida en que se compartan objetivos } \\
\text { intersectoriales comunes es posible que ellas y ellos } \\
\text { alcancen su desarrollo integral. }\end{array}$ & $\begin{array}{l}\text { Con la expedición del Código de Infancia y Adolescencia, por medio de la Ley } 1098 \\
\text { de } 2006 \text {, Colombia armonizó su legislación con los postulados de la Convención de } \\
\text { los Derechos del Nino; en el artículo } 29 \text { del mismo se consigna el derecho al desarrollo } \\
\text { integral en la primera infancia, entendiendo esta como la etapa del ciclo vital en la que } \\
\text { se establecen las bases para el desarrollo cognitivo, emocional y social de todo ser } \\
\text { humano. }\end{array}$ \\
\hline si & $\begin{array}{l}\text { No, pero se encuentra incluida dentro de las etapas de } \\
\text { ciclo vital priorizadas. }\end{array}$ & 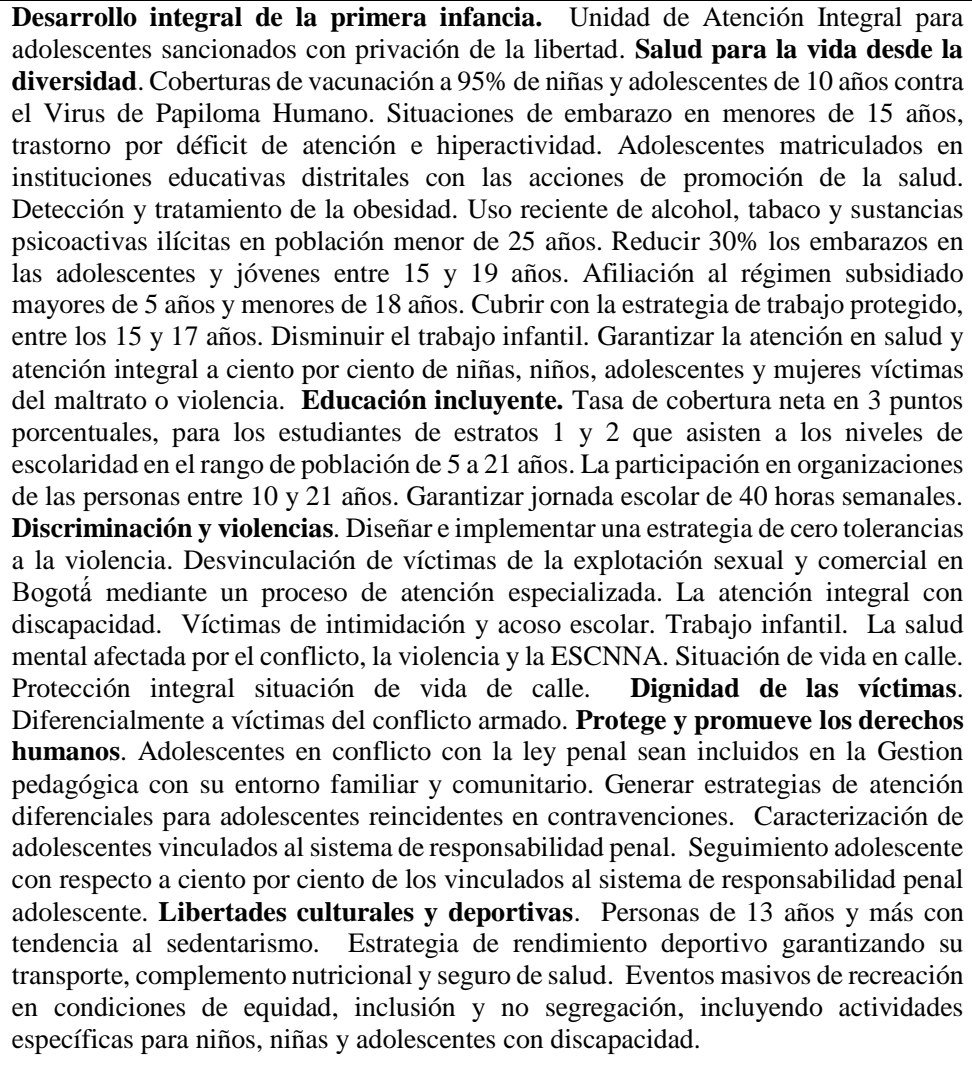 \\
\hline
\end{tabular}


CRITERIOS TÉCNICOS

POLÍTICA PÚBLICA

CONPES SOCIAL 147 LINEAMIENTOS PARA EL $\begin{array}{lll}\text { DESARROLLO } & \text { DE } & \text { UNA } \\ \text { ESTRATEGIA } & \text { PARA } & \text { LA }\end{array}$ ESTRATEGIA PARA LA
PREVENCIÓN DEL EMBARAZO EN LA ADOLESCENCIA Y LA PROMOCIÓN DE PROYECTOS DE VIDA PARA LOS NIÑOS, DE VIDA PARA LOS NINOS,
NINAS, ADOLESCENTES Y JÓVES, ADOLESCENTES Y EN Y 19 AÑOS.

\section{RESOLUCION NUMERO 00412} DE 2000

\section{ADOLESCENCIA COMO SUJETO DE POLÍTICA}

\begin{tabular}{|c|c|c|}
\hline inclusión & DEFINICIÓN & EJERCICIO DE DERECHOS \\
\hline $\mathrm{Si}$ & $\begin{array}{l}\text { Implicaciones en el desarrollo y en la calidad de vida de los } \\
\text { adolescentes, de sus familias y de las sociedades, la } \\
\text { ocurrencia de embarazos a temprana edad ha sido } \\
\text { considerada, a partir de la década de los setenta, una } \\
\text { problemática social y de salud pública necesaria de ser } \\
\text { intervenida a fin de procurar un mejor desarrollo } \\
\text { individual, una mejor calidad de vida y mejores índices de } \\
\text { desarrollo. }\end{array}$ & $\begin{array}{l}\text { Se mantienen las diferencias urbano/rural y las diferencias entre las mujeres sin } \\
\text { educación y las más educadas; de tal manera que se aprecia un crecimiento en las tasas } \\
\text { de embarazo adolescente en todos los niveles educativos. Formación de agentes } \\
\text { educadores de la sociedad. Participacion y empoderamiento efectivo de los niños, } \\
\text { niñas y adolescentes. Desarrollo de oportunidades para los niños, niñas, adolescentes } \\
\text { y jóvenes. } \\
\text { Desarrollo de oportunidades para los niños, niñas, adolescentes y jóvenes. Acciones } \\
\text { para niños, niñas, adolescentes y jóvenes con alto riesgo de deserción del sistema } \\
\text { educativo y en embarazo. Acciones para niños, niñas, adolescentes y jóvenes } \\
\text { desertores o no escolarizados. Acciones de intervención generalizadas en población } \\
\text { escolarizada. Acciones de protección, garantía y restitución de derechos. } \\
\text { Transformación de prácticas sociales. Servicios de salud con calidad. Servicios de } \\
\text { Educación Sexual. Desarrollo de competencias en SSR y DSR en la población } \\
\text { objetivo. }\end{array}$ \\
\hline $\mathrm{Si}$ & $\begin{array}{l}\text { La adolescencia es una etapa del ciclo vital de desarrollo } \\
\text { humano que se caracteriza por el crecimiento y maduración } \\
\text { biológica, fisiológica, psicológica y social del individuo. } \\
\text { Su inicio lo marca la capacidad biológica de reproducir- se } \\
\text { y su final la capacidad social de reproducirse. Durante este } \\
\text { proceso el adolescente se humaniza, se apropia y recrea las } \\
\text { características y atributos de la historia social de su gente, } \\
\text { se individualiza e independiza, transforma el entorno y el } \\
\text { mundo que habita a la vez que este lo transforma a ellos } \\
\text { (Turbay, C. 1994, OMS, 1993). } \\
\text { Adolescencia temprana o inicial - } 10 \text { - } 13 \text { años } \\
\text { En esta etapa el adolescente se ajusta a los cambios } \\
\text { puberales, los cuales marcan el inicio de la misma. Este se } \\
\text { encuentra ambivalente sobre separar- se de sus padres o no } \\
\text { y Prefiere socializar con "pares" del mismo sexo. Conserva } \\
\text { un pensamiento concreto con planes hacia el futuro vagos. } \\
\text { En esta etapa inicia la curiosidad sexual principalmente a } \\
\text { través, pero no exclusivamente, de la masturbación. Se } \\
\text { centra mucho en sí mismo y explora qué tan rígido o } \\
\text { flexible es el sistema moral de sus padres o figuras de } \\
\text { autoridad. }\end{array}$ & $\begin{array}{l}\text { Detección temprana de las alteraciones del desarrollo del joven (10-29 años); } \\
\text { Detección temprana de las alteraciones del embarazo; Guía de atención al menor } \\
\text { maltratado. }\end{array}$ \\
\hline
\end{tabular}


CRITERIOS TÉCNICOS

POLÍTICA PÚBLICA

DECRETO 031 DE 2007

\begin{tabular}{|l|l|l|}
\hline \multicolumn{3}{|c|}{ 3. ADOLESCENCIA COMO SUJETO DE POLÍTICA } \\
\hline inclusión & DEFINICIÓN & EJERCICIO DE DERECHOS \\
\hline $\mathrm{Si}$ & $\begin{array}{l}\text { La implementación de la Política Pública es dirigida a la } \\
\text { población que se encuentra en las siguientes etapas del } \\
\text { transcurrir vital: Primera infancia (niña y niño de 0 a 5 años } \\
\text { y 11 meses), infancia (niñas y niños de 6 a 11 años y once } \\
\text { meses) y adolescencia (entre los 12 y 17 años y once } \\
\text { meses). Desde el artículo 34 del Código Civil se entiende } \\
\text { por niño o niña a las personas entre los 0 y 12 años y } \\
\text { adolescentes entre los 12 y 17 años. }\end{array}$ & $\begin{array}{l}\text { Reconociéndolos como "sujetos activos en capacidad de aportar al desarrollo social y } \\
\text { sutuares de derechos, la garantía como cumplimiento de los mismos, la Prevención de } \\
\text { desarrollo del principio del interés superior" (Artículo 8, Decreto 520 de 2011) }\end{array}$ \\
\hline $\mathrm{Si}$ & No & \\
\hline
\end{tabular}

\begin{tabular}{|c|c|c|c|}
\hline $\begin{array}{l}\text { CRITERIOS TÉCNICOS } \\
\text { POLÍTICA PÚBLICA }\end{array}$ & 4. ENFOQUES CLAVE & 5. DESCRIPCIÓN DE LA ESTRUCTURA & 6. EVALUACIÓN \\
\hline $\begin{array}{lr}\text { LEY 1098: CÓDIGO } & \text { DE } \\
\text { INFANCIA } & \\
\text { ADOLESCENCIA. } & \end{array}$ & $\begin{array}{l}\text { 1) Protección integral. 2) Derechos. 3) Obligaciones de la } \\
\text { Familia. 4) Obligaciones del Estado. 5) Obligaciones de la } \\
\text { sociedad. 6) Obligaciones especiales de las instituciones } \\
\text { educativas. 7) Obligación ética fundamental de los } \\
\text { establecimientos educativos. 8) Prohibición de sanciones crueles, } \\
\text { humillantes o degradantes. 9) Obligaciones especiales del } \\
\text { Sistema de Seguridad Social en Salud.10) Obligación del } \\
\text { restablecimiento de los derechos de los niños, las niñas y los } \\
\text { adolescentes. 11) Requisitos para adoptar. 12) Defensorías de } \\
\text { Familia. 13) Comisarias de familia. 14) Restitución internacional } \\
\text { de los niños, las niñas o los adolescentes. }\end{array}$ & $\begin{array}{l}\text { El código se divide en dos libros: I Sobre la protección } \\
\text { integral, II sobre el sistema de responsabilidad penal } \\
\text { para adolescentes y procedimientos especiales para los } \\
\text { niños, las niñas o los adolescentes son víctimas de } \\
\text { delitos. }\end{array}$ & Ninguna. \\
\hline $\begin{array}{lrr}\text { PLAN NACIONAL } & \text { PARA } \\
\text { LA NIÑEZ } & \text { YA } \\
\text { ADOLESCENCIA } & 2009 \\
\text { 2019. COLOMBIA: } & \text { NIÑAS, } \\
\text { NIÑOS Y ADOLESCENTES } \\
\text { FELICEN Y } & \text { CON } \\
\text { IGUALDAD } & \text { DE } \\
\text { OPORTUNIDADES. } & \end{array}$ & $\begin{array}{l}\text { 1) Familia. 2) Comunidad. 3) Estado. 4) Estructura institucional } \\
\text { del poder ejecutivo. }\end{array}$ & $\begin{array}{l}\text { Se realiza mediante ejes. Eje central: garantías } \\
\text { universales básicas. Primer eje complementario: } \\
\text { garantías especiales para superar las limitaciones de } \\
\text { acceso a los mecanismos universales. Segundo eje } \\
\text { complementario: garantías de emergencia para enfrentar } \\
\text { las situaciones de despojo de los derechos. Difusión, } \\
\text { Sensibilización y Promoción de los derechos. Política de } \\
\text { Informacion sobre Infancia y Adolescencia. } \\
\text { Cooperación Internacional. }\end{array}$ & $\begin{array}{l}\text { Se debe dar el 2019, con el seguimiento } \\
\text { a las metas propuestas. }\end{array}$ \\
\hline
\end{tabular}




\section{CRITERIOS TÉCNICOS}

POLÍTICA PÚBLICA

POLÍTICA POR LA

CALIDAD DE VIDA DE

NIÑAS, NIÑOS

ADOLESCENTES

BOGOTÁ 2008 - 2011.

DE

\section{Responsabilidad en el ejercicio de los derechos, 4 Desas, humano individe ejercicio de los derechos, 4. Desarrollo}

(2)

PROSPERIDAD PARA TODOS. PLAN NACIONAL DE DESARROLLO 2010 2014 MÁS EMPLEO, MENOS POBREZA Y MÁS SEGURIDAD.

RESOLUCIÓN 1841 DE 2013. PLAN DECENAL DE SALUD PÚBLICA 2012 2016.

Enfoque de ciclo de vida. Enfoque de género. Enfoque étnico. E Plan Decenal de Salud Pública PDSP, 2012-2021, tiene como meta central alcanzar la equidad y el desarrollo humano sostenible, afectando positivamente los Determinantes Sociale

\begin{tabular}{|l|}
\hline \multicolumn{1}{|c|}{ ENFOQUES CLAVE } \\
\hline $\begin{array}{l}\text { 1. perspectiva de ciclo vital, 2. Sujeto titular de derechos, 3. } \\
\text { Responsabilidad en el ejercicio de los derechos, 4. Desarrollo } \\
\text { humano individual y social. }\end{array}$ \\
\hline
\end{tabular}

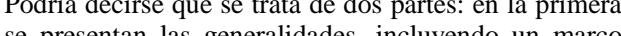
se presentan las generalidades, incluyendo un marco analítico con datos sobre la situación de la niñez y la adolescencia. En una segunda parte se de la estructura como tal de política que incluye objetivos, principios, y los ejes de implementación. Eje 1. Niños, niñas, adolescentes en ciudadanía plena. Eje 2. Bogotá construye una ciudad con los niños, las niñas y los adolescentes. Eje 3. Gobernanza por la calidad de vida de la infancia y la adolescencia. de la Salud y mitigando los impactos de la carga de la enfermedad sobre los años de vida saludables. dimensiones prioritarias. que son: salud ambiental;
Se desarrolla a través de pilares y ejes: tres pilares: crecimiento sostenido, igualdad de oportunidades, consolidad la paz. Con los ejes de innovación, buen gobierno, relevancia internacional, sostenibilidad ambiental.

Como parte del diseño estratégico, además de la visión, meta central y de los objetivos estratégicos, el PDSP 2012-2021 se despliega mediante estrategias que se configuran como un conjunto de acciones para ocho (8) sexualidad y derechos sexuales y reproductivos; seguridad alimenta $\mathrm{y}$ salud mental; vida saludable y enfermedades transmisibles; vida saludable y condiciones no transmisibles; salud publica en emergencias y desastres; y salud en el entorno laboral. De igual forma se cuenta con dimensiones transversales se promueve la acción transitoria, la corresponsabilidad de todos los sectores y actores para afectar positivamente los Determinantes Sociales de la Salud y propiciar las condiciones de vida

\section{EVALUACIÓN}

De acuerdo al decreto 520 de 2011 por medio del cual se adopta la política pública de infancia y adolescencia en Bogotá en su Artículo $13^{\circ}$. Habla sobre Seguimiento y evaluación a la política. La Política Publica de Infancia y Adolescencia de Bogotá, D.C. cuenta Adolescencia de Bogota, D.C., cuenta con el Sistema de Monitoreo de la Condiciones de Vida de la Infancia y la Adolescencia de que trata el Acuerdo 238 de 2006 y el Decreto 031 de 2007. En cumplimiento y desarrollo de este sistema, las entidades del Gobierno Distrital con competencia zarán un informe, cada cuatro meses, que dé cuenta de los avances del plan de acción de la Política Pública de Infancia y Adolescencia.

Se define una línea de base y unas metas a 2014 de un grupo de 11 indicadores donde 9 están enfocados en la primera infancia.

El Plan Decenal de Salud Pública PDSP, 2012-2021, establece el sistema de monitoreo y evaluación de los objetivos y las metas formuladas a través de las dimensiones. Se plantean 94 indicadores de resultados y 127 estión para un total de 216 indicadores, ordenados por de 216 indicadores, ordenados por las dimensiones propuestas en el plan. 
CRITERIOS TÉCNICOS

POLÍTICA PÚBLICA

PLAN DE DESARROLLO 2012 - 2016 BOGOTA

HUMANA.

\begin{tabular}{|c|c|c|}
\hline & $\begin{array}{l}\text { dimensiones transversales se encuentra: el desarrollo } \\
\text { integral de niños, niñas y adolescentes. }\end{array}$ & \\
\hline $\begin{array}{l}\text { Reducir la desigualdad y la Discriminación social, económica y } \\
\text { cultural. Destacar los principios de igualdad, equidad y } \\
\text { diversidad. Ampliar las capacidades que permitan a la ciudadanía } \\
\text { la apropiación de saberes. Incrementar la capacidad financiera y } \\
\text { económica de los más pobres. Generar trabajo decente y digno } \\
\text { como el principal mecanismo para que la población bogotana } \\
\text { pueda gozar con autonomía de sus derechos. Reconocer y } \\
\text { garantizar el ejercicio, restablecimiento y reparación de los } \\
\text { derechos para toda la ciudadanía. Construir un territorio donde se } \\
\text { garantice el acceso equitativo a la ciudad. Fortalecer el tejido } \\
\text { productivo de la ciudad con énfasis en la economía popular. } \\
\text { Visibilizar al territorio rural como parte integral de la } \\
\text { sustentabilidad de la ciudad y de la región. Visibilizar el medio } \\
\text { natural y el entorno del agua y situar la naturaleza en el centro de } \\
\text { las decisiones para la planeación del desarrollo de la ciudad. } \\
\text { Construir un sistema de movilidad con enfoque ambiental y } \\
\text { humano. Reducir la vulnerabilidad de la ciudad y los grupos } \\
\text { humanos respecto al cambio climático y los desastres naturales. } \\
\text { Promover cambios culturales y facilitar las condiciones para la } \\
\text { transformación de la ciudad. Reducir la cantidad de basuras y } \\
\text { escombros que produce la ciudad. Consolidar el proceso de } \\
\text { integración de Bogotá con la región. Construir un nuevo modelo } \\
\text { de participación ciudadana. Fortalecer la gobernabilidad } \\
\text { democrática local. Recuperar la confianza ciudadana en las } \\
\text { instituciones. Construir territorios de paz con seguridad } \\
\text { ciudadana. Garantizar una estructura administrativa distrital } \\
\text { eficiente y comprometida con las necesidades de la ciudadanía. }\end{array}$ & $\begin{array}{l}\text { El documento se presenta en dos tomos. En el primero } \\
\text { se desarrollan los contenidos y en el segundo se muestra } \\
\text { el plan de inversiones. Dentro del primero, se puede } \\
\text { encontrar la distribución por los tres ejes principales, } \\
\text { dentro de los cuales se encuentran estrategias, } \\
\text { programas y proyectos en cada caso. En el segundo } \\
\text { tomo se puede observar cómo se adjudican recursos } \\
\text { financieros, responsables, indicadores y metas para cada } \\
\text { una de las apuestas del plan. }\end{array}$ & $\begin{array}{l}\text { Los ejes, estrategias, programas y } \\
\text { proyectos se encuentran en directa } \\
\text { relación con metas, indicadores e } \\
\text { inversión lo cual hace posible una } \\
\text { evaluación directa de los objetivos } \\
\text { planteados por el plan. Al terminar la } \\
\text { vigencia, la administración distrital hace } \\
\text { entrega de la evaluación realizada a la } \\
\text { implementación del plan a través de la } \\
\text { veeduría distrital. De igual forma se } \\
\text { realiza rendición de cuentas a la } \\
\text { comunidad. }\end{array}$ \\
\hline
\end{tabular}




\section{CRITERIOS TÉCNICOS}

POLÍTICA PÚBLICA

CONPES SOCIAL 147 LINEAMIENTOS PARA EL DESARROLLO DE UNA ESTRATEGIA PARA LA EMBARAZO EN LA ADOLESCENCIA Y LA PROMOCIÓN PROYECTOS DE VIDA PARA LOS NIÑOS, NIÑAS, ADOLESCENTES Y JÓVENES EN EDADES ENTRE 6 Y 19 AÑOS.

\section{RESOLUCION NUMERO} 00412 DE 2000

\begin{tabular}{|l|l|}
\hline 4. ENFOQUES CLAVE \\
\hline La teoría de los Determinantes Sociales. Determinantes \\
\hline
\end{tabular}

La teoría de los Determinantes Sociales. Determinantes próximos. Determinantes intermedios. Modelo ecológico. Enfoque de Derechos. Enfoque de Desarrollo Humano. Enfoque de resiliencia. Enfoque de Capital social. Enfoque diferencial.

Norma técnica. Es el documento mediante el cual se establecen as actividades, procedimientos e intervenciones costo-efectiva de obligatorio cumplimiento, a desarrollar en forma secuencial y sistemática en la población afiliada, para el cumplimiento de las acciones de protección específica y de detección tempran establecidas en el Acuerdo 117 del Consejo Nacional de Seguridad Social en Salud. Guía de atención. Es el documento mediante el cual se establecen las actividades, procedimientos intervenciones a seguir y el orden secuencial y lógico para el adecuado diagnóstico y tratamiento de las enfermedades de interés en salud pública establecidas en el Acuerdo 117 del Consejo Nacional de Seguridad Social en Salud y a cargo de las Entidades Promotoras de Salud, Entidades Adaptadas y Administradoras del Régimen Subsidiado. Demanda inducida. Son todas las acciones encaminadas a informar y educar a la población afiliada, con el fin de dar cumplimiento a las actividades, procedimientos e intervenciones de protección específica y detección temprana establecidas en las norma técnicas. Protección específica. Es el conjunto de actividades, procedimientos e intervenciones tendientes a garantizar la protección de los afiliados frente a un riesgo específico, con el fi de evitar la presencia de la enfermedad. Detección temprana. Es el conjunto de actividades, procedimientos e intervenciones que permiten identificar en forma oportuna y efectiva la enfermedad, facilitan su diagnóstico precoz, el tratamiento oportuno, la reducción de su duración y el daño causado, evitando secuelas, incapacidad y muerte.

\section{ESCRIPCIÓN DE LA ESTRUCTURA}

Mapa estratégico para la prevención del embarazo adolescente y promoción de los proyectos de vida de los niños y jóvenes entre los 6 a los 19 años. Lineamientos Para El Fortalecimiento De La Intersectorial dad. Nivel Nacional. Nivel Territorial. Lineamientos Para La Promoción Del Desarrollo Humano Y Proyecto De Vida. Lineamientos Para La Oferta De Servicios En Educación Sexual, Salud Sexual Y Reproductiva Y Derechos Sexuales Y Reproductivos. Lineamientos Para El Monitoreo, Seguimiento, Evaluación Y Gestion Del Conocimiento.

Respecto a la norma técnica para la detección temprana de alteraciones del joven, se reglamentan como características del servicio una consulta para la detección de las alteraciones del desarrollo, la cual incluye información y orientación, historia familiar y médica personal, examen físico, enseñanza de autoexamen de senos y testículos, prescripción de exámenes de laboratorio y plan de intervención. Dadas las cifras de embarazo en adolescentes se tiene en cuenta la norma técnica para la detección de alteraciones del embarazo, cuya características del servicios plantean la identificación e inscripción de las gestantes en el control prenatal, consulta de primera vez por medicina general, que incluye elaboración de la historia clínica e identificación de factores de riesgo, examen físico, solicitud de exámenes paraclínicos, administración de toxoide tetánico y diftérico, formulación de micronutrientes, educación individual a la madre, compañero y familia, remisión a consulta odontológica general, diligenciar y entregar el carné materno y educar sobre la importancia de su uso. Además, se presente las consultas de seguimiento y control, de las cuales se encuentran el control prenatal por médico (consulta de control o seguimiento de programa por medicina general y contra pre Luego, viene a Guía de atención al menor trabajador

\section{EVALUACIÓN}

Municipios priorizados posteriores al piloto para implementar la estrategia Nacidos vivos por edad de la madre. De 10 - 14 años, De 15 a 19 años. Anexo 5. Matriz de plan de acción y financiamiento.

Indicador. Responsable, Metas.

Entidades que integran el Sistema de Monitoreo. Las entidades y organismos que hacen parte del Sistema de Monitoreo son: la Secretaŕa Distrital de Salud la Secretaŕa de Salud, la Secretaría de Educación Distrital, la Secretaria Distrital de Cultura, Recreación y Deporte, la Secretaría Distrital de Ambiente, la Secretaría Distrital de Integración Social y la Empresa de Acueducto y Alcantarillado de Acueducto Alcantarillogó Parágrafo: En cualquier momento se podrán incorporar al Sistema de Monitoreo otras entidades distritales que con sus acciones aporten a la garantía de los derechos de los niños, niñas y adolescentes. La incorporación de las nuevas entidades se producir de Secreta de In Entidades Promotoras de Salud y Entidades Adaptadas, deberán radicar ante la Dirección de Promoción y Prevención del Ministerio de Salud o la dependencia que haga sus veces, informe de gestion trimestal, informe de gestión trimestral, dentro de 
CRITERIOS TÉCNICOS

POLÍTICA PÚBLICA

DECRETO 031 DE 2007

\begin{tabular}{|c|c|c|}
\hline 4. ENFOQUES CLAVE & 5. DESCRIPCIÓN DE LA ESTRUCTURA & 6. EVALUACIÓN \\
\hline & $\begin{array}{l}\text { aunque en esta solo se hace alusión a niños y niñas, la } \\
\text { caracterización realizada respecto al maltrato infantil y } \\
\text { la tipología del maltrato aplica para la población } \\
\text { adolescente, al igual que los factores protectores. Dentro } \\
\text { de las características de la atención del maltrato físico, } \\
\text { se encuentra la sospecha de maltrato, el diagnóstico que } \\
\text { parte de los signos y síntomas, e historia clínica. El } \\
\text { tratamiento del agredido, la atención psicológica } \\
\text { durante la urgencia, la hospitalización, y la intervención } \\
\text { al posible agresor (a). Posteriormente vendrá la } \\
\text { notificación, la denuncia y el seguimiento. En el caso de } \\
\text { maltrato psicológico no se realiza tratamiento del } \\
\text { agredido por parte de hospitalización. La atención que } \\
\text { más requiere un despliegue en la atención a menores } \\
\text { víctimas de abuso sexual. La cual requiere unas } \\
\text { entrevistas para evitar la re victimización durante la } \\
\text { organización de los exámenes y la toma de muestras. El } \\
\text { tratamiento de este maltrato incluye sobre enfermedades } \\
\text { de transmisión sexual y prevención de embarazo. Como } \\
\text { casos especiales, se catalogan la gestación y el maltrato, } \\
\text { el síndrome de bebé zarandeado y la negligencia. }\end{array}$ & $\begin{array}{l}\text { al vencimiento del respectivo trimestre, } \\
\text { en forma impresa y en medio } \\
\text { magnético, de acuerdo con el "Anexo } \\
\text { Técnico 6-2000 Especificaciones para } \\
\text { la transferencia de Datos sobre } \\
\text { ejecución de Acciones de Protección } \\
\text { Específica, Detección Temprana y } \\
\text { Atención de Enfermedades de Interés en } \\
\text { Salud Pública". }\end{array}$ \\
\hline $\begin{array}{l}\text { Derechos, agrupados en las siguientes categorías: a) a la vida y } \\
\text { la supervivencia; b) al desarrollo, c) a la participación, y d) a la } \\
\text { protección. Se incluye además la categoría e) indicadores de } \\
\text { gestión para la garantía de los derechos. }\end{array}$ & $\begin{array}{l}\text { El Sistema de Monitoreo de las condiciones de vida de } \\
\text { la infancia y la adolescencia del Distrito Capital tendrá } \\
\text { como estructura básica un conjunto de indicadores } \\
\text { organizados por Derechos, agrupados en las siguientes } \\
\text { categorías: a) a la vida y la supervivencia; b) al } \\
\text { desarrollo, c) a la participación, y d) a la protección. Se } \\
\text { incluye además la categoría e) indicadores de gestión } \\
\text { para la garantía de los derechos. Cada indicador contará } \\
\text { con una ficha técnica de identificación que incluirá al } \\
\text { menos la siguiente información: nombre del indicador, } \\
\text { grupo de clasificación, periodicidad del cálculo, } \\
\text { periodos disponibles, forma de cálculo, fuente de datos, } \\
\text { y definición del indicador. Estos datos se registrarán en } \\
\text { la Ficha de Identificación del Indicador del Sistema de } \\
\text { Indicadores Sociales, establecida por la Secretaría } \\
\text { Distrital de Planeación. }\end{array}$ & $\begin{array}{l}\text { La Secretaria Distrital de Integración } \\
\text { Social, preparará anualmente, durante el } \\
\text { primer trimestre de cada año, el informe } \\
\text { sobre los resultados del sistema de } \\
\text { monitoreo señalando las posibles } \\
\text { recomendaciones que se puedan derivar } \\
\text { de esas evaluaciones, para ser } \\
\text { presentado por la Alcaldía Mayor o por } \\
\text { la instancia que esta defina, al Concejo } \\
\text { Distrital y a la comunidad. }\end{array}$ \\
\hline
\end{tabular}


CRITERIOS TÉCNICOS

POLÍTICA PÚBLICA

Política pública nacional de primera infancia, infancia adolescencia

\begin{tabular}{|c|c|c|}
\hline 4. ENFOQUES CLAVE & 5. DESCRIPCIÓN DE LA ESTRUCTURA & 6. EVALUACIÓN \\
\hline $\begin{array}{l}\text { Identificación de problemas relevantes, prioridades en clave del } \\
\text { ciclo vital, familia y el sueño colectivo hacia la protección } \\
\text { integral de los niños, las niñas y los adolescentes. }\end{array}$ & $\begin{array}{l}\text { En esta herramienta encontraran cinco componentes } \\
\text { mínimos necesarios para formular una política pública } \\
\text { de primera infancia, infancia y adolescencia que cumpla } \\
\text { con los lineamientos normativos establecidos en el } \\
\text { Código de Infancia y Adolescencia. } \\
\text { El componente uno trata la sensibilización y el análisis } \\
\text { del contexto situacional y territorial, además responde } \\
\text { las preguntas más significativas de esta fase preparatoria } \\
\text { en cuanto a: contacto inicial, identificación de actores, } \\
\text { conformación y cualificación del grupo Lider, análisis } \\
\text { de contexto territorial y proceso de formación. } \\
\text { En el componente dos se abarcan las decisiones de } \\
\text { política de primera infancia, infancia y adolescencia que } \\
\text { responden a: identificación de problemas relevantes, } \\
\text { prioridades en clave del ciclo vital, familia y el sueño } \\
\text { colectivo hacia la protección integral de los niños, las } \\
\text { niñas y los adolescentes. } \\
\text { El componente tres trata el plan de Gestion de la política } \\
\text { pública que responde a: objetivos, acciones, metas, } \\
\text { indicadores, recursos y responsables en el corto, } \\
\text { mediano y largo plazo. Mesa Nacional de Infancia y } \\
\text { Adolescencia. Lineamientos de política publica de } \\
\text { Infancia y Adolescencia en los departamentos y } \\
\text { municipios. Guía Conceptual y Operativa. } 2012 \text {. } \\
\text { El cuarto componente es el seguimiento que responde a } \\
\text { un proceso continuo de análisis y recolección de } \\
\text { información, indicadores y control en el marco de la } \\
\text { Política Pública. } \\
\text { Finalmente, en el quinto componente, está la rendición } \\
\text { pública de cuentas que presenta el proceso de rendición } \\
\text { publica de cuentas para la garantía de derechos, su } \\
\text { obligatoriedad según la Ley } 1098 \text { de } 2006 \text { y los pasos } \\
\text { para realizarla. }\end{array}$ & $\begin{array}{l}\text { El cuarto componente es el seguimiento } \\
\text { que responde a un proceso continuo de } \\
\text { análisis y recolección de información, } \\
\text { indicadores y control en el marco de la } \\
\text { Política Pública. } \\
\text { Finalmente, en el quinto componente, } \\
\text { está la rendición publica de cuentas que } \\
\text { presenta el proceso de rendición } \\
\text { publica de cuentas para la garantía de } \\
\text { derechos, su obligatoriedad según la } \\
\text { Ley } 1098 \text { de } 2006 \text { y los pasos para } \\
\text { realizarla }\end{array}$ \\
\hline
\end{tabular}




\section{RELACIONES DIALÓGICAS}

Como relaciones dialógicas vamos a entender, al igual que en la semántica, a las articulaciones modales que se llevan a cabo entre dos conceptos. Dichas relaciones provienen de la comparación entre los enunciados identificados en la política pública para la adolescencia vigente en el contexto nacional y distrital.

Se clasificaron en seis criterios de evaluación presentados en el apartado anterior, con sus respectivos contenidos, los cuales permiten la comprensión del diseño de la política pública por medio de cinco relaciones dialógicas, presentadas a continuación:

Figura 1. Relaciones dialógicas en el diseño de Políticas Públicas para la adolescencia en Colombia

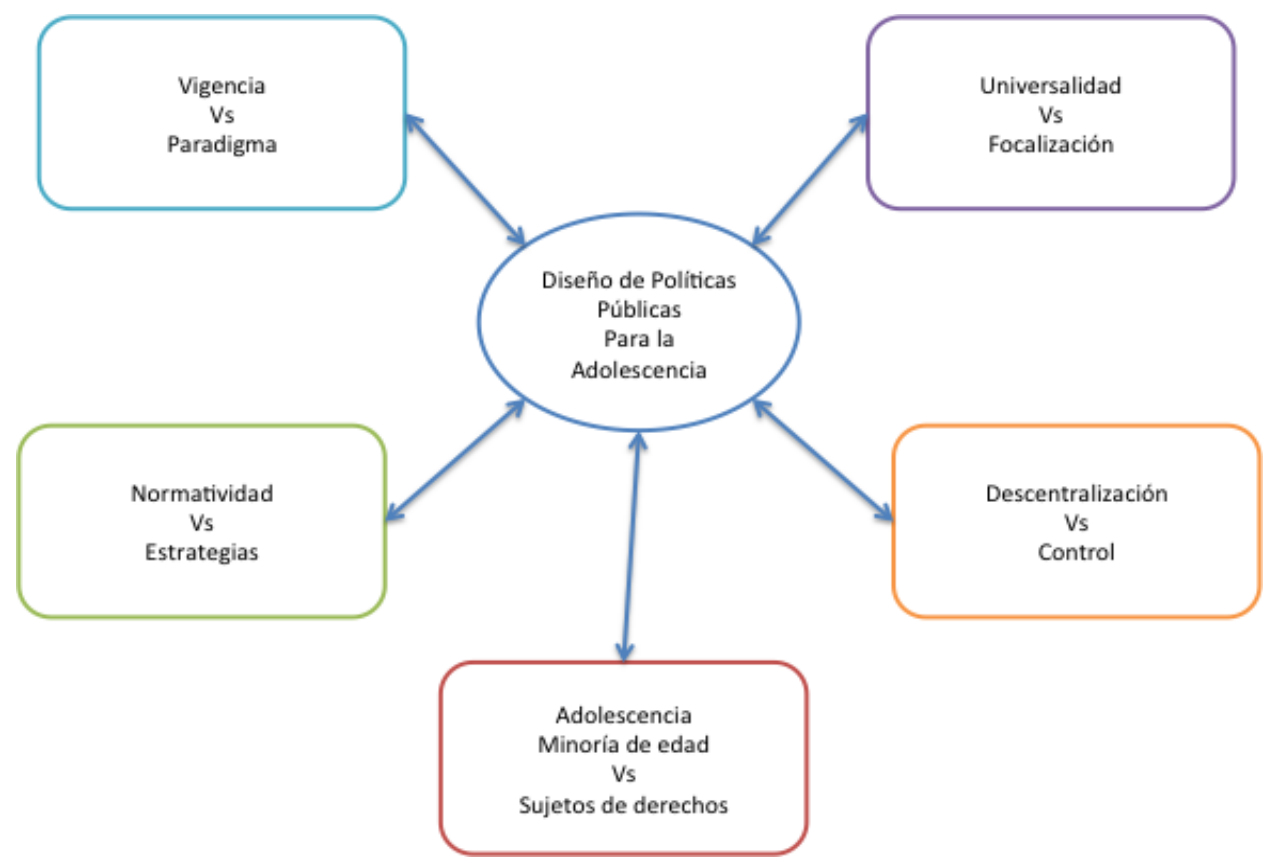

Fuente: elaboración propia, agosto de 2016 
Vigencia - Paradigma: la vigencia para el diseño de la política pública en Colombia está ampliada a un plazo de 15 años de garantías de derechos, lo cual hace pensar en si el problema vaya o continuar, de igual forma, la política deberá reiterarse en la búsqueda de paradigmas globales del desarrollo humano. En Colombia el proceso es dialógico, por tanto, se encuentran ejemplos desde una mirada clásica de la ley, hasta un interés para la salud pública, desde la transectorialidad, como enfoque integral para la garantía de los derechos. Se debería preguntar ¿por qué hace falta una reiteración de la política pública?

El tiempo de la política pública para la adolescencia desde el paradigma de los derechos humanos se constituye en el año 2006 con la Ley 1098, y en su vigencia se proyecta un plazo hasta el año 2021, tanto para el PDSP como para la política pública distrital. Del código de infancia y adolescencia, a la política pública distrital se pueden hallar los mismos principios de protección integral para la prevalencia de los derechos.

Universalidad - Focalización: los ajustes realizados a la Ley 1098 dan cuenta del debate suscitado para la defensa de los derechos en la población menor de edad como garantía de potenciar el capital humano representado por el Estado. La universalidad de los derechos presentada en la convención de derechos de los niños realizada en el año 1989 y ratificada para Colombia mediante la Ley 12 de 1991, reivindica el enfoque de derechos para la reglamentación de su política pública, que representa la voz del Estado. 
El paso hacia la focalización aún es difuso. La política para la construcción de derechos se fundamenta en la priorización otorgada a la atención integral de la primera infancia y en los fines de la institucionalidad que debe responder a las necesidades de este grupo poblacional. De acuerdo con el Conpes Social 147, los lineamientos presentan ejes temáticos de la siguiente manera: fortalecimiento de la intersectorialidad, promoción del desarrollo sano y proyecto de vida, oferta de servicios, educación y derechos sexuales y reproductivos, monitoreo, evaluación y seguimiento. Con ello, se expresa la demanda por ratificar la ley al nivel de desarrollo de los países respecto a Latinoamérica y El Caribe. El paso que va de la primera infancia a la adolescencia suele costarle a los Estados lo que se puede llamar según la Cepal, un salto demográfico al encontrar el incremento de embarazos a temprana edad.

Descentralización - Control: la política pública para la adolescencia en Colombia se debate entre una débil descentralización y una institucionalidad con limitada presencia para este momento del curso vital en contextos de vulnerabilidad. La descentralización se entiende como la corresponsabilidad establecida con los sectores públicos, pero, además, como parte de la relación con el sector privado y la comunidad, entre otros.

Así como la política trata de compartir responsabilidades con los actores, también debe llamar, desde el autocontrol, a definir medidas para su evaluación y cumplimiento de metas. Algunos programas incluyen dentro de sus procesos de rendición de cuentas, información desagregada por momentos del curso de vida, en donde se encuentra la adolescencia. Dentro de la política distrital de infancia y adolescencia, en relación al atributo de 
transparencia se encontró que: "Suele incluirse dentro de la rendición de cuentas anual distrital, un apartado para las acciones de la política, sin embargo, no se planea la participación y el desarrollo metodológico para dirigirla a niños, niñas y adolescentes. Salvo algunos intentos en algunas instituciones distritales del orden local” (38).

Minoría de edad - sujeto de derechos: un dilema constante en la evaluación y análisis de la política pública para la adolescencia se trata sobre definir las edades exactas para establecer el tránsito biológico, psicológico y social el cual se da lugar durante la etapa adolescente. Como paradigma en cuanto a objetivos de la política pública, la adolescencia se mueve entre su comprensión como menores de edad y lo que esto implica frente a su reconocimiento como sujetos de derechos.

Las implicaciones, en efecto, crean un marco sobre el cual se darán estrategias de atención y respuesta, definidas por la normatividad sobre la cual se construye su comprensión. Entendida la adolescencia como minoría de edad, si bien enmarca su protección fundamental, deja expuesta a esta población a una baja participación y decisión sobre lo que se esperaría de ella y en la edificación de sus proyectos de vida.

Normatividad - Estrategias: este dilema podría resumirse como muchas normas proclamadas y pocas estrategias efectivas ante los problemas identificados en esta etapa. En los lineamientos de la estrategia para la prevención del embarazo en la adolescencia y la promoción de proyectos de vida para los niños, niñas, adolescentes y jóvenes en edades entre 6 y 19 años, (documento que comenzó en el 2012 y tiene vigencia hasta el 2015) se 
establecen: "Dadas las implicaciones en el desarrollo y en la calidad de vida de los adolescentes, de sus familias y de las sociedades, la ocurrencia de embarazos a temprana edad ha sido considerada, a partir de la década de los setenta, una problemática social y de salud pública necesaria de ser intervenida a fin de procurar un mejor desarrollo individual, una mejor calidad de vida y mejores índices de desarrollo” (39).

Parece que el problema sobre ¿cómo entender a la adolescencia?, determina el modo en el cual se van a desarrollar las acciones de respuesta para los principales flagelos de este momento del curso vital. El desarrollo de su proyecto hacia la adultez está condicionado a factores característicos como: el género, la orientación sexual, la etnia, la estratificación socioeconómica, el ser víctima del conflicto armado interno y/o pertenecer a alguna forma de organización (culturas urbanas alrededor de la tecnología y las redes sociales y/o colectivos de barristas alrededor del fútbol). Aunado a esto, se encuentra el estigma de ser habitante de una localidad ubicada al sur de la ciudad, lo cual conlleva a la segregación a un fragmento de territorio, excluyéndolo de oportunidades para el desarrollo humano. 


\section{MARCO SITUACIONAL LOCALIDAD SÉPTIMA DE BOSA, D.C.}

La localidad séptima de Bosa se ubica al suroccidente del Distrito Capital, su delimitación se encuentra marcada al norte por el río Tunjuelo y la localidad de Kennedy; al sur con la Autopista Sur, la localidad Ciudad Bolívar y el municipio de Soacha (Cundinamarca); al oriente con el río Tunjuelo y la localidad de Kennedy y al occidente con el río Bogotá y con los municipios de Soacha y Mosquera (Cundinamarca).

Mapa 1. Ubicación de la localidad de Bosa

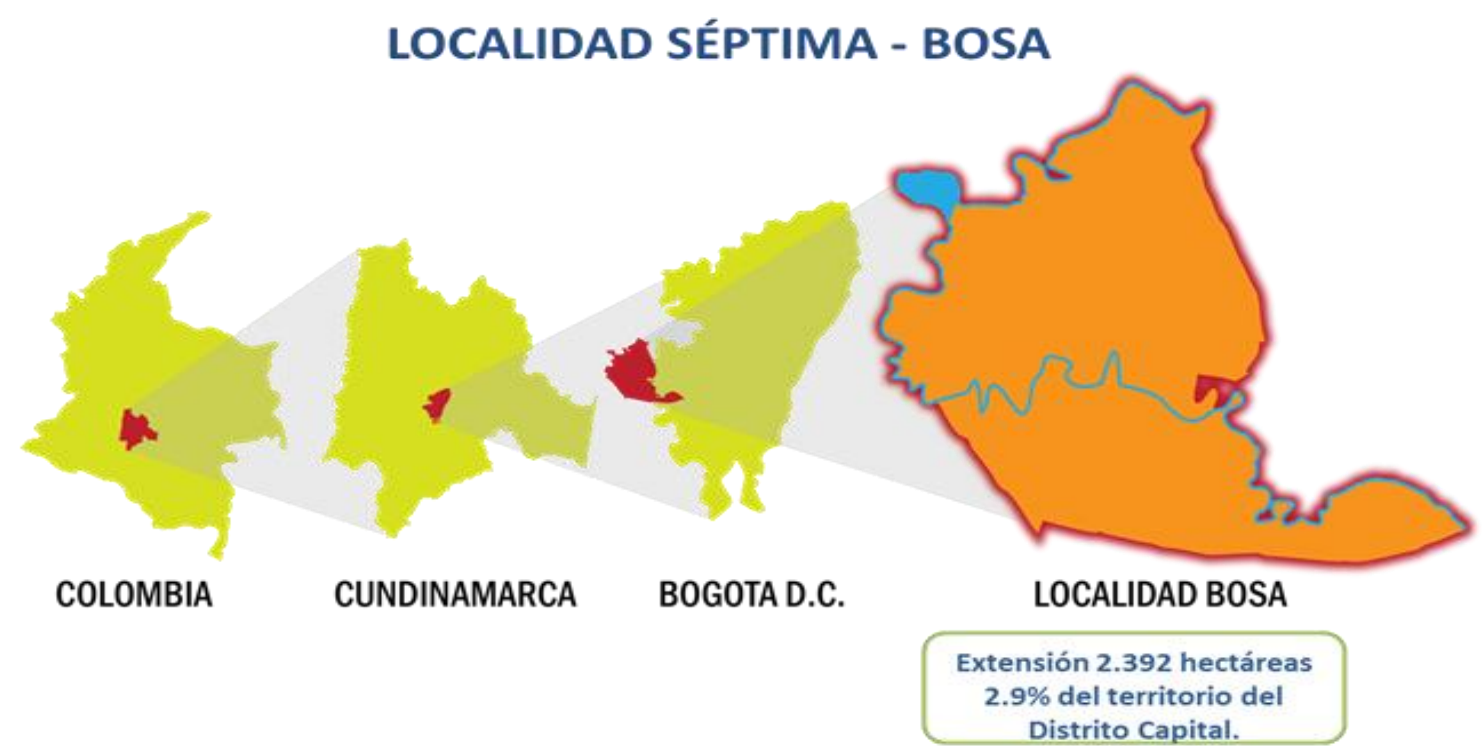

Fuente: Hospital Pablo VI Bosa, georreferenciación, 2015

Su división político administrativa contiene cinco UPZ, de las cuales una es de tipo residencial consolidado, dos son de tipo residencial de urbanización incompleta y los dos 
restantes tienen potencial para el desarrollo de proyectos de vivienda de interés social y vivienda de interés prioritario (ejecución que se ha intensificado desde el año 2005).

Los principales determinantes de la salud de la población de Bosa, se relacionan con una alta densidad poblacional y una vulnerabilidad considerable debido a su frágil infraestructura en vivienda y usos dotacionales, aunado a las zonas de inundación propias del sistema hidrográfico de la localidad, el cual se encuentra conformado por las cuencas del río Tunjuelo y Bogotá, así como por las Chucuas (humedales).

\section{Mapa 2. Hidrología localidad de Bosa, 2009}

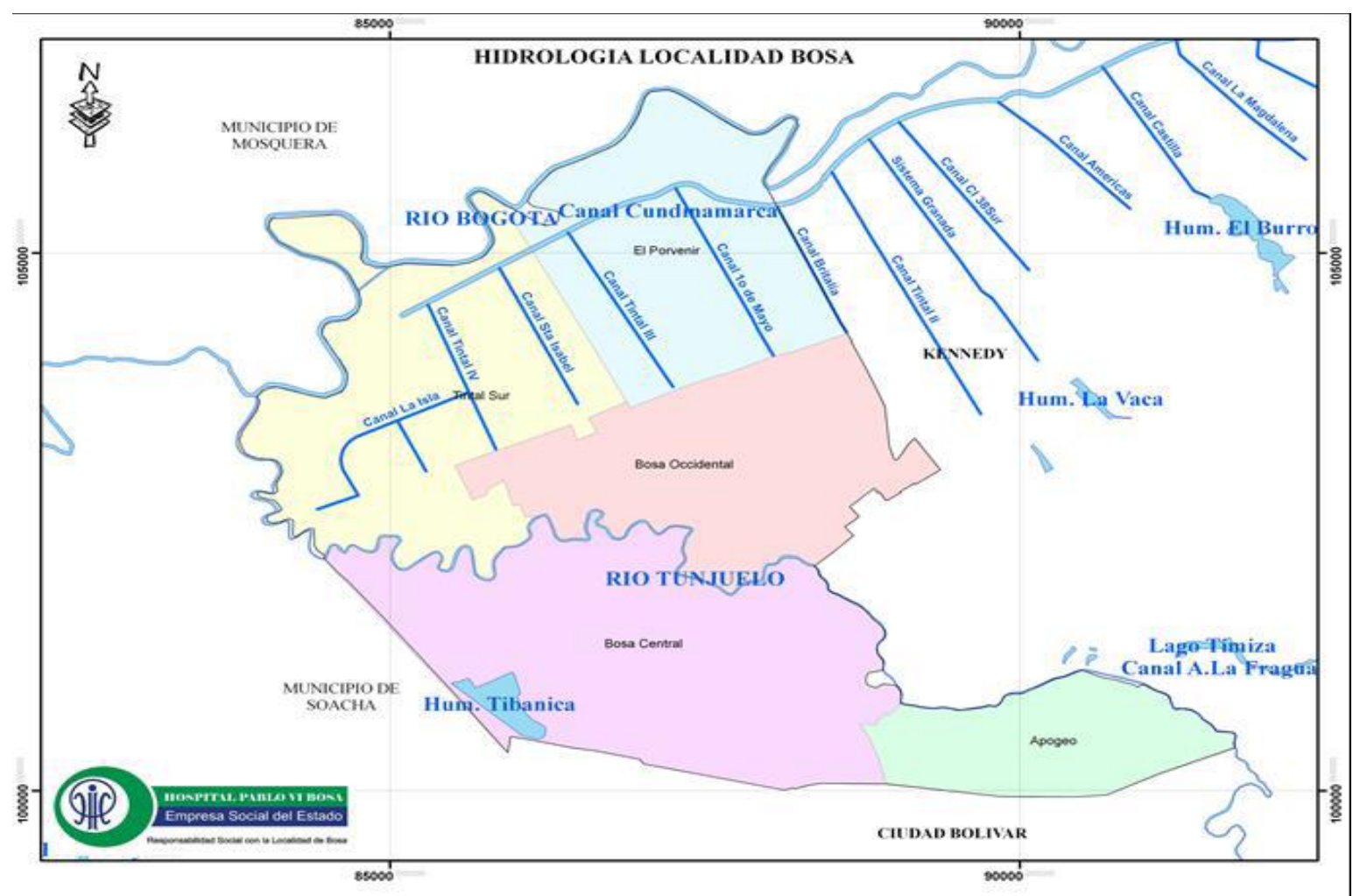

Fuente: Hospital Pablo VI Bosa cartografía, hidrografía, 2009 
Dentro de los conflictos ambientales identificados por su afectación en la salud de la población de Bosa se encuentran: contaminación hídrica, contaminación atmosférica, tenencia inadecuada de animales, manejo inadecuado de residuos sólidos, contaminación de alimentos, ruido, vectores y movilidad. Estas problemáticas fueron identificadas y priorizadas en ejercicios comunitarios e institucionales de carácter local a finales del año 2010, en el marco de la construcción de la Política Distrital de Salud Ambiental (6).

De otro lado, según las proyecciones del DANE, para el año 2015 residían 629.066 personas en la localidad (40), en los 381 barrios reconocidos por Planeación Distrital (41).

Figura 2. Pirámide poblacional, localidad de Bosa, comparativo 2000 - 2005 - 2015

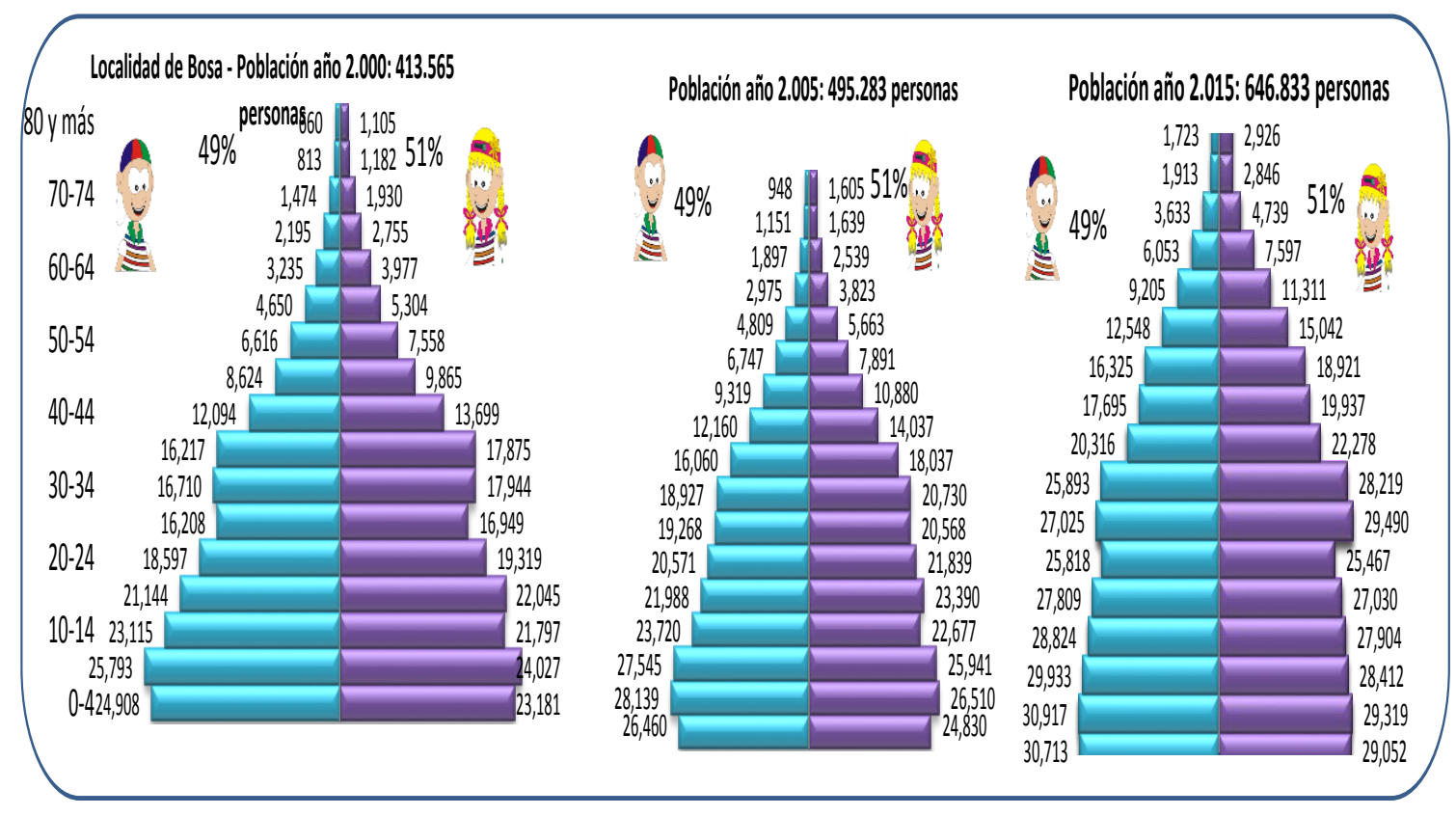

Fuente: DANE, proyecciones de población, 2000 - 2015 
La población de Bosa presenta un comportamiento creciente, pasando de 413.565 habitantes en el 2000 a 495.283 en el 2005, y 646.833 personas proyectadas para el 2015 . Su estructura poblacional es compatible con una población joven, sin embargo, en la última década se observa una disminución progresiva en la etapa del ciclo vital infancia y un incremento importante en el número de personas adultas y mayores de 60 años.

La tasa de crecimiento del $2.8 \%$ anual es explicada principalmente por la migración neta de 11.2 x 1.000 y la tasa de natalidad de 20.3 x 100 mujeres en edad fértil, así como la esperanza de vida (70.26 para hombres y 76.53 para mujeres) para el quinquenio 2005 2010 (42).

Tabla 1. Distribución de la población por momentos del curso vital, localidad de Bosa, 2000 -2015

\begin{tabular}{|c|c|c|c|c|c|c|}
\hline \multirow{2}{*}{ M omento del curso de vida } & \multicolumn{2}{|c|}{2000} & \multicolumn{2}{|c|}{2005} & \multicolumn{2}{|c|}{2015} \\
\hline & N. & $\%$ & N. & $\%$ & N. & $\%$ \\
\hline Infancia (0 a 9 años) & 97.909 & $24 \%$ & 105.939 & $22 \%$ & 120.001 & $19 \%$ \\
\hline Juventud (10 a 26 años) & 159.174 & $38 \%$ & 187.671 & $38 \%$ & 221.197 & $34 \%$ \\
\hline Adultez (27 a 59 años) & 137.156 & $33 \%$ & 174.624 & $35 \%$ & 253.689 & $39 \%$ \\
\hline Vejez (mayores de 60 años) & 19.326 & $5 \%$ & 27.049 & $5 \%$ & 51.946 & $8 \%$ \\
\hline Total & 413.565 & $100 \%$ & 495.283 & $100 \%$ & 646.833 & $100 \%$ \\
\hline
\end{tabular}

Fuente: DANE, proyecciones de población, 2000 - 2015

Respecto a la distribución por momento del curso de vida, para el año 2015 el 39\% de la población correspondió a adultos; en los niños se evidenció una disminución, pasando del $24 \%$ del total de la población en el año 2000 al 19\% en el año 2015; por su parte, en la vejez se registró un incremento, pasando del 5\% en el 2000 al 8\% en el 2015. De acuerdo 
con las proyecciones poblacionales, el momento del curso de vida adolescencia (10 a 14 años), para el 2015 representó un 9\% del total de la población (n: 58.345).

Si bien es cierto que los grupos poblacionales con mayor densidad en la localidad son juventud (incluida adolescencia) y adultez, es necesario profundizar en las condiciones particulares de esta etapa de transición, puesto que es en este momento de la vida donde se definen muchas de las características que permitirán la consolidación de proyectos de vida saludables y coherentes con las metas de desarrollo propuestas por la ciudad y el país.

De manera complementaria, se presenta la distribución de la población según el estrato socioeconómico, en Bosa el 11,9\% de los hogares se clasifican sin estrato, el 10,4\% pertenece al estrato 1 , el 75,4\% se clasifica en estrato 2 y el 2,2\% corresponde al estrato 3 (6); no se encuentra clasificación en los demás estratos, lo cual expresa un contexto marcado por condiciones difíciles para satisfacer las necesidades básicas.

Es importante resaltar que la migración de habitantes es considerable en la localidad, lo anterior obedece a políticas territoriales, ubicación estratégica para la conexión vial con la región y la caracterización del suelo como zona de expansión urbana. Entre las motivaciones para la migración se encuentran: búsqueda de mejores oportunidades (movilización de población hacia centros urbanos), desplazamiento forzado por la violencia y el conflicto armado, asignación de vivienda de bajo costo y la transición de la infraestructura habitacional a la vivienda multifamiliar en desarrollos verticales. 
Bajo este marco general del contexto local se desarrollan complejas relaciones que determinan la calidad de vida y salud de la población (6), tales como:

- Bosa ocupa el tercer lugar en Inseguridad Alimentaria y Nutricional en el Distrito Capital. Coexisten diversas formas de violencia y exclusión social que afectan principalmente a niños, niñas, adolescentes, mujeres y personas mayores. Alto índice de embarazos en adolescentes. Falta de oportunidades laborales y mecanismos que favorezcan la productividad.

- Bosa es la segunda localidad de Bogotá receptora de víctimas del conflicto armado (4.876 personas según datos de la Alta consejería distrital para las Víctimas) (6).

- Bosa cuenta con el mayor número de personas con discapacidad incluidas en el registro Distrital de Discapacidad (15.744 personas), quienes señalan como sus principales problemáticas la exclusión social y la falta de infraestructura amigable.

- La población étnica local reúne a 1.218 personas afro descendientes y 15.032 indígenas, que se encuentran organizados en cinco cabildos (Muisca de Bosa y de Suba, Kichwas, Inga y Pijao).

- En la localidad se reconocen 13 organizaciones de recicladores, 2.890 carreteros (personas que derivan su sustento de actividades en vehículos de tracción animal y tracción humana) y 534 UTI.

- Los sectores Lgbti de Bosa presentan un subregistro importante, sin embargo, se han identificado 276 personas con esta condición diferencial (6). 
Con respecto al aseguramiento en salud, se evidencia una disminución importante en la población no afiliada, a expensas del incremento del régimen contributivo. Debido a que en Bosa la oferta de IPS con servicios para afiliados al régimen contributivo es mínima, la población residente en la localidad requiere desplazamientos a otras zonas, determinando barreras de acceso geográfico a los servicios de salud (43).

Figura 3. Distribución poblacional según régimen de aseguramiento en salud, localidad de Bosa, 2013 - 2015

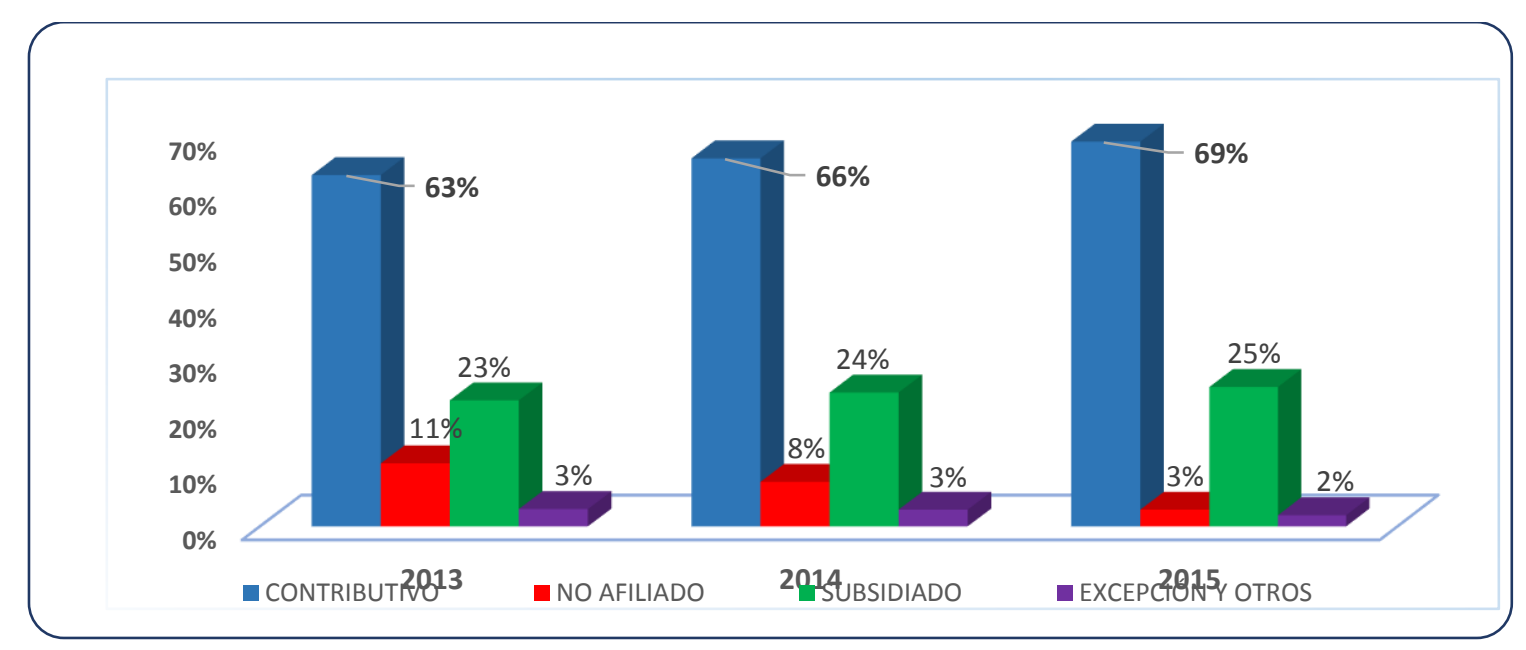

Fuente: Secretaria Distrital de Salud, Dirección de Aseguramiento, 2013 - 2015; Hospital Pablo VI Bosa, Mercadeo

La complejidad de la situación de la localidad se ve reflejada al comparar la estratificación socioeconómica con el aseguramiento en salud. Pues resulta contradictorio que en una localidad donde el estrato más alto es el tres, (expresando bajos niveles de ingresos para constituir viviendas dignas), se presente el mayor porcentaje de personas afiliadas al 
régimen contributivo, el cual está conformado por población con capacidad adquisitiva suficiente para contribuir al Sgsss.

De otro lado, para el 2011 la localidad llegaba a una tasa de equipamientos generales de 13 por 10.000 habitantes, la cual se encuentra por debajo de la tasa de ciudad (13 Vs 18) (44). Dentro de los equipamientos con una mayor infraestructura se encuentran bienestar social y educación, con una menor representación se identifican recreación y deporte, abastecimiento de alimentos, seguridad, defensa y justicia y salud.

La diversidad cultural, las condiciones socio económicas y ambientales, la falta de equipamientos, así como las dificultades de acceso a servicios, al trabajo formal y las escasas oportunidades para desarrollar proyectos de vida, son generadores de problemáticas de convivencia e inseguridad. En este orden de ideas, las principales problemáticas de la localidad de Bosa se pueden resumir en: acceso a servicios básicos, inseguridad, convivencia, contaminación ambiental y productividad.

\section{LA SITUACIÓN DE LA ADOLESCENCIA EN BOSA}

Según Mas Colombo, citado por Risueño y Motta, la adolescencia es caracterizada por su heterogeneidad, lo que la hace producto del constructo de su experiencia: "El desarrollo del adolescente se caracteriza por los cambios que se relacionan con los procesos que 
conducen a la construcción de la conciencia de sí mismo a partir del desarrollo de la identidad del yo corporal, del yo psíquico y del yo social” (45).

En el año 2009, fueron caracterizados niñas y niños trabajadores con edades entre los 5 a 14 años de edad; el proceso se realizó en su mayoría por medio de búsqueda activa, además, por la articulación con la mesa local de trabajo infantil y por la información recibida por parte de la comunidad (6).

Se puede afirmar que el $22 \%$ de niñas y niños de edades entre los 5 y los 11 años, identificados y caracterizados por la intervención de trabajo infantil se desempeñan en la actividad económica de comercio al por menor en establecimiento o local comercial, este porcentaje corresponde a la mayor parte del total abordado. También es notorio, que entre las niñas abordadas por la intervención existe un $12 \%$ que están ejerciendo la venta ambulante callejera y un $1 \%$ el trabajo doméstico, catalogados como peores formas de trabajo infantil.

La actividad de venta ambulante tiene su origen en el acompañamiento que realizan los niños y niñas a sus padres, y que poco a poco se va transformando en un moldeamiento del trabajo en calle; ésta actividad se realiza cada vez con mayor frecuencia por los niños y niñas, los cuales son caracterizados por ser quienes realizan las actividades de "pregonero", de atención al público, organización de la mercancía y recepción del dinero; el mismo 
entorno permite en los niños empezar a concebir la posibilidad de un puesto de trabajo propio.

Para las adolescentes de 12 a 14 años la actividad económica predominante es el comercio al por menor en establecimiento comercial y/o local (14\%). Por otro lado, la venta ambulante callejera y el reciclaje son peores formas de trabajo en las cuales estas niñas se están desempeñando (9\% y $7 \%$ respectivamente) (46).

Figura 4. Erradicación y prevención del trabajo infantil y adolescente, Ámbito Laboral, localidad de Bosa, 2011 - 2014

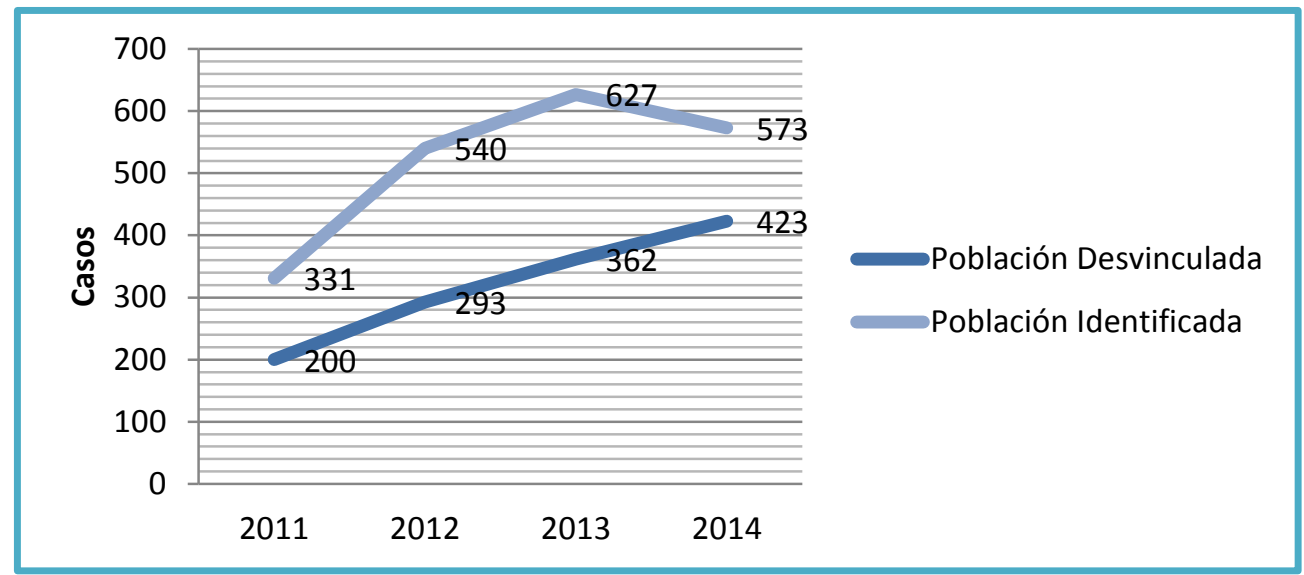

Fuente: Hospital Pablo VI Bosa I Nivel E.S.E., Diagnóstico en Salud población Adolescente, marzo 05 de 2015 ,

Preliminar

De acuerdo con cifras del Hospital Pablo VI Bosa para el año 2014, el total de población infantil y adolescente identificada con trabajo infantil ascendió a 573 con respecto a 331 menores en el año 2011; así las cosas, según la percepción de la situación, la intervención no llega a cubrir el universo de casos que existe, dado el pico que se logra en el año 2013 
con un total de 627 intervenciones. La anterior situación, hace pensar en el trabajo infantil como una coerción de los derechos acordados para el sano desarrollo de la adolescencia (46).

Del año 2011 al año 2014 la intervención crece en una proporción del 58\% en la cobertura del ámbito laboral en salud pública para la localidad de Bosa. Pero la proporción de población desvinculada crece en el transcurso de esta cohorte. Mientras en el 2011 la proporción de la población desvinculada era del $60 \%$, sobre el total de la población identificada, para el 2014, asciende al $73 \%$ considerando el mismo total para este año. Durante estos años, el porcentaje de eficiencia llego al 13\% de lograr la meta de erradicación de este flagelo. El proceso de desvinculación del trabajo infantil en una localidad como Bosa, implica el despliegue de todo tipo de organismos encargados en garantizar los derechos en una etapa vulnerable como la adolescencia.

En educación, el analfabetismo se entiende como la proporción de personas que no saben leer ni escribir sobre el total de personas mayores de 15 años. Para el 2011, en Bosa se presentaba una tasa del 2,2, mientras que en el distrito llegaba al 1,6 (44). Según datos de la OEA (2013) la proporción de personas que no saben leer ni escribir se redujo de 10,4 a 8,6 en la década del 2000 al 2010, producida por la expansión de la escolarización básica y las políticas de alfabetización y educación en adultos, lo cual se ve reflejado en la reducción del analfabetismo funcional en el período de vida de los 15 a los 24 años. 
La educación entonces debe generar procesos de participación para el diálogo entre los derechos y las oportunidades para el desarrollo. El pronto arribo de los adolescentes al sector productivo sin procesos educativos es generadora de informalidad laboral y baja capacidad debido a ingresos económicos.

El estudio de la Celade y la OIJ encargado por la Cepal, sobre la adolescencia y juventud en América Latina (47), muestra una representación paradójica del rol de la población adolescente en el desarrollo de las naciones que hacen parte de dicha región. De esta forma, la adolescencia es abordada desde una doble representación, como activos del desarrollo por su potencial contributivo para la transformación de la problemática actual, pero a la vez enfrentados a un aumento de la exclusión social.

Este mismo informe se basa en problemas comunes entre hogares de escasos recursos como lo son: el acceso inequitativo a una educación de calidad, el trabajo infantil y adolescente, en la salud, especialmente en la reproductiva, así como la relación entre juventud y violencia.

Bajo estas características generales de la población adolescente de la región es como también se empieza a delinear la exclusión (47). En primer lugar, se encuentra la exclusión de tipo social secundaria a la incapacidad para ingresar al mercado laboral debido a la baja cualificación, lo cual redunda en una ausencia de prestaciones sociales, además de las dificultades del Estado para renovar los sistemas educativos y de capacitación acordes a los requerimientos del mercado laboral actual, familias incompletas e inestables y 
población de bajos ingresos marginada de las posiciones laborales mejor remuneradas, entre otras formas de exclusión; así mismo, se produce un efecto de concentración demográfica, donde coinciden los adolescentes con un bajo nivel educativo y con altas tasas de fecundidad, favoreciendo la pobreza desde los primeros momentos del curso vital.

En segundo lugar, surge la exclusión espacial, la cual se basa en la segregación residencial, separación de los espacios públicos y segmentación de los servicios básicos. Dichos procesos de exclusión producen en la población adolescente menos favorecida la identidad con subculturas marginales, pandillas y barras. Los códigos que producen estas subculturas generan un sentido de filiación en adolescentes y jóvenes que los hace permanecer en ellas, sin aportar al funcionamiento de la sociedad. Tratar de desvincular a la población de estas subculturas generaría violencia e incentivaría la deserción de los ámbitos públicos de la clase media, reforzando el fenómeno de la segregación social.

En el marco de la gestión estratégica, la población adolescente se vislumbra desde una doble perspectiva, en primer lugar, como beneficiarios de las políticas públicas que buscan responder a la exclusión social, fomentando su integración a la, y, en segundo lugar, como actores estratégicos con una participación protagónica en la aplicación de dichas políticas públicas.

Así mismo, el informe publicado por la Cepal en 2014 titulado "Panorama social de América Latina", presenta en un primer momento, el contexto de la región a partir de índices de la pobreza dimensional y la distribución de los ingresos que determinan las 
clases sociales en los países latinoamericanos; luego de esto, ubica las brechas en los ámbitos juventud y desarrollo, desigualdad de género en el mercado laboral y segregación residencial urbana en el centro del análisis.

El capítulo IV de este documento profundiza en la relación entre juventud y desarrollo. De esta misma forma, plantea la relación estrecha entre educación y empleo como ejes de la inclusión social en este momento del desarrollo humano y social. Así mismo, realiza recomendaciones encaminadas a erradicar la estigmatización de aquellos jóvenes que se encuentren fuera de la institucionalidad de la educación y el trabajo, como orígenes de la idea de una juventud violenta en la región. Es así, como se debe incluir a las juventudes en la elaboración de estrategias para el desarrollo, lo cual puede lograr salidas innovadoras para la resolución de conflictos propios de la juventud.

En este capítulo se plantea el pronunciamiento reiterativo de la Cepal desde su consideración sobre el desarrollo, "la igualdad como el horizonte del desarrollo, el cambio estructural como el camino y la política como el instrumento para alcanzarlo" (48). En este sentido, la igualdad se piensa en una perspectiva más allá de la distribución de ingreso e integra la mirada de las oportunidades y capacidades. Esta idea de la igualdad implica reconocer el pleno ejercicio de la ciudadanía y el reconocimiento recíproco de los actores. De acuerdo con eso, se requieren políticas que promuevan la autonomía de los sujetos y busquen la atención de sus vulnerabilidades. 
Desde los determinantes estructurales y particulares de la región de Latinoamérica y el caribe, la adolescencia se encuentra condicionada por problemas relacionados con la vivencia de su sexualidad en cuanto dimensión singular, en tanto que se encuentra determinada por diferencias de género y orientación sexual, culto, etnia y estratificación socioeconómica, entre otras. Como aspectos derivados de la infancia, se encuentran contextos familiares marcados por situaciones opuestas que van desde la sobreprotección, hasta el abandono. Las relaciones familiares son complejas, aunque urbanas, aún conservan características de ruralidad, dada su ubicación en la periferia de la ciudad, pero además por la tradición indígena Muisca, desde el vínculo con el territorio ancestral, así como con la migración y el desplazamiento interno a causa del conflicto armado, las cuales llegan a la localidad como territorio adoptivo con el desarraigo del campesinado o de la pertenencia étnica.

Las condiciones ambientales, de igual forma, marcan la vulnerabilidad de quienes habitan la localidad de Bosa, rodeada por el río Bogotá y dividida por el río Tunjuelito, afluentes altamente contaminadas por las dinámicas propias de la industria y la urbanización del distrito capital y la región. Aun cuando se encuentren en zonas de riesgo por inundación, con episodios catastróficos como la emergencia del año 2012, se ha generado la ocupación de terrenos y la edificación informal en barrios ilegales; sin embargo, estas viviendas se encuentran en mal estado, con deficiente acceso a servicios públicos.

En un escenario como este, pronto se generan situaciones de violencia tanto en el ámbito familiar, como en relación a la seguridad en el contexto comunitario. El abuso sexual, inicia 
desde la infancia y puede llegar a extenderse hasta la adolescencia si no se cuenta con una red de apoyo proximal que permita a las poblaciones más aisladas tener contacto con las instituciones que imparten justicia.

De igual forma, como se produce en el orden nacional, en el orden distrital es posible encontrar un reflejo en menor proporción del conflicto armado interno. Aunque las autoridades locales no estén autorizadas para confirmarlo, se sabe de la presencia y actuación delictiva de representantes de grupos armados ilegales, lo cual expone a la población adolescente al riesgo de reclutamiento, así como a la trata de personas para la explotación sexual y comercial.

Otro flagelo social que afecta a la adolescencia, se refiere al tráfico y microtráfico de estupefacientes, dado que en estas edades pueden ser reclutados por grupos delincuenciales para traficar drogas o promover el consumo entre sus pares. Si bien no se tiene evidencia de la relación entre los capos de las barras de futbol y los expendedores de SPA, si es cierto que el consumo al interior de estas organizaciones es regular, provocando incluso prácticas sexuales inseguras y enfrentamientos violentos (en algunas ocasiones con consecuencias mortales).

En cuanto a su formación académica, la adolescencia en Bosa se encuentra marcada por una educación básica fundamentada en nociones religiosas, con una baja continuidad en la educación profesional, en cuyo caso se presenta una mayor proporción en escenarios de formación técnica y tecnológica, principalmente por la oferta pública para el sector 
educativo. La población que no continúa su formación académica, es lanzada al trabajo informal desde temprana edad, muchas veces motivados por sus padres, dadas las condiciones de bajos ingresos económicos en familias extensas. 


\section{ANÁLISIS DE LA INFORMACIÓN CUALITATIVA}

Este proyecto de investigación se enmarca en una perspectiva cualitativa, en la cual los diferentes discursos referentes a la política pública de infancia y adolescencia son centrales en la comprensión de la misma, tanto en términos de contenidos como en términos de apropiación de nociones y vivencias sentidas de la población. A través de los discursos se vislumbra una dimensión simbólica en la que los sujetos se hacen una representación de lo que experimentan. En este mismo sentido, es a través de la simbolización, que el ser humano se ha acercado a la construcción del conocimiento (49).

Cabe destacar que la metodología cualitativa permite captar, según Iñiguez (50): “(...) los significados profundos que estructuran la realidad analizada (...)". De esta forma, se aplicaron dos técnicas pertenecientes a la metodología cualitativa, tratando de que cada una se ajustara a las capacidades y disponibilidades de la población analizada.

Para cumplir con los objetivos de la investigación se desarrollaron entrevistas individuales a diez personas que trabajan con población adolescente desde el sector público. Para éstas se seleccionaron actores clave relacionados con el sistema de protección social en el orden local, distrital y nacional, y que adelantaran acciones en la localidad de Bosa.

En lo local, se estableció contacto con referentes de la DILE y referentes del Hospital Pablo VI Bosa, relacionados con las políticas públicas de Infancia y Juventud, igualmente, se logró contactar a la referente de la Casa de Igualdad de Oportunidades para las Mujeres. 
En el orden Distrital, por un lado, se realizó contacto con profesionales de la SDIS, con representación en el Comité de Infancia y Adolescencia, el Consejo para la Atención Integral a Víctimas de Violencia Intrafamiliar, la Red del Buen Trato y el Comité de Familias. Por otro lado, se encontraron acciones para la adolescencia desde la SDIS a través del Centro Amar; igualmente, se contactó al gestor educativo del IDRD. En el orden Nacional, sobresalen las acciones del ICBF.

La presente investigación se enmarcó en los principios de la bioética declarados por Childress (51), en cuanto al "respeto a la autonomía, la no maleficencia, la beneficencia y la justicia"; sin embargo, su carácter social no implica un desprendimiento de las consideraciones ya planteadas en las pautas éticas de CIOMS-OMS que definen la investigación como “(...) un tipo de actividad diseñada para desarrollar o contribuir al conocimiento generalizable (...)" (52). De esta manera, se informó a los participantes, respecto a los procedimientos a realizar durante el desarrollo de las herramientas metodológicas empleadas en la recolección de información. Para ello, se diligenció un consentimiento informado individual, previó a la realización de cada entrevista. Para la realización de los grupos focales se emplean consentimientos informados colectivos dada la categorización como "Sin Riesgo".

No obstante, se garantizó el anonimato de quienes participaron en la investigación, para lo cual se informó con claridad el uso que tendría la información recopilada durante este ejercicio. Asimismo, se aclaró que durante todo el proceso de procesamiento, análisis y presentación de los resultados de la investigación se mantendría un adecuado tratamiento 
de los datos, además de garantizar que no serían usados para otros fines diferentes a los propuestos por la investigación. Ninguno de ellos refirió su deseo de no participar de este ejercicio bajo la metodología planteada. Por el contrario, el tema fue muy bien recibido dadas sus preocupaciones actuales.

Acto seguido y con el fin de rescatar los conocimientos prácticos y teóricos de quienes trabajan en proyectos que buscan fomentar el bienestar de los adolescentes, se indagó sobre problemáticas percibidas por dichas personas en su interacción con los adolescentes, para así distinguir sus representaciones sociales acerca de este grupo etario; para ello se emplearon entrevistas semiestructuradas, es decir, el entrevistador contó con una guía de preguntas para direccionar la entrevista. Esta herramienta, permite cierta flexibilidad permitiendo que las entrevistas se desarrollen en conversaciones fluidas y espontáneas, lo que contribuye a la calidad de la información recolectada; de hecho, la sensación de que el entrevistador sea un participante más es ampliamente apreciada en la obtención de la información y opiniones de las personas entrevistadas (50).

Finalmente, se realizaron cuatro grupos focales con niños, niñas y adolescentes de 10 a 14 años, habitantes de la localidad de Bosa. El tamaño de cada grupo estuvo sujeto a la disponibilidad de la población (situación no extraña para la aplicación de esta metodología), siendo el grupo más pequeño de cinco personas y el más grande de 15 personas; los grupos focales se basaron en una guía de preguntas predeterminada. En estos grupos se exploran las nociones de derecho, niños-niñas/adolescentes, así como deberes para el caso de los adolescentes participantes, esto con el fin de dilucidar sus 
representaciones sociales y cómo construyen sus subjetividades. Esta técnica, tiene un alto grado de validez subjetiva, en tanto la información respeta las expresiones específicas en que las personas enuncian sus opiniones (53).

De esta manera, el proceso de sistematización de la información se desarrolló en dos fases; la primera representada en la transcripción de los audios de las entrevistas individuales y de los grupos focales. La transcripción se hizo conforme lo expresado, rescatando así las expresiones exactas de todos los participantes, ya que la metodología cualitativa se encarga de abordar los sentidos y las representaciones a través del análisis del discurso (49). Una segunda fase, corresponde al análisis discursivo de las transcripciones, desarrollada con apoyo del software para análisis de datos cualitativos - Atlas. Ti., este software permite asociar códigos con pasajes específicos de los textos analizados, como transcripciones de las entrevistas y los grupos focales, para así indagar sobre imaginarios, comprensiones y opiniones de los participantes acerca de los temas abordados. Resultado de ello, se busca que los códigos elegidos den cuenta de preguntas o temáticas recurrentes y sus distintas interpretaciones, para de este modo facilitar el análisis del discurso. Así mismo, permite graficar conexiones entre dichos códigos o citas específicas, esto con el objetivo de profundizar en el estudio de las representaciones.

Como resultado de este análisis, se espera dilucidar tanto la comprensión de los derechos que tienen los adolescentes, como sus referencias de construcción de subjetividades. Lo anterior, se desarrolló partiendo del análisis del discurso, el cual permite comprender cómo se configuran las relaciones y sus significados (50). Asimismo, se analizaron los resultados 
obtenidos de las entrevistas, identificando convergencias y divergencias de los profesionales que trabajan en temas de adolescencia, respecto a la política pública y su población objetivo. Finalmente, hay que considerar que autores como Gasper, Apthorpe (54) e Iñiguez (50) sugieren que "el análisis del discurso como método cualitativo puede variar, desde aproximaciones lingüísticas hasta análisis de orden ideológico".

Una primera lectura dio lugar a un acercamiento a la información, dando paso una lluvia de ideas, buscando rescatar temas o inquietudes que se identificaran como recurrentes en la lectura y que pudieran relacionarse con los objetivos de la investigación; esto con el fin de construir un primer esquema de codificación de los discursos presentes en los textos.

Posteriormente, se incluyeron las transcripciones realizadas en el software Atlas. Ti. Ya en el análisis de los textos, se construyeron códigos como categorías de análisis, en los cuales se fueron agrupando las temáticas o nociones a explorar. Cabe mencionar que la construcción de dichos códigos es cambiante, ya que pueden aparecer más códigos durante la relectura detenida de los documentos; sin embargo, se construyeron 13 códigos que se pueden consolidar en tres grandes grupos.

\section{Cuadro 4. Grupos y códigos de análisis cualitativo}

\begin{tabular}{ll}
\hline Grupo & Códigos \\
\hline Ciudadanías y política pública & $\bullet$ (Des)igualdad. \\
& - Ciudadanía como ejercicio de derechos. \\
& - Ciudadanía como responsabilidad social. \\
& - Institucionalidad y participación. \\
& - Imaginario de eficacia de la política pública. \\
& - Pertinencia de la política pública. \\
Los derechos & - Vulneraciones a los derechos.
\end{tabular}


- (Des)igualdad.

- Derechos como paradojas.

- Derecho, protección, bienestar.

- "Derecho", ¿cuál, de quienes, donde, por qué?

Representaciones de la - Vulneraciones a los derechos.

adolescencia

- Riesgos de los adolescentes.

- Adolescencia como tránsito entre infancia y juventud.

- Adolescencia y potencialidades.

Fuente: elaboración propia.

La conformación de estos grupos permitió construir redes comprensivas que dieran cuenta de semánticas lingüísticas, desde las cuales se pudiera interpretar el significado de los conceptos abordados por los participantes del estudio. A continuación, se presenta un ejemplo de red para el análisis de la representación de adolescencia. 
Figura 5. Ejemplo de redes semánticas para el análisis de la representación de adolescencia

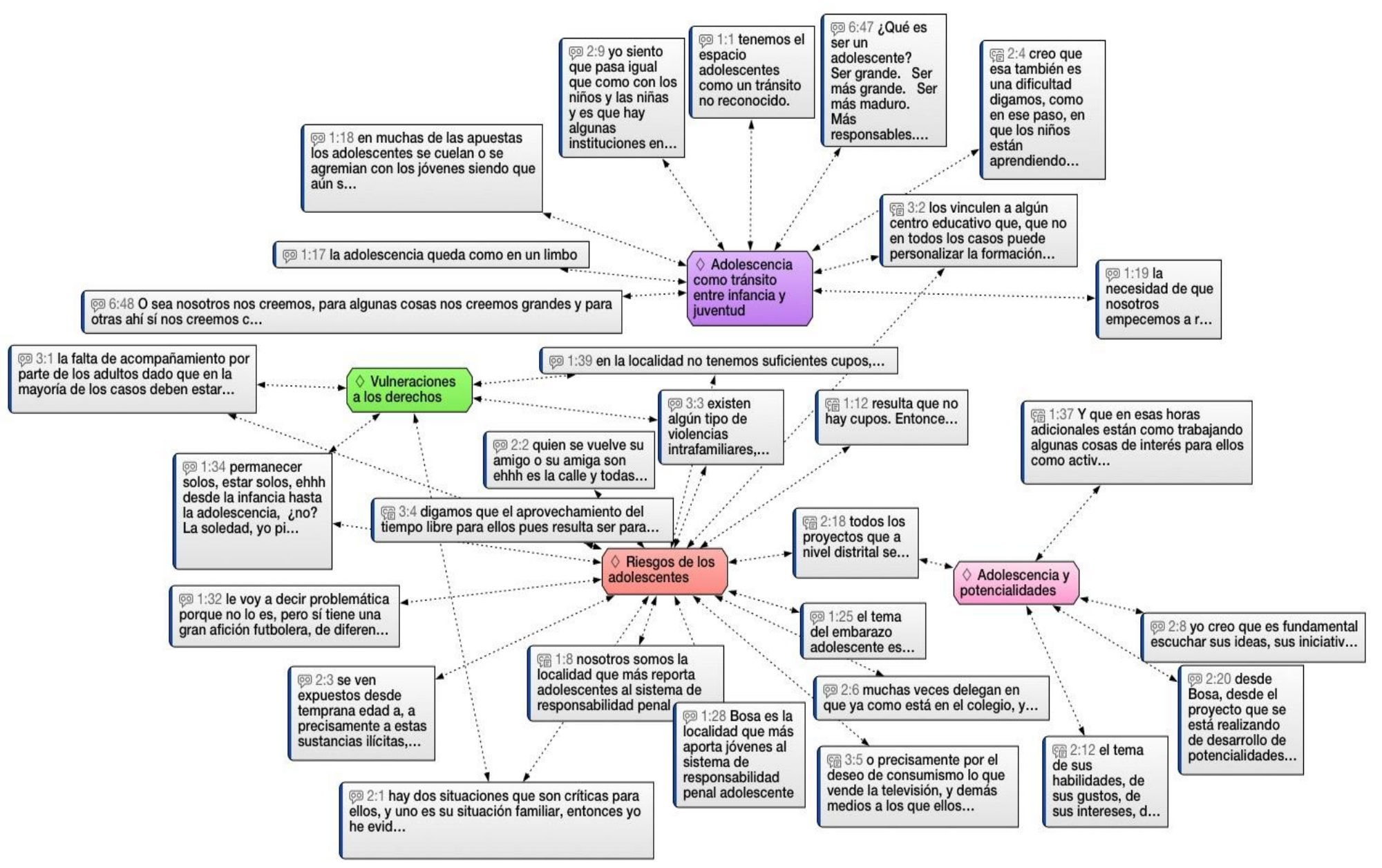

Fuente: elaboración propia 
Es importante mencionar que la versión utilizada de Atlas.ti era la versión de prueba, que acepta un máximo de 10 documentos. Teniendo en cuenta que se realizaron 10 entrevistas con funcionarios y 4 grupos focales con adolescentes, por razones de practicidad se tomó la decisión de unir los documentos de transcripción de las entrevistas. En ese sentido, se analizaron en un mismo documento dos entrevistas. Así, las entrevistas 1 y 2 se analizaron en el Documento 1; las entrevistas 3 y 4 conformaron el Documento 2; las entrevistas 5 y 6 se analizaron en el Documento 3; las entrevistas 7 y 8 se abordaron en el Documento 4; finalmente las entrevistas 9 y 10 conformaron el Documento 5. El grupo focal 1 fue el Documento 6. Los documentos 7, 8, y 9 corresponden a los grupos focales 2, 3 y 4 respectivamente.

Cuadro 4. Índice de Actores incluidos en las metodologías cualitativas

\begin{tabular}{|c|c|c|c|}
\hline METODOLC & CARGO & INSTITUCIÓN & FUENTE \\
\hline Entrevista 1 & PROFESIONAL PLANEACIÓN & ALCALDÍA LOCAL & Documento 1 \\
\hline Entrevista 2 & $\begin{array}{l}\text { REFERENTE DE INFANCIA Y } \\
\text { ADOLESCENCIA }\end{array}$ & $\begin{array}{l}\text { COMITÉ DE INFANCIA Y } \\
\text { ADOLESCENCIA }\end{array}$ & \\
\hline Entrevista 3 & REFERENTE DE VIOLENCIAS Y FAMILIA & $\begin{array}{l}\text { CONSEJO PARA LA } \\
\text { ATENCIÓN INTEGRAL A } \\
\text { VICTIMAS DE VIOLENCIA } \\
\text { INTRAFAMILIAR- RED DEL } \\
\text { BUEN TRATO - COMITÉ DE } \\
\text { FAMILIAS }\end{array}$ & Documento 2 \\
\hline
\end{tabular}

\begin{tabular}{|c|c|c|c|}
\hline Entrevista 4 & COORDINADOR & CENTRO AMAR & \\
\hline Entrevista 5 & TRABAJADORA SOCIAL & IDIPRON UPI BOSA & Documento 3 \\
\hline Entrevista 6 & GESTOR EDUCATIVO & IDRD & \\
\hline Entrevista 7 & PSICOLOGA & $\mathrm{ICBF}$ & Documento 4 \\
\hline Entrevista 8 & PROFESIONAL COBERTURAS & SECRETARIA DE EDUCACIÓN & \\
\hline Entrevista 9 & COORDINADORA & SECRETARIA DE LA MUJER & Documento 5 \\
\hline Entrevista 10 & REFERENTE INFANCIA & HOSPITAL PABLO VI BOSA & \\
\hline Grupo focal 1 & ADOLESCENTES & ESCOLARIZADOS & Documento 6 \\
\hline
\end{tabular}




\begin{tabular}{llll}
\hline Grupo focal 2 & ADOLESCENTES & ESCOLARIZADOS & Documento 7 \\
\hline Grupo focal 3 & ADOLESCENTES & ESCOLARIZADOS & Documento 8 \\
\hline Grupo focal 4 & ADOLESCENTES & ESCOLARIZADOS & Documento 9 \\
\hline
\end{tabular}

Fuente: elaboración propia

Se hará referencia a las citas de acuerdo a su ID en el programa. El ID de la cita está compuesta por el número del documento y un número que da cuenta de la secuencia cronológica en la que una cita fue creada en el documento. Así, la cita 3:5 viene del documento 3 y fue la quinta cita creada en ese documento.

COMPRENSIONES DE LA ADOLESCENCIA DESDE PERSPECTIVAS DEL DESARROLLO

\section{- Riesgos y vulnerabilidades: de una infancia a una adolescencia demandante}

La noción de adolescencia fue explicada anteriormente como tránsito entre la etapa de la infancia y la juventud, desemboca en la identificación como una etapa de continuación y a la vez de transformación de la infancia. En este sentido, la información recolectada da cuenta de que las problemáticas iniciales se asocian a la falta de capacidad reflexiva y crítica, así como un débil autocuidado y que por ende demanda un cierto acompañamiento y cuidado; por ejemplo, la soledad se reconoce como una problemática recurrente en la población infantil y adolescente de la localidad, y no solamente se asocia con la vulneración del derecho a la protección especial, sino que la falta de acompañamiento aumenta la posibilidad de riesgo en todo ámbito, de ahí que un servidor público se exprese así: “(...) permanecen solos en sus 
casas, cierto, porque los adultos generalmente están dedicados a proveer económicamente, muchos de ellos salen de la localidad, entonces permanecen mucho tiempo solos sin el cuidado de una persona adulta (...)" (1:35).

Ahora bien, la falta de acompañamiento adulto a los adolescentes no solamente puede ser abordada por falta de voluntad, sino especialmente, desde un contexto socioeconómico que limita las posibilidades de dicho acompañamiento adulto, en tanto que las necesidades económicas son inmediatas y configuran la jerarquización de prioridades en las familias. En una entrevista, se afirma que "(...) la falta de acompañamiento por parte de los adultos, dado que, en la mayoría de los casos, deben estar asumiendo casos de, no sé, temas de producción, de trabajo, y eso suele ocuparles bastante tiempo (...)" (3:1)

La anterior idea es mencionada reiteradamente, ya que los adultos suelen dedicarse a “(...) la producción de trabajo, y eso suele ocuparles bastante tiempo (...) eso implica que los vinculen a algún centro educativo que, que no en todos los casos puede personalizar la formación, es decir, ehhh, pues los cuidan, cuidan entre comillas (...)” (3:1).

Por otra parte, se reconoce que durante la infancia no solo se suscita una responsabilidad de cuidado por parte de la familia, sino que el Estado debe garantizar ciertos mínimos para que este grupo pueda desarrollarse en condiciones favorables que exceden la esfera familiar. De ahí que, en muchas de las entrevistas, se haga alusión al énfasis que se le ha dado desde la política pública a programas para la primera infancia; incluso uno de los entrevistados dice: “(...) es que yo creo que la dificultad está en que, pues, todo se ha dirigido a primera infancia, ¿sí? no es que la política no contemple la adolescencia, sino que todo se ha dirigido a primera 
infancia, y cuando ya hablamos de juventud como que ellos no sienten que están ahí incluidos $(\ldots) "(5: 21)$.

En otra entrevista, también se menciona que “(...) lo que hay que hacer es ampliar los rangos para que se cobije realmente esa población que de alguna manera está desprotegida, porque igual la política de infancia y adolescencia, el problema que ha tenido es que se ha hecho un énfasis en infancia, y sobre todo en primera infancia, ¿sí? y se ha dejado desprotegidos a los adolescentes (...)" (1:44). Aunque no se trata de negar la importancia de tener programas que garanticen desde el inicio del desarrollo una mejor calidad de vida para las personas, resulta urgente preguntarse por las consecuencias discursivas de priorizar unas etapas sobre otras, como si el desarrollo fuera una secuencia de etapas más que un proceso en sí mismo.

De esta forma, centrar la atención en la primera infancia, parece haber producido una especie de invisibilización discursiva respecto a qué programas existen para los adolescentes (aunque este fenómeno no sucede de manera exclusiva con los adolescentes), lo cual lleva a que los adolescentes y sus familias no conozcan lo que se ofrece por el gobierno del Estado. Lo anterior se puede evidenciar en lo referido por uno de los entrevistados: “(...) lo que pasa es que de pronto nos hemos dedicado un poco más a primera infancia y se le ha dado más prioridad, y ellos desconocen qué es lo que existe, ¿sí? entonces pienso que esa es la principal barrera, el desconocimiento, no saben (...)" (5:22).

Hay otro elemento a tener en cuenta, y es que cuando se entra a la etapa de la adolescencia, el cuidado que parece ser evidente para los niños y niñas, deja de serlo para el adolescente; al respecto, uno de los entrevistados menciona que: 
(...) Ellos manifiestan siempre que no reconocen como ¿cuál es la oferta que tienen las instituciones para ellos? ¡Sí!, para prestarles como atención ya en ese cambio que están haciendo (...), se sienten muy solos, ¿sí? de pronto a veces como que todas las instituciones, las administraciones se han como concentrado un poco en la primera infancia y ellos sienten que ya hay como un vacío, no sienten apoyo. Entonces tienen como muchas dudas frente a ¿qué sigue?, o ¿a qué puedo ir?, ¿qué puedo hacer si tengo equis situación? (5:17).

Se puede entonces sugerir que la falta de apoyo referido por los y las profesionales que trabajan con población adolescente, parece estar asociado no tanto con la inexistencia de programas que los cubran como población, como si a un desconocimiento de los mismos, lo que también estaría relacionado con la concepción que se tiene de la adolescencia como tránsito híbrido entre dos etapas mejor establecidas dentro de la política pública (infancia y juventud).

Es así, como se percibe una carencia de cuidado hacia la población adolescente desde los discursos de los adultos; sin embargo, los mismos adolescentes identifican dicha diferencia en los cuidados que se les brinda a los niños y niñas, pero que ya no los cubren a ellos, incluso en uno de los grupos focales, uno de los participantes dijo que:

Yo soy una persona que vivo muy lejos, en Bosa El Recuerdo, y tengo que llegar, uno acá faltando 5 para las 6 para que le den refrigerio, y a las seis 
uno llega y no hay. Digamos yo, ¿a qué horas pues ellos creen que yo voy a salir de mi casa para llegar acá?, y lo peor es que uno llega temprano y no, tiene que esperarse a que abran la puerta a las seis, seis y diez, uno hace la fila, no más dan como dos refrigerios y ya. Sale. Ósea, es como yo dije allá ese día, le dije chévere, o sea no es porque yo esté en contra de algo, pues a los niños les dan porque ya tienen que crecer y tienen que eso, pero es que ellos también tienen que darse cuenta que hay niños acá en bachillerato, que no tienen ni recursos para comprarse un desayuno, recursos para que le den plata a uno, o recursos para que tenga cójase eso para que compre algo, no. Pero ellos solo digamos, es como yo ese día dije, si hay para ellos, que también haya para digamos la mitad de nosotros, o la mayoría (7:14).

Este comentario representa el sentir de los adolescentes, frente a que ya no se consideran tan importantes para la sociedad, en la medida en que no reciben muchos de los beneficios que los niños y niñas reciben, como, por ejemplo, los refrigerios escolares.

Lo anterior implica dos cosas, por un lado, que, durante el momento vital, el tránsito de una etapa a otra, no ha logrado concebirse como un proceso desde la operativa de las acciones de política pública que se llevan a cabo para atender las necesidades de la población, reflejadas en un marco programático que se desprende de las políticas públicas. De aquí surgiría entonces la sensación de abandono que tanto adolescentes como adultos refieren respecto a las políticas públicas de adolescencia. Los adolescentes perciben, que comparativamente hablando, los niños y niñas reciben muchos beneficios que no los cubren a ellos por el hecho de ser adolescentes; incluso una de las participantes de los grupos focales hace la siguiente 
reflexión: "Porque como los niños tienen que crecer nosotros también tengamos debilidades, digamos él sufre de asma, qué tal que ese refrigerio también le pueda ayudar a él, o hay gente que se viene sin desayunar de la casa, no sé, algo, y aguanta hambre y no tiene digamos plata para comprarse algo, ver a esa persona comer, no sé cómo que dan ganas de comerse algo $(\ldots) "(7: 15)$.

De otro lado y como segunda consecuencia a considerar es el hecho de que se asocie un derecho con una acción tan puntual como lo es recibir alimentos, lo cual podría facilitar formas asistencialistas de acción en la medida en que se atienden necesidades inmediatas que dan cuenta de un sistema desigual e inequitativo, y que no necesariamente desarrollan las capacidades de empoderamiento y agencia de los jóvenes y sus familias que les permitan superar sus situaciones de vulnerabilidad.

- Transiciones de la vulnerabilidad infantil a la autonomía de la juventud: la transgresión de la adolescencia problemática

Siguiendo con la comprensión de la adolescencia como etapa de tránsito, la referencia a la adolescencia se hace como uno de esos "problemas complejos" (3:16), pues implica que el tránsito se vea como una atención a requerimientos actuales, seguramente conectados con la culminación de la infancia, pero sin desvincularse totalmente de sus ordenamientos y códigos. En ese orden de ideas, uno de los entrevistados propone que “(...) un perfil muy importante que digamos, por ejemplo, a la hora de concretar una política de adolescencia, pues es en algún sentido, la prolongación de la niñez, sí, poder seguir teniendo espacios de juego, de diversión (...)" (3:13). 
Al mismo tiempo, la perspectiva de adolescencia como tránsito implica una proyección a futuro de una idea de ciudadano que se construye en estas etapas. En uno de los grupos focales, los adolescentes definieron su etapa del ciclo vital de la siguiente manera: "Pues es como entrar a una etapa nueva de la vida. / Es como pensar diferente, uno pensaba antes como un niño y ahora piensa ya como más, como más (...) / Más responsablemente (...)” (8:19). La asociación de la noción de responsabilidad con la etapa de la adolescencia habla entonces de cómo este momento vital implica una expectativa social distinta.

Entonces, la adolescencia se asocia discursivamente con una noción de población problemática, con su “(...) fama de ser tan cansones (...)” (3:19), lo que refleja una cierta tendencia a estereotipar a los adolescentes, así como, a limitar sus comprensiones. También hay una referencia de la adolescencia como proceso de construcción sobre un lienzo en blanco, de un ciudadano esperado, autónomo y con capacidad de decisión. En una de las entrevistas se menciona que “(...) da la cuestión que el niño pasa, no sé, a primaria, y llega un punto neutro, no sé, vacío, en el que esté ahí mientras llega noveno, décimo y once y puede decidir algo (...)" (3:17). Ese tránsito, al parecer, demanda ser reflexivo para no quedarse simplemente en el cumplimiento de una implementación de política, sino en una transformación social.

Esa relación entre adolescentes y complejidad problemática es también sentida por los mismos adolescentes, quienes sin expresar la palabra "tránsito", definen este momento del curso vital al hacer una constante comparación: la adolescencia es ser "más grande, más maduro (...) más responsables (...)" (6:40) mientras los niños tienen "menos deberes" (6:41), 
lo que justamente permite intuir el tránsito. Ahora bien, la referencia a que los preadolescentes fueran "fenómenos" (6:42) habla de la sensación de alienación respecto a otros grupos etarios.

Es entonces donde los adolescentes reconocen en medio de risas que ellos tratan de aprovechar al máximo la ambigüedad de su etapa de ciclo vital tratando de maximizar los beneficios sin aumentar los “costos”. Un participante de los grupos focales menciona “(...) nosotros nos creemos (...), para algunas cosas nos creemos grandes y para otras ahí sí nos creemos chiquitos (...)" (6:43).

Por otro lado, la siguiente expresión evidencia como los adolescentes se reconocen como parte de una etapa de grandes cambios con una fuerte comparación con las etapas de ciclo previas y posteriores.

A uno lo mezclan, las responsabilidades de adulto y las (...), o sea como la forma de divertirse de niño. Porque uno de adolescente pues, o sea, uno puede hacer en algún sentido lo que quiera, y a la vez no, porque si yo llego tarde a la casa pues mi mamá me regaña (...) pero de niño no podía salir solo, entonces ahí va la diferencia (9:18).

Estas contradicciones referentes a poder hacer ciertas cosas que las personas adultas hacen, pero también hacer cosas propias de la niñez, se evidencian en lo cotidiano de las experiencias de vida de los adolescentes; a pesar que no parezca que el discurso de la protección social logre asir esta particularidad, sin embargo, hacen parte de cualquier proceso de aprendizaje. 
El tránsito en sí es una noción compleja de adecuar respecto a un abordaje específico para una población. De ahí que en una de las entrevistas se sostenga que “(...) creo que esa también es una dificultad digamos, como en ese paso, en que los niños están aprendiendo a ser autónomos y a tomar sus propias decisiones, digamos ya en un nivel ehh superior, y desde ahí creo que se presentan bastantes dificultades (...)" (2:4). El tránsito implica entonces ambigüedad respecto a las relaciones de poder, entre la autonomía juvenil y la dependencia infantil.

De allí, es necesario resaltar cómo desde algunos sectores se plantea que la adolescencia, cuya naturaleza radicaría en esa transitoriedad, es ignorada en términos sociales. Uno de los participantes plantea al respecto que “(...) tenemos el espacio de adolescentes como un tránsito no reconocido (...)" (1:1). De ahí, que ese espacio remoto quede, al menos en apariencia, por fuera de las categorías definidas desde la política pública. En este mismo sentido, uno de los entrevistados del sector público hace referencia a que “(...) lo de primera infancia está muy marcado, hay un estatuto de la juventud que está muy marcado, pero ellos quedaron ahí como en un limbo, como en la brecha entre ambos (...)”(4:13), justamente para referirse a cómo los adolescentes parecen pasar desapercibidos en el discurso de la protección social por no lograr ubicarse dentro de la niñez o dentro de la juventud.

Continuando con el tránsito entre momentos del ciclo, hay otra problemática que surge y es el hecho de que, al ser la adolescencia comprendida como una continuación de la niñez, se asume que dicha población aún no se encuentra en un estado del desarrollo que permita una agencia real a través de sus voces. Uno de los participantes en las entrevistas plantea en ese 
sentido que “(...) yo siento que pasa igual que como con los niños y las niñas, y es que hay algunas instituciones en donde no se les escucha por no ser mayores de edad, entonces, por ejemplo, si ellos tienen alguna denuncia, algún caso que vulnere algún derecho de ellos, tienen que ir representados por alguien. Y siento que es una falla grande (...)" (2:9). De esto surge entonces la pregunta sobre cómo se están atendiendo las necesidades de una población que no logra expresar sus expectativas en términos de incidencia política. En ese orden de ideas, un entrevistado dice que:

Tenemos una deuda muy grande con todo el país, con toda Latinoamérica, acerca de la formación afectiva sexual. Mucho de lo que le pasa a un niño o niña tiene incidencias en toda su vida, en todo su futuro. Pero el adolescente que en algún sentido hace un poco más de conciencia respecto de las relaciones con el mundo, con los demás, pues tiene muchísimos retos en cuanto al conocimiento de sí mismo, a la exploración de su propio cuerpo, al reconocimiento de, digamos de lo que es y de lo que significa el otro, entonces pienso yo que desde el punto de vista de la formación afectiva sexual, desde el punto de vista relacional, de crecimiento integral ósea hay muchos retos que, que vuelve y juega, se difuminan y votamos a ver qué le cae ahí, pero no tenemos, de pronto, aspectos de formación específica para ellos (...) (3:14).

Así, uno de los temas que surge de la exploración cualitativa es el que atañe a la forma en que se comprende a la población. Una de las personas entrevistadas habla de “(...) la necesidad de que nosotros empecemos a revisar no solamente la definición de la edad, sino ese tránsito qué implica desde lo emocional, cognitivo y actitudinal, para entender ¿quién es 
realmente el adolescente?” (1:19) haciendo un llamado a una comprensión más profunda de la adolescencia desde una perspectiva integral, en la que se deberían tener en cuenta no solamente el criterio edad, sino que también se deberían explorar cambios a nivel psicológico para poder comprender, y no únicamente definir a esta población.

Incluso, la alusión a la comprensión explicitada en el párrafo anterior implicaría un abordaje de la población desde un punto de vista humano y holístico, y no solamente operativo en términos de las edades límite que definirían a la población; sin embargo, esta delimitación de la edad a la que corresponde la adolescencia se menciona en una de las entrevistas como un parámetro necesario en la consideración de la política pública:

(...) Deberíamos mirar cómo nosotros la estamos implementando y qué acciones intersectoriales estamos articulando para que los adolescentes tengan una respuesta óptima y efectiva. Tal vez no otra política pública, pero si nos pusiéramos de acuerdo en ¿qué edades?, ¿qué criterios etarios hay para clasificar la adolescencia?, ahí habría un buen paso para articular acciones $(\ldots)(1: 33)$.

Es así como una participante de las entrevistas concluye “ (...) a veces pretendemos darles soluciones simples a problemas complejos, y el tema de adolescencia, el tema de aceptación de ese cambio de niño a adolescente, el tema de previsión acerca de lo que viene en la juventud (...)" (3:16). En el discurso se encuentran paradojas entorno a, por un lado, la necesidad de definir la adolescencia desde criterios estándar que garanticen la aplicabilidad de los programas, por otro lado, existe la urgencia de acercarse a la adolescencia como una 
etapa cuya particularidad radica en su naturaleza borrosa e híbrida, cuya comprensión se hace compleja.

\section{- El discurso de los derechos: contexto de las vulneraciones de derechos:}

La naturaleza de la adolescencia es comprendida desde una perspectiva dinámica en tanto se construye mediante sus interacciones con el contexto. De esa forma, las problemáticas que representen un riesgo para esta población y sus derechos van a estar ligadas a los contextos en los cuales los adolescentes viven y se desarrollan.

Consideremos en primer lugar el asunto de la localización, Bosa es la localidad limítrofe al sur occidente de Bogotá. En una de las entrevistas se menciona que los adolescentes son una “población desocupada (...) marcada por el mal uso del tiempo libre por temas que a veces vinculan el consumo de SPA y todo lo que ello deriva como tráfico de estupefacientes y vinculación con actores del conflicto armado" (5:1). Acerca de esto, se encontró lo siguiente:

(...) Diríamos que haría parte de esa exclusión social, al entender que no hay mucha presencia institucional en algunos lugares de la localidad, que fueron considerados desde el año 95 como lugares de expansión urbana y que aún no han terminado de urbanizarse, ehh la presencia institucional al no existir, ha dado pues que los jóvenes, frente a su tema de garantía y restitución de derechos, no encuentren digamos las respuestas más asertivas de parte del Estado (5:2). 
Esta asociación implica que la misma geografía de la localidad ubicada hacia los límites de la ciudad y la falta de presencia institucional de lugar a desigualdades y exclusión de su población. En ese orden de ideas, se hace difícil garantizar los derechos de los adolescentes como efectivamente lo argumenta otro entrevistado:

También en la localidad hay barreras geográficas, hay sectores que quedan muy distantes de donde se genera la oferta, ehh, donde las personas tienen que pagar no solamente un transporte, dos transportes, donde tienen que hacer recorridos largos si se desplazan a pie o si se desplazan en bicicleta o en algún tipo de, de patineta o algo, ehh geográficamente también hay barreras (4:6).

La distribución de la ciudad demarca límites aparentemente invisibles, pero que se materializan en la experiencia de vida de su gente. Esto representa una serie de barreras de acceso a servicios, pero también define dinámicas sociales y económicas específicas. En esto, la participación de los adultos en la vida de los adolescentes será determinada justamente por dicho contexto. Al respecto, Bosa presenta problemáticas de violencia y abandono que marcan la pauta en términos de interacción, como lo evidencia en el siguiente comentario:

Hay dos situaciones que son críticas para ellos, y uno es su situación familiar, entonces yo he evidenciado que hay ehhh bastantes casos de, no sé si todos son de maltrato ehhh infantil o de violencia intrafamiliar, pero sí hay muchos casos donde, por ejemplo, los padres se han separado, o son padres que tienen que trabajar todo el tiempo, entonces son niños que están mucho tiempo solos $(2: 1)$. 
En segundo lugar, y en una mirada desde los sectores de atención a la adolescencia, se detecta que los altos índices de violencia que experimentan los adolescentes, no solamente en forma de violencia intrafamiliar o maltrato físico, sino también en términos de abandono, representa vulneraciones a su derecho a una vida libre de violencia.

El papel de los adultos entonces resulta también parte de la problemática en el sentido de ser constituyente de una serie de dinámicas dadas en un contexto determinado. Los adultos pueden plantear a los adolescentes experiencias que afectan su desarrollo de manera positiva o negativa. En este orden de ideas, respecto al tema de sustancias psicoactivas, pues ya no es suficiente con prevenir, por ejemplo, el consumo de dichas sustancias, sino que se hace necesario que en paralelo se enfrente la problemática del tráfico a la cual están expuestos los adolescentes. En una entrevista se puede evidenciar lo anterior:

(...) Los problemas que presentan los adolescentes en Bosa son muy diversos en relación a que, uno, el tema de sustancias psicoactivas, ¿ya? Y no es efectivamente un problema de los jóvenes, sino que es un problema de los adultos que generan todo un mercado para que los jóvenes estén involucrados en eso, aprovechándose de sus situaciones de inestabilidad familiar, todo el proceso de crisis de su crecimiento (...) (4:16).

Hay que decir entonces que garantizar los derechos de los adolescentes es también una responsabilidad de los adultos, en la medida en que son los adultos quienes crean un contexto particular de desarrollo para la población, y al parecer en la localidad dicho contexto no está 
necesariamente acompañado, y esto impacta en la forma en que los adolescentes toman decisiones y ocupan su tiempo libre. Esto se puede inferir del siguiente comentario de un entrevistado: “(...) comienzan a no ocupar el tiempo libre en temas productivos, en temas adecuados, a estar en la calle, comienzan a armar parches, a consumir drogas, hay otro problema también, es el abandono familiar dentro del mismo hogar" (4:2). De esa manera, la vulneración de derechos relaciona diferentes riesgos del contexto que ponen en peligro a los adolescentes.

En tercer lugar, y en el marco del ámbito escolar, el contexto socioeconómico de los adolescentes y sus familias en la localidad de Bosa les implica riesgos, respecto a escoger entre estudiar, lo que desde un discurso del desarrollo pretende ser la clave para el progreso, o trabajar, debido a la inmediatez de las necesidades que la población enfrenta. En varias entrevistas se hace al menos una mención a la dimensión de la problemática del trabajo adolescente como "bastante crítico" (1:26). Efectivamente, en otra entrevista se argumenta:

(...) Estratos bajos, lo que suelen argumentar es que hay unas prioridades en la familia que son como económicas, y al no tener medios económicos para subsistir, para (...), digamos para solucionar temas tan específicos como la comida de cada día, deciden en conjunto con su familia o por presión de la misma salir a trabajar. Entonces hay personas que podemos asumir como desescolarizadas en ese momento, ehhh y pues digamos la barrera es eso, escoger entre una u otra opción (...) (3:11). 
Ahora bien, se puede decir que, para los adolescentes, los derechos se materializan en cuestiones pragmáticas como el acceso a la alimentación. Por ejemplo, al responder si algún derecho les está siendo vulnerado, uno de ellos contestó:

El derecho a la alimentación, a la buena alimentación (...) si nos van a dar algo, que nos lo den bueno, digamos, que si yo me como algo, no sea que me mande de una al baño, porque estaba dañado, sino que esté bien, o sea si me van a dar algo que me den algo que yo pueda comer bien y que me haga bien, no que me haga un mal" (7:19).

Asimismo, el comentario "estamos hablando de que 36000 personas en Bosa se acuestan sin comer" (1:30). Implica que en la seguridad alimentaria se evidencia cómo los derechos están atados a un contexto socioeconómico que permite, o no, que dichos derechos sean experimentados por los adolescentes.

De esta forma, los adolescentes hablan de un derecho como algo que "se les debe cumplir", lo cual habla de la responsabilidad estatal en garantizar los derechos de sus poblaciones. Sin embargo, hay una referencia a una experiencia en la que el Estado, en vez de garantizar un derecho, atenta contra él. Así no fuera directamente un derecho de los adolescentes, eso les genera una visión de irrespeto por parte del Estado, hacia los derechos que debería garantizar. Uno de los participantes de los grupos focales mantuvo que "(...) el derecho es algo que nos deben cumplir a nosotros, como, por ejemplo, el derecho a que un niño estudie, me parece algo muy importante, es algo importante que nos deben dar a nosotros, a la gente, como tal (...)” (7:2). De esa forma se reconoce uno de los límites más interesantes de la experiencia 
adolescente, y es el de empezar a reconocer sus derechos, sin poder realmente ser garantes de los mismos, ya que dependen todavía de sus contextos socioeconómicos y relacionales.

Paradójicamente a dicha dependencia, varios estudiantes mencionan el derecho a la libertad como uno de los más importantes: "Pues, que, desde hace mucho, nosotros no vivimos como esclavos y que somos libres para hacer nuestra voluntad" (8:4); "los derechos son estudiar, la libertad” (9:1); “(...) O sea sí he oído hablar, pero no, como que, como que no entiendo (...) Como que, uno tiene que ser libre, las personas no lo tienen que... qué forzar a uno a que haga otras cosas" (9:9). La garantía de la libertad como un derecho podría asociarse a la reivindicación del proceso de individuación por el que atraviesan los adolescentes, en el sentido en que, a medida, que van creciendo pueden tomar más decisiones de forma individual, sin el mismo apoyo adulto que necesitaría un niño.

Finalmente, cabe resaltar la mención al derecho a la vida como derecho fundamental: ¿Derechos a la vida? (...) Pues que todos tenemos derechos a vivir.” (6:3). Sin embargo, este derecho suscita debates en torno a donde empieza la vida, y en referencia específica al aborto, tal como menciona un estudiante: "Es como algo que nos obliga como personas, digamos el derecho a la vida, (...) a las personas, a las mujeres que abortan están haciendo digamos, o yo lo diría como un delito porque le están quitando la vida a alguien” (7:6).

- Los derechos para la protección y el bienestar: respuesta a necesidades de poblaciones "vulnerables". 
Los adolescentes mencionan que “(...) todos tenemos derecho a vivir (...) la vida es un derecho porque, digamos a ti te llega a pasar algo, el otro, el que te hizo el daño no tenía derecho a maltratarlo a uno (...)" (6:4). La expresión "tener, o no, derecho" amarra esta noción al sujeto. Hay una referencia al cuidado o a la protección al hablar de derecho.

Al considerar el ejemplo a la luz del derecho penal, su misión sería aquella de proteger los valores fundamentales y demás bienes jurídicos que el Estado considera que sus ciudadanos tienen. El carácter positivo del derecho es entonces aquel de proteger. Así mismo, se tiene referencia a un posible castigo asociado con la vulneración de aquello que se está protegiendo. De ahí que los adolescentes planteen que “(...) mi tía fue la que me dijo que, si uno tiene un animal amarrado, muriendo de hambre o herido, le tumban la puerta, se lo llevan para la cárcel y al perro se lo quitan (...)" (6:2). El anterior ejemplo da cuenta de que no solo la vulneración activa de un derecho es vulneración, ésta puede ser pasiva, o como se dice en derecho penal, hay también una conducta por omisión, dicha omisión estaría atentando en contra de los valores de cuidado en los cuales se fundamenta el ordenamiento social.

Al indagar en los adolescentes sobre sus derechos, se suscitó la siguiente conversación:

Al apellido (...)/Algo que a mí no me dieron (...)/ ¿Cómo así que no te dieron? / Mi papá (...) no me dio el apellido/ ¿No te dio el apellido? /Yo tengo los apellidos de mi abuelita y mi abuelito/De tu abuelita y tu abuelito. ¿Cómo te sientes con eso? /Mal. Yo por una parte estoy muy brava con él, aunque no lo conozco, porque listo, si no quería responder por mí, dé el apellido y ya. Listo, ya, váyase, ¿sí? Pero no me gustó eso de que fuera al 
hospital, le dijera a mi mamá que me iba a traer una paca de pañales y se desapareció (6:37).

Este ejemplo da cuenta del nivel de la subjetividad, incluso un tema de identidad se ve afectado en la vulneración de los derechos de los adolescentes, ya que el abandono impacta de una forma definitiva a la persona en términos emocionales en el proceso de desconocerla como sujeto de derechos. De ahí la relevancia de adoptar una visión de los derechos no solamente como algo que se tiene o no, sino como una serie de nociones que aportan a construir el cuidado de las poblaciones.

El cuidado, en tanto protección, puede hacerse desde un ámbito institucional. Hay espacios como el colegio, o ciertas instituciones como el ICBF, que son asociados con la protección de los adolescentes. Por ejemplo, en una de las entrevistas se expone que “(...) la permanencia en el colegio, ellos (los adolescentes) lo ven y lo sienten como un espacio seguro y protector, en donde pueden estar bien, en donde pueden aprender (...)" (2:5). Asimismo, una adolescente de uno de los grupos menciona que ha “(...) visto a jóvenes y a niños que están en la calle, así sucios, y como que los papás los dejaron por ahí tirados y la policía los recoge para que tengan una mejor vida, y los metan al Bienestar Familiar (...)" (9:23), lo que implica que en ocasiones las instituciones juegan un rol primordial en la protección de los niños.

A pesar de eso, pensar la protección social desde lo institucional se hace insuficiente, aunque la asociación más evidente sea esa, debido a las limitaciones logísticas de la institucionalidad. Uno de los expertos consultados alude a: 
Los vinculen a algún centro educativo que, que no en todos los casos puede personalizar la formación, es decir ehhh pues los cuidan, cuidan entre comillas, los, les promueven de pronto un sano crecimiento físico, pero hay muchos aspectos de su personalidad que se están viendo quizá frustrados, porque no, no cuentan con ese ser que, que esté continuamente al lado de ellos pedagógicamente hablando, ehh y que les pueda compartir su historia, lo que ha vivido, lo que son, lo que sueñan ser, bueno, etcétera, ehh, bueno en el peor de los casos pues que los cuiden en un, en un jardín, que alguien haga las veces de niñero o niñera pero pues normalmente son grupos muy grandes que no permiten de pronto un desarrollo digamos cualificado, $\mathrm{y}, \mathrm{y}$ bueno..." (3:2).

Se podría, entonces, pensar que la interacción uno a uno es necesaria, si se quiere impactar a un nivel lo suficientemente sostenible como para interiorizar y materializar los derechos. Dicha dinámica estaría, más bien, en el espacio doméstico, en donde la cotidianidad de un cuidado asumiría una dimensión íntima, capaz de movilizar la subjetividad.

Sin embargo, cabe destacar que desde el ámbito familiar las visiones que mantienen las personas entrevistadas no son muy alentadoras. En una de las entrevistas, el participante sostiene que los adolescentes "(...) comienzan a no ocupar el tiempo libre en temas productivos, en temas adecuados, a estar en la calle, comienzan a armar parches, a consumir drogas, hay otro problema también, es el abandono familiar dentro del mismo hogar (...)" $(4: 2)$. Se refiere entonces a un “(...) cambio de roles de los padres de familia, los abuelos son 
jóvenes y también trabajan, y no tienen un acompañamiento familiar en el día (...)” (4:3). El abandono se entiende como una forma de violencia, que vulnera los derechos de los adolescentes, y que representa un riesgo, al no protegerlos de conductas nocivas como el posible consumo de SPA.

Anteriormente, se había propuesto esta relación entre distintos factores de riesgo que conllevaban a una vulneración de derechos de los adolescentes. Sin embargo, hay que también explorar que este tipo de interpretaciones permiten concebir otras formas de acercarse al tema de los derechos de los adolescentes, desde la búsqueda del bienestar y la protección y, por lo tanto, no es únicamente algo que les compete a los mismos adolescentes, sino que se trata de un esfuerzo a ser realizado de parte de todos los actores sociales, pero especialmente de aquellas personas que hacen parte de su cotidianidad. Tal vez es por eso que uno de los entrevistados plantea la importancia de "una movilización social que (...) tenga la capacidad de ser agente generador de propuestas de cambio. Entendiendo que el desarrollo no se reduce solo a crecimiento económico sino a transformación de calidad de vida de las personas (...)" (5:7).

- Del discurso a la materialización de las interacciones sociales: derechos como paradojas.

En una de las entrevistas, la servidora pública plantea que la adolescencia queda:

(...) Como en un limbo, que muchas veces, si nosotros lo miramos intersectorialmente, para algunas instituciones la adolescencia empieza 
desde los 12, para otros desde los 14, para otros incluso desde los 17. Eso afecta las acciones interinstitucionales, y a la hora de hacer acciones coordinadas de todas las instituciones con asiento en lo local, eso frente a la adolescencia particularmente, me parece que es un impedimento clave a la hora de implementar las políticas públicas (...) (1:4).

Hay una cierta contradicción en el hecho de que la estandarización de edades sea necesaria para el reconocimiento de los derechos, el acceso a los servicios y, por tanto, la eficacia de la política pública. Se podría hablar de una noción de paradoja, en la que dichas categorizaciones estandarizadas (en este caso, por edades) no dan cuenta de la naturaleza transitiva de la etapa o del desarrollo humano en general, pero son necesarias para garantizar los derechos de las poblaciones. En este sentido, una de las entrevistas ilustra este punto:

(...) Deberíamos mirar cómo nosotros la estamos implementando y qué acciones intersectoriales estamos articulando para que los adolescentes tengan una respuesta óptima y efectiva. Tal vez, no otra política pública, pero si nos pusiéramos de acuerdo en qué edades, qué criterios etarios hay para clasificar la adolescencia, ahí habría un buen paso para articular acciones $(\ldots)(1: 33)$.

Por otra parte, uno de los estudiantes menciona que define un derecho como "Algo que se puede hacer..." (8:2). En ese sentido, el derecho, en la expresión "tener derecho", no necesariamente se refiere a los derechos como el reconocimiento de libertades inherentes a una población específica, sino que esconde también una noción de poder, en el sentido de 
tener poder para hacer algo y de la ética implícita en dichas acciones. Así, un participante de grupo focal mantiene que "Los hombres no tienen derecho a pegarles a las mujeres porque sí. /Pero, ¿y a veces lo hacen? /Sí profe, eso amerita demanda (...)” (6:14). Este tipo de reflexiones dan cuenta de un cierto carácter moral asociado al tema de los derechos, que debería delimitar el camino a seguir de las interacciones sociales, y que, sin embargo, no se evidencia en lo cotidiano de la vida de los adolescentes. Otro de los participantes de los grupos focales dice al respecto:

(...) Yo pienso también que por qué existen los derechos sí, mucha gente no los va a cumplir. Por ejemplo, digamos los niños, por qué los tienen que maltratar, por ejemplo, digamos por lo que no hacen algo o por lo que no cumplieron algo, o sea no, no los cumplen, y mucha gente por ejemplo digamos a mucha gente le pegan simplemente por no hacer algo o no cumplir algo. O sea ¿para qué existen si no los van a cumplir? Mucha gente no los va a cumplir (...) (7:45).

Así, al evidenciar los adolescentes la contradicción entre el discurso de los derechos y su efectivo ejercicio, nace una paradoja en torno a la razón de ser de los derechos, su utilidad real y los modos en que son vistos.

- La educación: construcción de significados.

Teniendo en cuenta que el ámbito escolar juega un papel fundamental en el cuidado de los 
adolescentes, el sentido construido sobre la experiencia de la escolaridad está basado en si ésta, es o no útil para la consecución de trabajo, recursos y mejor calidad de vida o como experiencia de interacción social, empero, parece carecer de sentido respecto a la utilidad del conocimiento recibido. De estas particularidades, en el sentido del estudio para los adolescentes de Bosa, se desprenden desigualdades a futuro, es decir, si el colegio solo es pertinente en la medida en que facilita la consecución de un trabajo a posteriori, hay que pensar qué tipos de trabajos hay disponibles para la preparación de los bachilleres.

Los adolescentes reconocen el derecho a la educación en varias oportunidades: "los derechos son estudiar (...)" (9:1); "la educación hoy es obligatoria para el gobierno, se supone..." (9:2); "Derecho al estudio" (6:33). Sin embargo, pertenecer a un contexto socioeconómico vulnerable implica que la educación no sea necesariamente una prioridad en tanto derecho a garantizar para los adolescentes. A la pregunta “¿Y los niños trabajan?” (6:21), algunos estudiantes respondieron "No. / No. / ¿Y por qué? / Porque es ilegal. / Porque ¿eso es negar el estudio o algo así? / Eso es... ¿cómo así negar el estudio? / ¿Maltrato infantil? / ¿No tener el derecho al estudio?” (6:21). La protección de los niños y adolescentes encomendada a la escuela para garantizar el derecho a la educación, entra en tensión con las condiciones de vulnerabilidad.

Uno de los estudiantes menciona los cambios históricos en términos de privilegiar la educación por encima de otros espacios como el laboral: "mi mamá podía trabajar de niña y como ahora quitaron la ley, entonces pueden digamos, yo quiero trabajar en una tienda y entonces al señor le pueden sellar la tienda, y él me puede demandar digamos a mí, porque 
yo no tenía derecho a ir a trabajar en la tienda" (6:22). Al respecto, una estudiante también menciona que "a mí me gustaría tener un trabajo, ganarme mi propia plata (...)" (7:33). La idea de tener dinero propio se evidencia también en el siguiente comentario de un estudiante: ¿A ti te gustaría qué? / Pues trabajar, para tener uno, pues sí, tener plata, tener ropa, tener o sea más ropa que la que uno tiene, ¿sí? De la que a uno le da la mamá y el papá” (8:13).

Los trabajos disponibles son diferentes (en tareas y salarios) a los ofrecidos en los escenarios técnico, tecnológico y profesional. Así, en una de las entrevistas se menciona que “(...) desde el punto de vista educativo lo que la gente busca es un título para poder obtener un trabajo, pero no porque le interese tener eso, no porque le interese ir allá al colegio (...)” (3:12).

Ahora bien, en otra entrevista, se menciona que la educación superior no parece estar contemplada como posibilidad para los adolescentes: “(...) el acceder a la educación superior, para los chicos que ya están terminando bachillerato, me parece que es casi imposible, casi que las únicas alternativas que se les brindan son las que brinda el Sena, que es una formación técnica, pero como que no existe una consciencia de que debe ser una educación superior, una educación superior, entonces muchos de los chicos nuestros no ingresan a la universidad (...)" (1:41).

La toma de decisiones de los adolescentes al respecto de la educación está relacionada con las condiciones en las éstos viven, y con las necesidades sentidas que experimentan. Un participante de grupo focal menciona al respecto: 
La verdad yo tuve un, digamos, una amistad que estuvo 10 años en el Bronx. (...) Pero entonces yo le dije que, pues por qué no aprovecha, tiene 14 años, y yo dije por qué no aprovecha y estudia para no volverse como digamos, terminar digamos en un bicitaxi o algo así, por decir. Y entonces él dijo "no, pues no, pues ¿para qué yo estudiar si puedo trabajar y ayudar a mi mamá?" y yo dije no, pues yo no tengo esa mente para hacer eso $(7: 39)$.

Las barreras que impone el contexto socioeconómico de los adolescentes sobre su construcción de proyecto de vida implican desigualdad en términos de sus derechos, en la medida en que sus posibilidades de acceder a una educación superior de calidad, y por ende, tener más oportunidades para ascender socialmente (así como también su participación en el sistema laboral) se ven truncadas. 


\title{
6. RECOMENDACIONES DE POLÍTICA PÚBLICA
}

\author{
"Todo lo que hemos ganado en este continente durante tantos años en prevenir \\ las muertes de niños cuando son pequeños por cuestiones de salud como diarrea, \\ desnutrición, lo estamos perdiendo cuando llegan a la adolescencia”
}

José Bergua, asesor regional de protección de Unicef.

Como lo mostró la evaluación del diseño de políticas públicas y como varios de los funcionarios entrevistados mencionaron, la política actual de Infancia y Adolescencia parece ser bastante completa en el papel, no obstante, hay una sensación común respecto al esfuerzo que se está haciendo, relacionado con su focalización en la primera infancia. Efectivamente, los indicadores muestran un impacto positivo en esta etapa, como, por ejemplo, un descenso en la mortalidad en recién nacidos, son evidencia de cómo las políticas públicas tratan de garantizar un buen inicio del desarrollo del individuo. En esta medida, resulta entonces interesante que se le invierta a la infancia, tratando justamente de apostarle a un bienestar en términos de proceso, desde la idea que, si logramos impactar el inicio o el fundamento del proceso del curso vital, estaremos justamente impactando el desarrollo mismo.

Sin embargo, las acciones se quedan cortas respecto a esa expectativa de impacto, porque no se logran traducir este tipo de protecciones a conceptualizaciones culturales o de construcción de sociedad. Entonces, Los adolescentes conocen sus derechos de manera general, no obstante, hay múltiples alusiones a que en realidad se sienten vulnerados. Al final, la adolescencia representa una vulnerabilidad, en tanto desprotección hacia esta población, lo 
cual está justamente ligado al hecho de que los jóvenes reconozcan una serie de derechos, cuyo ejercicio real depende de una serie de circunstancias socioeconómicas y culturales que, en el caso de la localidad de Bosa, son desfavorables para la población. Por ejemplo, en el abordaje del tema de la seguridad alimentaria se evidencia cómo los derechos están atados a un contexto socioeconómico que permite o no, que dichos derechos sean experimentados por los adolescentes.

La desigualdad se lee en clave de pobreza cuando los adolescentes reconocen que no todo el mundo tiene los mismos derechos, y que muchas veces el factor económico define quienes son importantes y quienes no lo son para el Estado. Las barreras que impone el contexto socioeconómico de los adolescentes sobre su construcción de proyecto de vida implican desigualdad en términos de sus derechos, por ejemplo, en la medida en que se ven truncadas sus posibilidades de acceder a una educación superior de calidad y, por ende, tener más oportunidades para ascender socialmente. Lo que afecta a los adolescentes es su paso a la juventud, en tanto exposición a la sociedad desde entornos de riesgo en lo social, político y económico, y de carácter crítico en lo ambiental.

Uno de los riesgos planteados es que los adolescentes estén bombardeados mediáticamente por la lógica crematística. De hecho, el sistema neoliberal promueve la sociedad de consumo como pilar del crecimiento económico. Sin embargo, para los adolescentes de Bosa, quienes, en primer lugar, aún no tendrían fuentes de ingresos y cuyos padres, generalmente, son socioeconómicamente vulnerables; la noción de consumo va en contravía de sus posibilidades de adquisición, limitando desde el inicio sus proyecciones en términos de capacidades reales, al menos en el presente. 
Esta deficiencia en el poder adquisitivo de las familias obliga a los padres a presionar a sus hijos desde temprana edad a incursionar en el sector productivo, muchas veces desde la informalidad, generando trabajo infantil en sus peores formas. Los adolescentes marcados por el flagelo del trabajo infantil asumen el cambio en sus proyectos de vida, muchas veces fuera del sistema educativo, ocasionando una replicación de la pobreza por destinarse a oficios de mano de obra barata que generan bajos ingresos.

En los grupos focales, ha quedado evidenciada la existencia de una paradoja en torno a la relación entre los derechos y deberes en el momento de la adolescencia como tránsito de la infancia a la juventud. Por un lado, los derechos se revelan como las garantías que la familia y las instituciones ofrecen a ellos para su bienestar y lo que implica una vida buena. Pero de otro lado, los adolescentes no parecen ser consecuentes con la responsabilidad que ello implica en términos de realización de unos deberes para con la sociedad. Asumiendo solo el ámbito de los derechos para su beneficio propio, pero obviando los deberes como la corresponsabilidad que se asume desde la ciudadanía.

Resulta entonces fundamental pensar, desde la política pública, cómo se podría acompañar a la población durante la experiencia de dicha paradoja, garantizando sus derechos desde la infancia, pero también mostrándoles cómo esos derechos existen gracias a la responsabilidad conexa que permite un estado de protección. De esa manera, la construcción de subjetividades políticas se podría dar de manera consecuente con la complejidad de dicho momento del ciclo vital. 
La ciudad se convierte entonces en una oportunidad para institucionalizar el proceso de desarrollo humano desde la protección social y el paradigma de los derechos para construir la ciudadanía frente al bienestar. Pero en la adolescencia, dicho paradigma debe llevarse a la complejidad del contexto y debe poder experimentarse desde ámbitos cotidianos, de forma tal que los derechos no constituyan una larga lista de "lo que podemos y lo que no debemos hacer", sino, que su experimentación permita construir reflexivamente una visión de sociedad posible. Esa sería entonces la transformación cultural que posibilitaría niveles de agencia y empoderamiento más altos, así como un sentido de responsabilidad, construido desde lo colectivo hasta lo individual, en pro de un bienestar común.

Justamente, esa traducción se puede hacer si logramos conjugar lo que se ha tratado de hacer con los programas específicos de las instituciones en términos de una serie de reivindicaciones que vayan un poco más allá de la actividad en sí misma con los chicos, sino que les generen a ellos la consciencia de ser ese capital social para así ganar en agenciamiento y comprender, por ejemplo, que la nutrición no es solamente el refrigerio en sí, sino que en el momento en que pueden consumir los alimentos, reivindican un derecho a la protección y al cuidado. Al mismo tiempo, los programas y las políticas deben tratar de generar los contextos para que los niños y adolescentes se desenvuelvan en otras condiciones, ojalá unas más favorables a su desarrollo físico, cognitivo, social y cultural.

Lo anterior, implica acciones desde la política pública que reivindique procesos más que actividades sueltas, como bien lo dijeron algunos funcionarios en las entrevistas. La idea del proceso se convierte entonces en una oportunidad, no únicamente de sostenibilidad en el tiempo, sino que dicha sostenibilidad potencia cognitivamente aprendizajes de los 
adolescentes sobre los derechos, el individuo y su relación con la sociedad y el mundo. El aprendizaje de los derechos entonces, incluye la posibilidad de abrir debates como los que se suscitaban en los grupos focales por iniciativa de los adolescentes, en torno a temas de interés público como el aborto o la salud, o cuál es la relación entre derecho y responsabilidad.

Asimismo, si la política pública no logra impactar en la calidad de vida de la población adolescente, entonces el Estado no podrá exigir a la sociedad una teleología del desarrollo humano con enfoque en derechos para construir equidad social. La política pública debe funcionar como herramienta para generar una adaptación de la población al contexto donde se desenvuelven como ciudadanos y como sujetos de derechos.

Hay que tener en cuenta que desde esta perspectiva, no cambiaría solamente la forma de realizar acciones desde la política pública, ni su temporalidad, sino que incluiría la transformación del paradigma de las acciones, en el sentido de comprender que el bienestar que puede generarse desde dichas instancias, pasa también por una reconfiguración del proceso en tanto acción dialéctica. Así, la política pública funciona como lineamiento y como marco para abordar una problemática social compleja.

Una política pública de adolescencia debe, entonces, basarse en una visión ontológica de la adolescencia, en el sentido de conceptualizar la misma como etapa transitoria y así diversificar sus acciones para atender dicha transitoriedad. Sin embargo, orientar una política pública hacia las necesidades de la adolescencia debe entender este momento del curso vital desde sus contradicciones y diferentes maneras de expresarse. Esto puede relacionarse con la determinación social. La construcción de sujetos de derechos no se hace pintando sobre 
lienzos en blanco, porque los adolescentes llegan a esta etapa ya con representaciones e imaginarios que definen como comprenden e interactúan con el mundo y, en ese sentido, tienen que ser partícipes de dicha construcción. Así, la política pública debe justamente construirse desde esa perspectiva participativa y dialéctica para responder a las heterogeneidades de la población adolescente.

La importancia de los escenarios educativos con esta población no se limita a espacios de educación formal, sino que como reclaman los participantes de los grupos focales, el derecho a la cultura se hace relevante en la medida en que abarca concebir la educación en un sentido amplio y concreto. La educación no es exclusivamente tener un espacio físico como el de las instituciones, sino contar con espacios de pensamiento en la diversidad y el diálogo, espacios de reconocimiento de sí mismo y de los demás en tanto actores capaces de generar transformaciones internas (psicológicas) y externas (contextuales). La educación propuesta debe tender entonces a una apuesta crítica, en donde los adolescentes sean considerados partícipes activos del conocimiento que se imparte, de forma tal que se generen reflexiones más allá del afán de mantenimiento de un determinado status quo, ya que este, está de por sí cargado de inequidades, exclusiones y violencias.

Los escenarios educativos deben estar acompañados por el sector salud constantemente. La clave de apuntar al desarrollo a lo largo de las distintas etapas vitales, radica entonces en la articulación de los programas de diferentes sectores, pasando así de ser meras actividades puntuales a oportunidades de encuentro para que los jóvenes construyan, entre ellos y con otros grupos etarios, nociones que reivindiquen sus derechos. El tema de la salud se convierte entonces en una oportunidad para vivenciar de primera mano la protección que el Estado le 
debe a su población, y esto implica una perspectiva ética que pone en duda las lógicas actuales neoliberales desde las que se prioriza la eficiencia económica más que el impacto social.

El Estado debe garantizar a los adolescentes un fortalecimiento de sus capacidades frente al autocuidado para que sean considerados como capital social. Bajo la premisa que estas capacidades desarrolladas por los adolescentes, aunado a las oportunidades que le ofrece la sociedad se verán traducidas en mejores condiciones para el desarrollo, calidad de vida y salud, lo cual inmediatamente se traduce en un aumento del capital social producto de las políticas de protección social.

Pero, una perspectiva en cuyas intenciones está implícita la potencia de toda una generación futura marca el camino hacia la institucionalización o medicalización de la vida humana. El camino que va de la enfermedad al modo sobre cómo prevenirla, constituye el itinerario de los hábitos de vida de las personas. En una escena como la de la ciudad, cobra un valor indispensable el aporte que cada uno debe dar al estar bien.

Ahora bien, en este momento del desarrollo humano resulta clave abordar el inicio de la sexualidad como dimensión, ya no solamente individual, sino social. Lo anterior, considerando que se trata de la experiencia del individuo frente a la exploración de su sexualidad, pues ha dejado de ser un asunto privado y se ha convertido en uno relevante, tanto para la salud pública, como para la lectura de una dimensión personal desde lo político, lo cual en la actualidad representa uno de los debates más convulsos sobre las libertades y los derechos individuales, en contraposición al control social de los cuerpos y la diversidad 
de lo humano. De esta manera, el tránsito implica una ambigüedad respecto a las relaciones de poder, entre la autonomía juvenil y la dependencia infantil, que definen cómo se constituye una subjetividad política.

Por otra parte, en países de la Región de Latinoamérica y el Caribe, la violencia se ha incrustado en los contextos sociales definiendo el futuro inmediato de generaciones que han crecido en estas condiciones, las cuales vuelven a replicarse cada vez más pronto en el desarrollo humano, marcando desde una temprana edad el futuro de sociedades enteras. La violencia es el parámetro y la tendencia de destino de las formas de relacionarse de los adolescentes. Si la política pública apuntara no únicamente a acciones específicas, sino a la comprensión-reconstrucción de parámetros de interacción pacíficos, sería una herramienta poderosa, al permitirles a los adolescentes experimentar dimensiones sociales que probablemente ellos han relacionado por experiencia con la violencia.

Como determinantes estructurales de alta incidencia en esta población se encuentran también las políticas de educación y trabajo. Estas pretenden impactar sobre los determinantes particulares y singulares, pero como pronunciamientos globales se traducen para los sujetos como discursos gastados que no se adaptan a las expectativas de sus beneficiarios. Así, los adolescentes de contextos como la localidad de Bosa se mueven entre esperanzas acerca de un futuro mejor, y una cierta consciencia de que sus diminutas posibilidades de acceder a niveles educativos de calidad y posteriormente a trabajos calificados y en teoría mejor pagos.

Tal vez, entonces, la política pública pueda pensar en crear espacios alternativos acordes con actividades de interés para los adolescentes, para así potencializar en mayor medida 
capacidades y habilidades que les facilitan cumplir sus sueños. Sin embargo, también se reconoce que la institucionalidad puede asociarse con la reivindicación de derechos, así como mecanismos de defensa, tales como la tutela o las demandas judiciales.

La política como decisión gubernamental establece una lógica vertical que va de su legislación hasta su implementación, a través de lineamientos de gobierno, que, como directrices, producen una objetivación de la población. Por lo tanto, reducir la política pública a solo una voz institucional, no está tomando en serio la complejidad de las situaciones en las que se desarrollan los sujetos de derecho. Entonces, la participación debe darse con los diferentes actores alrededor de la población caracterizada. La comprensión de la adolescencia como una población con potencialidades en términos de habilidades, capacidades y desarrollo; automáticamente interviene el riesgo psicosocial que la población puede enfrentar, dinamizando las posibles acciones a ser llevadas a cabo para acompañar a esta población. 


\section{CONCLUSIONES}

Hasta este momento se ha realizado un recorrido que buscó poner en discusión la implementación de políticas públicas focalizadas para una población tan particular y especial como la adolescencia, a la luz de la situación caracterizada en la localidad séptima de Bosa, donde a diario se pone a prueba la efectividad de la intervención del Estado y cuyos impactos positivos pueden llegar a ser contundentes en la definición de proyectos de vida, que logren superar las condiciones de vulnerabilidad en las que conviven los adolescentes.

Se abordaron las políticas vigentes, tanto para el territorio nacional como para el distrital, con el ánimo de comprender desde su diseño ¿Cómo se piensa la protección social para la adolescencia desde el escenario planteado por un Estado Social de Derecho? A lo largo de la investigación se trató de poner a prueba los postulados de una política pública, respecto a la respuesta que ofrece a las dinámicas de riesgo en las cuales están inmersos los adolescentes, permitiendo una distribución social más equitativa desde su contribución a la promoción de los DESC.

En apariencia, la evaluación y análisis de las políticas públicas para la adolescencia revelan un bajo impacto entre su promulgación como leyes, hasta lograr responder a los hechos que hicieron necesaria su formulación. Esto se debe, en parte, a su formulación como política gubernamental que obedece a los planes de gobierno de turno, más que una verdadera interlocución con los actores sociales. Debido a esto, fue necesario profundizar en el análisis de los determinantes sociales de la adolescencia que habita la localidad de Bosa. 
Planteado desde el enfoque de los determinantes sociales, en el orden distal o estructural se vislumbran las políticas públicas instauradas por los gobiernos nacional y distrital, en los cuales la adolescencia, aun cuando el discurso se reconstruya desde los sujetos de derechos, la implementación queda relegada a una subpriorización, al incorporarse en otros grupos poblacionales como la primera infancia y la infancia, lo cual deriva en el ocultamiento de acciones específicas para el grupo sujeto de esta investigación.

En los determinantes intermedios o particulares se encuentra el hecho de ser adolescente en una localidad como Bosa, territorio marcado por una complejidad socioeconómica y ambiental de amplias magnitudes, donde confluyen dos cuencas hídricas con una fuerte contaminación, empero, el uso del suelo en la expansión urbana ha permitido un aumento de la densidad demográfica que sobrepasa las proyecciones poblacionales censales, sin la previsión de equipamientos e infraestructura necesaria para soportarla. A su vez, por ser territorio ancestral del cabildo Muisca, condiciona a la población al enfrentamiento de sus costumbres y cosmogonía frente a temáticas como legalidad de los predios y la medicina occidental. Estos flagelos se amplifican por el hecho de ser receptora de población desplazada víctima del conflicto armado, lo cual enfrenta a los adolescentes a situaciones de desarraigo por la ruralidad y los incrusta en una realidad urbana que suele ser avasalladora en cuanto al consumo de SPA y la exposición a diferentes experiencias de la sexualidad, para lo cual se debe indagar en ¿Cómo se está respondiendo a la situación de violencia y abuso sexual en la adolescencia, siendo la población con mayor vulnerabilidad en estos casos?

Ya en el orden proximal o singular se encuentran los individuos, en este caso el adolescente que finaliza su niñez, condicionado por este contexto particular y estructural antes descrito. 
Ahí radica la potencialidad que podría generar la política pública al abordar las problemáticas y necesidades de los adolescentes.

De esta manera, las políticas públicas representan a modo de determinantes estructurales que en teoría beneficiarían a la población adolescente, sin embargo, hay una ruptura entre las desagregaciones de los determinantes, en tanto las mismas no logran incidir como se espera sobre las situaciones particulares o las conductas individuales (12). Esto, probablemente, porque las políticas se construyen justamente desde las preconcepciones o los prejuicios de los contextos determinados o de ¿cuáles son las problemáticas? (13), en donde valdría la pena preguntarse sobre ¿Cómo las políticas públicas para la adolescencia han planteado la promoción de transformaciones de tipo social y cultural para la construcción de sujetos de derechos?

Ahora bien, estas conclusiones planteadas en términos de un análisis de los determinantes sociales de la población adolescente habitante de la localidad de Bosa sigue siendo exploratoria y limitada en cuanto a los objetivos propios de esta investigación, la cual tuvo que enfrentar dificultades respecto a cómo los determinantes proximales o individuales conllevan a que los adolescentes acudan a acciones delictivas. Lo cual amerita una discusión sobre cómo los determinantes sociales se relacionan entre sí en contra o a favor del desarrollo social y humano de los adolescentes.

Uno de las principales conclusiones de la investigación responde al problema del foco gubernamental sobre la etapa vital de primera infancia, que tiene que ver con una socialización y modelamiento de comportamientos y construcción de subjetividades que 
suceden en paralelo a la adolescencia. Esto quiere decir que, aunque el gobierno implemente acciones centradas particularmente en la primera infancia, la población de dicha etapa estará influenciada directamente (por socialización y modelamiento) por una adolescencia ya problemática y marginalizada, lo que pone en riesgo la inversión social realizada desde la perspectiva actual. Los actores de política pública deben entender que toda la inversión que se realiza en la primera infancia puede llegar a fracasar si no tiene resonancia en las etapas posteriores, tanto adolescencia, como juventud y adultez. Es entonces cuando la inversión social no redunda en capital humano.

Pensar la protección social desde un modelo económico como el neoliberal, el cual funciona como marco de las políticas públicas actuales, termina auto justificándose dentro de sistemas asistencialistas que van en contravía de acciones reales de empoderamiento de los sujetos, o incluso se podría hablar de una construcción de subjetividades políticas que se mueven en la paradoja de libertades individuales frente a construcciones contextuales del sistema económico, social y cultural. En ejemplos sobre ¿Cómo el sistema neoliberal autojustifica sus falencias, adjudicándole a las familias la facultad para infundir en los adolescentes la posibilidad de generar las transformaciones necesarias para su desarrollo social y humano, cuando debería ser una responsabilidad compartida, con líneas de política coherentes en este sentido?

La adolescencia como punto de quiebre respecto a la experiencia de la sexualidad, que implica unas conceptualizaciones a nivel abstracto sobre lo privado y lo público. Estas tensiones podrían relacionarse de manera cautelosa con la vulnerabilidad presente en esta población en torno a la violencia y abuso sexual. Cómo a partir de la adolescencia estas 
personas que se están constituyendo como sujetos de derechos se ven marcadas por una "sexualización” de la vida. Lo cual debe dar luces a las políticas públicas sobre cómo interactuar en temas como la sexualidad. La promoción de hábitos de vida saludables ya no debe ser bajo un discurso metafórico de las relaciones humanas, sino sobre un escenario real donde acontece la sexualidad.

Se podría abrir entonces la reflexión hacia el paralelo entre la construcción de subjetividades desde una perspectiva de derechos y las dimensiones de transformación afectiva y sexual que suceden durante la adolescencia. En este sentido, si las políticas públicas aún mantienen formas de interacción altamente verticales, la desconexión entre las políticas públicas y los sujetos a quienes están dirigidas es mayor.

Si se mantiene a los niños, niñas y adolescentes desde una perspectiva de inocencia como lo mencionaba Cajiao y otros (24), bajo la premisa que dicha inocencia fundamente la posterior conciencia moral que determine sus comportamientos en etapas de juventud y adultez, será paradójico querer formar sujetos de derechos, que a pesar de las influencias directas del contexto, sean capaces de auto determinarse, lo que implicaría no solamente una capacidad de auto designación, sino de transformación y control de su propio presente y futuro. Ese es el aspecto dialéctico de la construcción de subjetividades políticas.

Siguiendo a Sottoli (34), las políticas sociales son estrategias de desarrollo que terminan siendo más de orden económico que social, pues buscan ser eficientes, pero con bajo impacto en las desigualdades. Shore (37) muestra, además, cómo el modelo neoliberal ha incrustado en la cultura latinoamericana una relación unilateral entre la política pública y los sujetos de 
la misma. Cada vez el Estado llega a prescindir más de los actores beneficiarios o víctimas, que termina por desconocer que el modelo de sociedad se construye desde el individuo.

El análisis del marco normativo vigente se realizó mediante la deconstrucción discursiva de la política pública colombiana para la protección social de la adolescencia, a través de sus enunciados como apuestas para la garantía de derechos a partir del año 2000 y según lo proyectado para el año 2021. Como momento histórico para la evaluación discursiva propuesta, aun cuando las fuentes sean cortas, dada la baja reglamentación existente que cumpliera con el requisito de cubrir a la población adolescente como sujeto de las políticas públicas.

Se encontró en la adolescencia de Bosa, cómo bajo la vulnerabilidad persisten potencialidades enormes en sus adolescentes. Capacidades diversas y diferenciadas para transformar el contexto complejo sobre el cual se desenvuelven. Sin embargo, se deben fortalecer políticas encaminadas a la erradicación del trabajo infantil, mostrando como estrategias desde la salud pública pueden ser eficientes contando con la disposición de organismos y flujo entre sectores.

Según Risueño y Motta (45) la adolescencia por esencia es heterogeneidad, lo cual se demostró por medio del marco situacional de la localidad séptima de Bosa, abordando la complejidad desde un amplio margen de derechos, yendo a lo más básico de la formulación de las políticas públicas para encontrar que simplemente la respuesta del Estado como ente garante de los derechos se agota en la primera infancia. En el marco de las políticas públicas, efectos como los de Bosa, hacen pensar en la urgente necesidad de replantear su diseño desde 
el sentir de los adolescentes, disponiendo estrategias desde la construcción de ciudadanía, considerándolos no un actor secundario, sino sujetos de derechos, con todas las capacidades para generar impactos sostenibles e incremento del capital social. La protección social para esta población debería cumplir con un amplio margen de acción que responda a la complejidad de su situación. 


\section{AGRADECIMIENTOS}

Agradecemos a todas las personas que hicieron parte de la realización de esta meta, a la Universidad Santo Tomás por todo su apoyo, al Hospital Pablo VI Bosa E.S.E. I Nivel y a la comunidad de la localidad de Bosa. 


\section{REFERENCIAS}

1. Cecchini S, Martínez R. Protección social inclusiva en América Latina: una mirada integral, un enfoque de derechos. CEPAL. Santiago de Chile; 2011.

2. Organización Mundial de la Salud. Desarrollo en la adolescencia [Internet]. WHO. World Health Organization; 2015 [cited 2017 Apr 6]. Available from: http://www.who.int/maternal_child_adolescent/topics/adolescence/dev/es/

3. Craig, Grace J. Baucum D. Desarrollo Psicológico [Internet]. Novena. Pearson Educación, editor. México; 2009 [cited 2017 Apr 6]. Available from: https://psiqueunah.files.wordpress.com/2014/09/desarrollo-psicologico-9-ed-craigbaucum.pdf

4. Blos P. La transición de la adolescencia. Buenos Aires; 1981.

5. Planeación SD de. Monografias: Localidad Séptima de Bosa. Bogotá; 2012.

6. Secretaria Distrital de Salud. Diagnóstico Local en Salud 2010 - 2011. Bogotá; 2011.

7. Departamento Administrativo Nacional de Estadística. Proyecciones de población [Internet]. 2017 [cited 2017 Apr 6]. Available from: https://www.dane.gov.co/index.php/estadisticas-por-tema/demografia-ypoblacion/proyecciones-de-poblacion

8. Hospital Pablo VI Bosa 1 Nivel E. Indicadores Trazadores de la Salud Pública. Bogotá; 2014.

9. Secretaria Distrital de Salud. Informe Afiliación por Localidades. Bogotá; 2014.

10. Inmlycf. Cifras preliminares de lesiones de causa externa en Colombia. Bogotá; 2008.

11. Ceacsc. Seguimiento y Caracterización del Embarazo en Adolescentes. Bogotá; 2014.

12. Bazúa F, Valenti G, Xochimilco U. Políticas públicas y desarrollo municipal [Internet]. Xochimilco: el colegio Mexiquense; 1995 [cited 2017 Apr 6]. Available from: http://dgece.sev.gob.mx/docs/Bazua_y_Valenti_U-I_CL3.pdf

13. Velásquez GR. Hacia una nueva definición del concepto "política pública." Desafios, Bogotá (Colombia) [Internet]. 2009 [cited 2017 Apr 6]; Available from: file:///Users/dianafajardo/Downloads/433-1513-1-PB.pdf

14. Ponzone, J. Garello S. La concepción de sujeto presente en las políticas sociales neoliberales hasta nuestros días. Rupturas y continuidades. 2011 [cited 2017 Apr 6]; Available from: http://trabajosocial.sociales.uba.ar/wpcontent/uploads/sites/13/2016/03/38.pdf

15. Alvarez Leguizamón S. Trabajo y producción de la pobreza en Latinomérica y El Caribe. Sociales CL de C, editor. Buenos Aires; 2005.

16. Lautier B. Las políticas sociales en América Latina: propuestas metodológicas para analizar el cambio que se está produciendo [Internet]. VII. 2001. p. 22. Available from: http://www.redalyc.org/articulo.oa?id=13802204

17. Castrillón. V M del C. Entre la minoridad y la ciudadanía. Sensibilidades legales sobre la normatividad de protección de la niñez y la adolescencia en Colombia. Univ Humanística [Internet]. 2011 [cited 2017 Apr 6];87-106. Available from: file://Users/dianafajardo/Downloads/3631-13271-1-PB.pdf

18. Pilotti F. Globalización y convención sobre los derechos del niño: el contexto del texto [Internet]. 2000 [cited 2017 Apr 6]. Available from: 
http://pendientedemigracion.ucm.es/info/polinfan/2006/area-lectura/mod1/pilotti_contexto-del-texto.pdf

19. Casas F. Las representaciones sociales de las necesidades de niños y niñas, y su calidad de vida. Anu Psicol [Internet]. 1992 [cited 2017 Apr 6];27-45. Available from: file:///Users/dianafajardo/Downloads/61042-88974-1-PB.pdf

20. Moreno, A. Del Barrio C. La experiencia adolescente: a la búsqueda de un lugar en el mundo. Buenos Aires; 2000. Cap. 1-2.

21. Trujillo S. Consideraciones sobre la adolescencia desde la perspectiva del ciclo vital. 2000.

22. Corvera N. Participación ciudadana de los niños como sujetos de derechos. Pers y Soc. 2011;XXV(2):73-99.

23. Torney-Purta JA, Amadeo J. PARTICIPATORY NICHES FOR EMERGENT CITIZENSHIP IN EARLY ADOLESCENCE AN INTERNATIONAL PERSPECTIVE. Ann Am Acad Polit Soc Sci. 2011;180-200.

24. Cajiao, F. Parra, R. Castañeda, E. Parodi, Martha. León J. La cultura fracturada. Proyecto Atlantida. Estudio sobre el adolescente escolar en Colombia [Internet]. Segunda. 1997 [cited 2017 Apr 6]. Available from: file:///Users/dianafajardo/Downloads/08_pa_t1_la_cultura_fracturada.pdf

25. Margulis M, Urresti M. La construcción social de la condición de juventud. 1998 [cited 2017 Apr 6]; Available from:

http://www2.perio.unlp.edu.ar/catedras/system/files/mario_margulis_y_marcelo_urre sti_-_la_construccion_social_de_la_condicion_de_juventud_urresti.pdf

26. Prada, M. Ruiz A. Cinco fragmentos para un debate sobre subjetividad política. Rev Estud Interdiscip y Transdiscipl [Internet]. 2007 [cited 2017 Apr 6]; Available from: http://www.filosofiayliteratura.org/lindaraja/politica/subjetividad_politica.htm

27. Donzelot J. The policing of families. New York: Pantheon Books; 1979.

28. Correa Tapia MDLÁ. Los avatares de la pre-adolescencia: conflictos y propuestas para su transición. Boletín Científico Sapiens Res. 2012;2(1):31-5.

29. James A. To Be (come) or Not to Be (come): Understanding Children's Citizenship. Ann Am Acad Pol Soc Sci. 2011;633:167-79.

30. Ulriksen De Viñar M. Construcción de la subjetividad del niño. Algunas pautas para organizar una perspectiva. i. 2005 [cited 2017 Apr 9]; Available from: http://www.apuruguay.org/revista_pdf/rup100/100-ulriksen.pdf

31. Muñoz G. Temas y problemas de los jóvenes colombianos al comenzar el siglo XXI. Rev Latinoam Ciencias Soc NIñez y Juv [Internet]. 2003 [cited 2017 Apr 9];145-80. Available from: file:///Users/dianafajardo/Downloads/337-823-1-PB.pdf

32. Salazar C. La Evaluación y el análisis de políticas públicas. Opera [Internet]. 2009 [cited 2017 Apr 9];9:23-51. Available from:

file:///Users/dianafajardo/Downloads/La evaluación y el análisis de políticas públicas.pdf

33. Picado X. Criterios para realizar evaluaciones de calidad. Rev Ciencias Soc Univ Costa Rica [Internet]. 2002 [cited 2017 Apr 9];III:9-16. Available from: http://www.redalyc.org/articulo.oa?id=15309702

34. Sottoli S. La política social en América Latina: diez dimensiones para el análisis y el diseño de políticas. Papeles de Población [Internet]. 2002 [cited 2017 Apr 9];8.

Available from: file:///Users/dianafajardo/Downloads/La política social en América Latina- diez dimensiones para el análisis y el diseño de políticas.pdf 
35. Desarrollo BI de. La política de las políticas públicas. Progreso económico y social en América Latina [Internet]. 2006 [cited 2017 Apr 9]. Available from: http://www.iadb.org/res/publications/pubfiles/pubITO-2006_esp.pdf

36. Ministerio de Igualdad $\mathrm{G}$ de E. Manual de evaluación para políticas, planes, programas y actividades de juventud [Internet]. Madrid; 2008 [cited 2017 Apr 9]. Available from: http://xuventude.xunta.es/uploads/Manual_de_evaluacin_para_polticas_planes_progr amas_y_actividades_de_juventud.pdf

37. Shore C. La antropología y el estudio de la política pública: reflexiones sobre la "formulación" de las políticas. Antípoda [Internet]. 2010 [cited 2017 Apr 9];21-49. Available from: file:///Users/dianafajardo/Downloads/-data-Revista_No_1003_Meridianos_01.pdf

38. Alcaldía Mayor de Bogotá. Política por la calidad de vida de niñas, niños y adolescentes de Bogotá 2011 - 2021. Bogotá; 2011.

39. Consejo Nacional de Política Económica y Social. Documento Conpes Social 147: lineamientos para el desarrollo de una estrategia para la prevención del embarazo en la adolescencia y la promoción de proyectos de vida para los niños, niñas adolescentes y jóvenes en edades entre 6 y 19 años. [Internet]. 2012 p. 4. Available from: http://periodico.sena.edu.co/descargables/Conpes social 147 (2).pdf

40. Secretaria Distrital de Planeación. Bogotá en cifras. Bogotá; 2005.

41. Departamento Administrativo de Planeación Distrital. Plan de Ordenamiento Territorial. Bogotá; 2002.

42. Secretaria Distrital de Planeación. Separata proyecciones de población e indicadores demográficos. Bogotá; 2009.

43. Secretaria Distrital de Salud. Distribución de la Población según aseguramiento. Bogotá; 2016.

44. Secretaria Distrital de Planeación. 7 Bosa monografia 2011. Bogotá; 2012.

45. Risueño A, Motta I. Trastornos específicos del apredizaje: una mirada neuropsicológica. Bonum; 2010.

46. Hospital Pablo VI Bosa 1 Nivel E. Diagnóstico en salud para la población adolescente en la localidad de Bosa. Bogotá; 2015.

47. Cepal, Celade, OIJ. Adolescencia y juventud en América Latina y el Caribe: problemas, oportunidades y desafíos en el comienzo de un nuevo siglo. Santiago de Chile; 2010.

48. Cepal. Panorama social de América Latina. 2014.

49. Pérez A C. Sobre la metodología cualitativa. Rev Esp Salud Publica [Internet]. 2002;5:373-80. Available from: http://journals.cambridge.org/abstract_S0250569X0002077X

50. Iñiguez Rueda L. Investigación y evaluación cualitativa : bases teóricas y conceptuales [Internet]. Vol. 23, Atención primaria: Publicación oficial de la Sociedad Española de Familia y Comunitaria. 1999. Available from: http://dialnet.unirioja.es/servlet/articulo?codigo $=2893032 \&$ info=resumen\&idioma $=S$ PA

51. Childress TLBJF. Principles of Biomedical Ethics - Paperback. 2001; Available from: https://global.oup.com/ushe/product/principles-of-biomedical-ethics9780199924585; jsessionid=1814219BBE5E5824BFDAC4EF2DDF45F7?cc=be \&la ng=en\& 
52. Consejo de Organizacones Internacionales de las Ciencias Médicas. Pautas éticas internacionales para la investigación biomédica en seres humanos. Index Infectológico [Internet]. 2002;1-119. Available from:

http://www.gramonbago.com.uy/imgnoticias/16791.pdf\#page=11

53. García Calvente e MM, Mateo Rodríguez I. El grupo focal como técnica de investigación cualitativa en salud: diseño y puesta en práctica. Atención Primaria [Internet]. 2000;25(3):181-6. Available from:

http://www.sciencedirect.com/science/article/pii/S021265670078485X

54. Gasper D, Apthorpe R. Introduction: Discourse analysis and policy discourse. Eur J Dev Res. 1996;8(1):1-15. 